Cochrane Database of Systematic Reviews

\title{
Fecal transplantation for treatment of inflammatory bowel disease
} (Review)

Imdad A, Nicholson MR, Tanner-Smith EE, Zackular JP, Gomez-Duarte OG, Beaulieu DB, Acra S

Imdad A, Nicholson MR, Tanner-Smith EE, Zackular JP, Gomez-Duarte OG, Beaulieu DB, Acra S.

Fecal transplantation for treatment of inflammatory bowel disease.

Cochrane Database of Systematic Reviews 2018, Issue 11. Art. No.: CD012774.

DOI: 10.1002/14651858.CD012774.pub2.

www.cochranelibrary.com 
TABLE OF CONTENTS

ABSTRAC

PLAIN LANGUAGE SUMMARY

SUMMARY OF FINDINGS

BACKGROUND

OBJECTIVES

METHODS

RESULTS

Figure 1.

Figure 2.

Figure 3.

Figure 4.

DISCUSSION

\section{AUTHORS' CONCLUSIONS}

ACKNOWLEDGEMENTS

REFERENCES

CHARACTERISTICS OF STUDIES

DATA AND ANALYSES

Analysis 1.1. Comparison $1 \mathrm{Fecal}$ microbiota transplantation versus control for participants with ulcerative colitis, Outcome 1 Clinical remission at 8 weeks.

Analysis 1.2. Comparison 1 Fecal microbiota transplantation versus control for participants with ulcerative colitis, Outcome 2 Clinical remission at 12 Weeks.

Analysis 1.3. Comparison 1 Fecal microbiota transplantation versus control for participants with ulcerative colitis, Outcome 3 Clinical remission at 8 weeks: Subgroup analysis by route of administration.

Analysis 1.4. Comparison 1 Fecal microbiota transplantation versus control for participants with ulcerative colitis, Outcome 4 Clinical remission at 8 weeks: Subgroup analysis by type of donor.

Analysis 1.5. Comparison 1 Fecal microbiota transplantation versus control for participants with ulcerative colitis, Outcome 5 Clinical remission at 8 weeks: Sensitivity analysis using fixed-effect model.

Analysis 1.6. Comparison $1 \mathrm{Fecal}$ microbiota transplantation versus control for participants with ulcerative colitis, Outcome 6 Clinical remission: Composite of clinical score and endoscopic score.

Analysis 1.7. Comparison 1 Fecal microbiota transplantation versus control for participants with ulcerative colitis, Outcome 7 Clinical relapse at 12 weeks.

Analysis 1.8. Comparison 1 Fecal microbiota transplantation versus control for participants with ulcerative colitis, Outcome 8 Serious adverse events.

Analysis 1.9. Comparison 1 Fecal microbiota transplantation versus control for participants with ulcerative colitis, Outcome 9 Serious adverse events: Subgroup analysis by route of administration.

Analysis 1.10. Comparison 1 Fecal microbiota transplantation versus control for participants with ulcerative colitis, Outcome 10 Serious adverse events: Subgroup analysis by type of donor.

Analysis 1.11. Comparison 1 Fecal microbiota transplantation versus control for participants with ulcerative colitis, Outcome 11 Serious adverse events: Sensitivity analysis using fixed-effect model.

Analysis 1.12. Comparison 1 Fecal microbiota transplantation versus control for participants with ulcerative colitis, Outcome 12 Any adverse events.

Analysis 1.13. Comparison 1 Fecal microbiota transplantation versus control for participants with ulcerative colitis, Outcome 13 Clinical response at 8 weeks.

Analysis 1.14. Comparison 1 Fecal microbiota transplantation versus control for participants with ulcerative colitis, Outcome 14 Clinical response at 12 weeks.

Analysis 1.15. Comparison 1 Fecal microbiota transplantation versus control for participants with ulcerative colitis, Outcome 15 Endoscopic remission at 8 weeks.

Analysis 1.16. Comparison 1 Fecal microbiota transplantation versus control for participants with ulcerative colitis, Outcome 16 Endoscopic remission at 12 weeks.

Analysis 1.17. Comparison 1 Fecal microbiota transplantation versus control for participants with ulcerative colitis, Outcome 17 Endoscopic response at 8 weeks.

Analysis 1.18. Comparison 1 Fecal microbiota transplantation versus control for participants with ulcerative colitis, Outcome 18 Endoscopic response at 12 weeks. 
Analysis 1.19. Comparison 1 Fecal microbiota transplantation versus control for participants with ulcerative colitis, Outcome 19 Withdrawals.

Analysis 1.20. Comparison 1 Fecal microbiota transplantation versus control for participants with ulcerative colitis, Outcome 20 ESR at the longest follow up.

Analysis 1.21. Comparison 1 Fecal microbiota transplantation versus control for participants with ulcerative colitis, Outcome 21 CRP at the longest follow-up.

Analysis 1.22. Comparison 1 Fecal microbiota transplantation versus control for participants with ulcerative colitis, Outcome 22 Fecal calprotectin at the longest follow-up.

Analysis 1.23. Comparison 1 Fecal microbiota transplantation versus control for participants with ulcerative colitis, Outcome 23 Quality of life score: IBDQ.

ADDITIONAL TABLES

APPENDICES

CONTRIBUTIONS OF AUTHORS

DECLARATIONS OF INTEREST

SOURCES OF SUPPORT

DIFFERENCES BETWEEN PROTOCOL AND REVIEW

INDEX TERMS 
[Intervention Review]

\title{
Fecal transplantation for treatment of inflammatory bowel disease
}

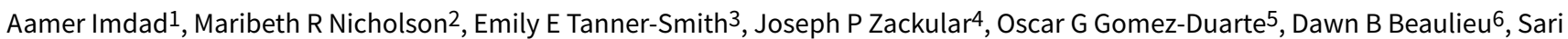 \\ Acra 2 \\ 1Department of Pediatrics, Karjoo Family Center for Pediatric Gastroenterology, SUNY Upstate Medical University, Syracuse, NY, USA. \\ 2Department of Pediatrics, D. Brent Polk Division of Gastroenterology, Hepatology and Nutrition, Vanderbilt University School of \\ Medicine, Nashville, TN, USA. ${ }^{3}$ Counseling Psychology and Human Services, University of Oregon, Eugene, Oregon, USA. ${ }^{4}$ Department \\ of Pathology, University of Pennsylvania, Philadelphia, PA, USA. ${ }^{5}$ Division of Pediatric Infectious Diseases, Department of Pediatrics, \\ University at Buffalo, State University of New York, Buffalo, NY, USA. ${ }^{2}$ Division of Adult Gastroenterology, Hepatology and Nutrition, \\ Department of Medicine, Vanderbilt University Medical Center, Nashville, TN, USA
}

Contact: Aamer Imdad, Department of Pediatrics, Karjoo Family Center for Pediatric Gastroenterology, SUNY Upstate Medical University, 725, Irving Street, Suit 501, Syracuse, NY, 13210, USA. aamer08@gmail.com.

Editorial group: Cochrane IBD Group.

Publication status and date: New, published in Issue 11, 2018.

Citation: Imdad A, Nicholson MR, Tanner-Smith EE, Zackular JP, Gomez-Duarte OG, Beaulieu DB, Acra S. Fecal transplantation for treatment of inflammatory bowel disease. Cochrane Database of Systematic Reviews 2018, Issue 11. Art. No.: CD012774. DOI: 10.1002/14651858.CD012774.pub2.

Copyright @ 2018 The Cochrane Collaboration. Published by John Wiley \& Sons, Ltd.

\section{A B S T R A C T}

\section{Background}

Inflammatory bowel disease (IBD) is a chronic, relapsing disease of the gastrointestinal tract that is thought to be associated with a complex interplay between microbes and the immune system, leading to an abnormal inflammatory response in genetically susceptible individuals. Dysbiosis, characterized by the alteration of the composition of the resident commensal bacteria in a host compared to healthy individuals, is thought to play a major role in the pathogenesis of ulcerative colitis (UC) and Crohn's disease (CD), two subtypes of IBD. There is growing interest to correct the underlying dysbiosis through the use of fecal microbiota transplantation (FMT) for the treatment of IBD.

\section{Objectives}

The objective of this systematic review was to assess the efficacy and safety of FMT for the treatment of IBD.

\section{Search methods}

We searched the MEDLINE, Embase, Cochrane Library, and Cochrane IBD Group Specialized Register databases from inception to 19 March 2018. We also searched ClinicalTrials.gov, ISRCTN metaRegister of Controlled Trials, and the Conference Proceedings Citation Index.

\section{Selection criteria}

Only randomized trials or non-randomized studies with a control arm were considered for inclusion. Adults or pediatric participants with UC or CD were eligible for inclusion. Eligible interventions were FMT defined as the administration of fecal material containing distal gut microbiota from a healthy donor to the gastrointestinal tract of a someone with UC or CD. The comparison group included participants who did not receive FMT and were given placebo, autologous FMT, or no intervention.

\section{Data collection and analysis}

Two authors independently screened the titles and extracted data from the included studies. We used the Cochrane risk of bias tool to assess study bias. The primary outcomes were induction of clinical remission, clinical relapse, and serious adverse events. Secondary outcomes included clinical response, endoscopic remission and endoscopic response, quality of life scores, laboratory measures of inflammation, withdrawals, and microbiome outcomes. We calculated the risk ratio (RR) and corresponding $95 \%$ confidence interval (95\% $\mathrm{Cl}$ ) for dichotomous outcomes and the mean difference and $95 \% \mathrm{Cl}$ for continuous outcomes. Random-effects meta-analysis models were 
used to synthesize effect sizes across trials. The overall certainty of the evidence supporting the primary and selected secondary outcomes was rated using the GRADE criteria.

\section{Main results}

Four studies with a total of 277 participants were included. These studies assessed the efficacy of FMT for treatment of UC in adults; no eligible trials were found for the treatment of CD. Most participants had mild to moderate UC. Two studies were conducted in Australia, one study was conducted in Canada, and another in the Netherlands. Three of the included studies administered FMT via the rectal route and one study administered FMT via the nasoduodenal route. Three studies were rated as low risk of bias. One study (abstract publication) was rated as unclear risk of bias. Combined results from four studies (277 participants) suggest that FMT increases rates of clinical remission by two-fold in patients with UC compared to controls. At 8 weeks, 37\% (52/140) of FMT participants achieved remission compared to $18 \%$ (24/137) of control participants (RR $2.03,95 \% \mathrm{Cl}, 1.07$ to $3.86 ; \mathrm{I}^{2}=50 \%$; low certainty evidence). One study reported data on relapse at 12 weeks among participants who achieved remission. None of the FMT participants (0/7) relapsed at 12 weeks compared to $20 \%$ of control participants (RR $0.28,95 \% \mathrm{Cl} 0.02$ to $4.98,17$ participants, very low certainty evidence). It is unclear whether there is a difference in serious adverse event rates between the intervention and control groups. Seven per cent (10/140) of FMT participants had a serious adverse event compared to $5 \%(7 / 137)$ of control participants (RR $1.40,95 \% \mathrm{Cl} 0.55$ to 3.58 ; 4 studies; I $^{2}=0 \%$; low certainty evidence). Serious adverse events included worsening of UC necessitating intravenous steroids or surgery; infection such as Clostridium difficile and cytomegalovirus, small bowel perforation and pneumonia. Adverse events were reported by two studies and the pooled data did not show any difference between the study groups. Seventy-eight per cent (50/64) of FMT participants had an adverse event compared to $75 \%$ (49/65) of control participants (RR $1.03,95 \% \mathrm{Cl} 0.81$ to $1.31 ; \mathrm{I}^{2}=31 \%$; moderate certainty evidence). Common adverse events included abdominal pain, nausea, flatulence, bloating, upper respiratory tract infection, headaches, dizziness, and fever. Four studies reported on clinical response at 8 weeks. Forty-nine per cent (68/140) of FMT participants had a clinical response compared to 28\% (38/137) of control participants (RR 1.70, $95 \% \mathrm{Cl} 0.98$ to $2.95, \mathrm{I}^{2}=50 \%$, low certainty evidence). Endoscopic remission at 8 weeks was reported by three studies and the combined results favored FMT over the control group. Thirty per cent (35/117) of FMT participants achieved endoscopic remission compared to $10 \%$ (11/112) of control participants (RR $2.96,95 \% \mathrm{Cl} 1.60$ to $5.48, \mathrm{I}^{2}=0 \%$; low certainty evidence).

\section{Authors' conclusions}

Fecal microbiota transplantation may increase the proportion of participants achieving clinical remission in UC. However, the number of identified studies was small and the quality of evidence was low. There is uncertainty about the rate of serious adverse events. As a result, no solid conclusions can be drawn at this time. Additional high-quality studies are needed to further define the optimal parameters of FMT in terms of route, frequency, volume, preparation, type of donor and the type and disease severity. No studies assessed efficacy of FMT for induction of remission in CD or in pediatric participants. In addition, no studies assessed long-term maintenance of remission in UC or CD. Future studies are needed to address the therapeutic benefit of FMT in CD and the long-term FMT-mediated maintenance of remission in $U C$ or $C D$.

\section{PLAIN LANGUAGE SUMMARY}

\section{Stool transplantation for treatment of inflammatory bowel disease}

\section{Background}

Ulcerative colitis (UC) and Crohn's disease (CD) are two types of inflammatory bowel disease (IBD) that lead to chronic inflammation in the digestive tract. The mechanism leading to inflammation in IBD is poorly understood, yet it is thought to involve a complex interaction between the immune system, the gut and gut microbes. New evidence suggests that the composition of gut microbes in a patient with IBD is different and possibly abnormal, and that correction of this abnormality might help control the inflammation seen in patients with UC and CD. Stool administration from healthy donors to patients with UC or CD is an intervention that seeks to restore a more healthy balance of gut microbes, and control IBD.

\section{Review question}

To assess the effectiveness of stool transplantation for the treatment of UC and CD.

\section{Review methods}

We searched multiple databases for randomized studies. A randomized study is a type of study where participants are allocated to an intervention or a control group in a random manner and is considered to be the most superior research design. We pooled data from different studies to obtain overall estimates of the effect of stool transplantation for the treatment of UC and CD. The literature search is current to 19 March 2018.

\section{Study characteristics}

We found four studies (277 participants) that assessed the effectiveness of stool transplantation for the treatment of adults with active UC. We did not find any randomized studies that assessed stool transplantation in participants with CD or in children. In addition, we did not find any studies that assessed maintenance of remission in participants with inactive IBD. Two of the identified studies were conducted 
in Australia, one in Canada, and one in the Netherlands. The dose, route, frequency, volume, type of donor, and severity of disease of recipients varied among the studies.

\section{Key results}

Combined results from four studies including 277 participants indicated that stool transplantation increased rates of resolution of symptoms (also termed clinical remission) of UC patients by two-fold compared to controls. At 8 weeks after transplantation, 37\% (52/140) of participants in the stool transplant group were in remission compared to $18 \%$ (24/137) of participants in the control group. Combined data from the same four studies showed similar rates of serious side effects. Seven per cent (10/140) of the stool transplantation group had a serious side effect compared to $5 \%(7 / 137)$ of the control group. Serious side effects included worsening of ulcerative colitis that required intravenous steroids or surgery; infections such as Clostridium difficile and cytomegalovirus, small bowel perforation, and pneumonia. The incidence of side effects were similar in both stool transplant and control groups and included abdominal pain, nausea, flatulence, bloating, upper respiratory tract infection, headaches, dizziness, and fever. Data from three included studies showed that stool transplantation helped improve UC when the assessment of disease resolution was made by the appearance of the intestinal lining when visualized with an endoscope.

\section{Quality of evidence}

We rated the overall quality of the evidence using the GRADE approach, which takes into account the type of studies, methodological flaws within studies, the consistency in reporting of results across studies, method of measurement of effect of intervention and statistical confidence in the summary estimates. Based on these criteria, we judged the overall quality of the evidence for most of the outcomes to be low based on a small number of events and participants and inconsistency of results.

\section{Conclusions}

Fecal microbiota transplantation may increase the proportion of participants achieving clinical remission in UC. However, the number of identified studies was small and the quality of evidence was low. There is uncertainty about the rate of serious side effects. Thus, no firm conclusions can be drawn regarding the benefits and harms of stool transplantation in people with active UC. We did not find any studies that addressed treatment of CD with stool transplantation or studies that assessed stool transplantation in children with IBD. In addition, we did not find any studies that assessed long-term maintenance of remission in participants with inactive IBD. More studies are needed to enhance the knowledge about use of stool transplantation for treatment of IBD. 


\begin{tabular}{|c|c|c|c|c|c|c|}
\hline \multicolumn{7}{|c|}{ Summary of findings for the main comparison. Fecal microbiota transplantation compared to control for treatment of ulcerative colitis } \\
\hline \multicolumn{7}{|c|}{ Fecal microbiota transplantation compared to control for treatment of ulcerative colitis } \\
\hline \multicolumn{7}{|c|}{$\begin{array}{l}\text { Patient or population: Participants with active ulcerative colitis inadequately controlled with medication } \\
\text { Setting: Outpatient } \\
\text { Intervention: Fecal microbiota transplantation via rectal or nasoduodenal routes } \\
\text { Comparison: Autologous fecal administration or normal saline placebo }\end{array}$} \\
\hline \multirow[t]{2}{*}{ Outcomes } & \multicolumn{2}{|c|}{$\begin{array}{l}\text { Anticipated absolute effects }{ }^{\star}(95 \% \\
\mathrm{Cl})\end{array}$} & \multirow[t]{2}{*}{$\begin{array}{l}\text { Relative effect } \\
(95 \% \mathrm{CI})\end{array}$} & \multirow{2}{*}{$\begin{array}{l}\text { No of partici- } \\
\text { pants } \\
\text { (studies) }\end{array}$} & \multirow{2}{*}{$\begin{array}{l}\text { Certainty of } \\
\text { the evidence } \\
\text { (GRADE) }\end{array}$} & \multirow[t]{2}{*}{ Comments } \\
\hline & $\begin{array}{l}\text { Risk with Con- } \\
\text { trol for Ulcera- } \\
\text { tive Colitis }\end{array}$ & $\begin{array}{l}\text { Risk with Fe- } \\
\text { cal Microbiota } \\
\text { Transplantation }\end{array}$ & & & & \\
\hline $\begin{array}{l}\text { Clinical remission } \\
\text { at } 8 \text { weeks }\end{array}$ & 175 per 1,000 & $\begin{array}{l}356 \text { per } 1,000 \\
(187 \text { to } 676)\end{array}$ & $\begin{array}{l}\text { RR } 2.03 \\
(1.07 \text { to } 3.86)\end{array}$ & $\begin{array}{l}277 \\
(4 \mathrm{RCTS})\end{array}$ & $\begin{array}{l}\oplus \oplus \Theta \odot \\
\text { LOW } 12\end{array}$ & $\begin{array}{l}\text { Clinical remission was defined by the included stud- } \\
\text { ies - see characteristics of included studies }\end{array}$ \\
\hline $\begin{array}{l}\text { Serious adverse } \\
\text { events } \\
\text { Follow up: 8-12 } \\
\text { weeks }\end{array}$ & 51 per 1,000 & $\begin{array}{l}72 \text { per } 1,000 \\
(28 \text { to } 183)\end{array}$ & $\begin{array}{l}\text { RR } 1.40 \\
\text { (0.55 to } 3.58)\end{array}$ & $\begin{array}{l}277 \\
(4 \mathrm{RCTS})\end{array}$ & $\begin{array}{l}\oplus \oplus \ominus \ominus \\
\text { LOW }^{3}\end{array}$ & $\begin{array}{l}\text { Serious adverse events included worsening ulcera- } \\
\text { tive colitis, Clostridium } \\
\text { difficile infection, cytomegalovirus infection, small } \\
\text { bowel perforation, cervix carcinoma and pneumonia }\end{array}$ \\
\hline $\begin{array}{l}\text { Adverse events } \\
\text { Follow-up: } 8 \\
\text { weeks }\end{array}$ & 754 per 1,000 & $\begin{array}{l}776 \text { per } 1,000 \\
(611 \text { to } 988)\end{array}$ & $\begin{array}{l}\text { RR } 1.03 \\
(0.81 \text { to } 1.31)\end{array}$ & $\begin{array}{l}129 \\
(2 \text { RCTs })\end{array}$ & $\begin{array}{l}\oplus \oplus \oplus \odot \\
\text { MODERATE } 4\end{array}$ & $\begin{array}{l}\text { Common adverse events included abdominal pain, } \\
\text { nausea, diarrhea, vomiting, colitis, } \\
\text { flatulence, bloating, upper respiratory tract infec- } \\
\text { tion, headache, dizziness, fever and transient borbo- } \\
\text { rygmus }\end{array}$ \\
\hline $\begin{array}{l}\text { Clinical response } \\
\text { at } 8 \text { weeks }\end{array}$ & 277 per 1,000 & $\begin{array}{l}472 \text { per } 1,000 \\
(272 \text { to } 818)\end{array}$ & $\begin{array}{l}\text { RR } 1.70 \\
\text { (0.98 to } 2.95)\end{array}$ & $\begin{array}{l}277 \\
(4 \mathrm{RCTs})\end{array}$ & $\begin{array}{l}\oplus \oplus \ominus \ominus \\
\text { LOW } 5,6\end{array}$ & $\begin{array}{l}\text { Clinical response was defined by the included stud- } \\
\text { ies - see characteristics of included studies }\end{array}$ \\
\hline $\begin{array}{l}\text { Endoscopic re- } \\
\text { mission at } 8 \\
\text { weeks }\end{array}$ & 98 per 1,000 & $\begin{array}{l}291 \text { per } 1,000 \\
\text { (157 to } 538)\end{array}$ & $\begin{array}{l}\text { RR } 2.96 \\
\text { (1.60 to } 5.48)\end{array}$ & $\begin{array}{l}229 \\
(3 \mathrm{RCTS})\end{array}$ & $\begin{array}{l}\oplus \oplus \oplus \ominus \\
\text { MODERATE } 7\end{array}$ & $\begin{array}{l}\text { Endoscopic remission was defined by the included } \\
\text { studies - see characteristics of included studies }\end{array}$ \\
\hline $\begin{array}{l}\text { Clinical relapse at } \\
12 \text { weeks }\end{array}$ & 200 per 1,000 & $\begin{array}{l}56 \text { per } 1,000 \\
(4 \text { to } 996)\end{array}$ & $\begin{array}{l}\text { RR } 0.28 \\
\text { (0.02 to } 4.98)\end{array}$ & $\begin{array}{l}17 \\
(1 \mathrm{RCT})\end{array}$ & $\begin{array}{l}\oplus \oplus \ominus \ominus \\
\text { LOW } 8\end{array}$ & \\
\hline
\end{tabular}

Comparison: Autologous fecal administration or normal saline placebo

Anticipated absolute effects ${ }^{\star}(95 \%$

Risk with Con- Risk with Fe-

trol for Ulcera- cal Microbiota

tive Colitis

356 per 1,000
(0.02 to 4.98$)$ 


\section{B A C K G R O U N D}

\section{Description of the condition}

Ulcerative colitis (UC), and Crohn's disease (CD), subtypes of Inflammatory Bowel Disease (IBD), are chronic, relapsing diseases of the gastrointestinal (GI) tract. One of the proposed mechanisms for the development of IBD involves the interplay between microbes and the immune system, which may then lead to an abnormal inflammatory response in genetically susceptible individuals (Abraham 2009; Cleynen 2016). UC is characterized by inflammation of the colonic mucosa and can affect variable lengths of the colon (Abraham 2009; Ananthakrishnan 2015). CD can cause transmural inflammation and affect any part of the $\mathrm{GI}$ tract from mouth to anus, with a particular predilection for the terminal ileum (Abraham 2009; Ananthakrishnan 2015). The prevalence of $U C$ and $C D$ is increasing in both developing and developed countries (Ahuja 2010; Dahlhamer 2016; Molodecky 2012; Weintraub 2014). IBD is associated with poor quality of life, significant economic burden, and increased morbidity including the need for hospitalizations and surgical procedures (Abraham 2009; Abraham 2012; Mehta 2016). Most current treatment strategies for IBD focus on the control of inflammation with medications, including corticosteroids, 5-aminosalicylic acid (5-ASA) preparations, immune-modulating drugs such as azathioprine, 6-mercaptopurine and methotrexate, and biologic therapies such as infliximab, adalimumab, vedolizumab and ustekinumab (Abraham 2009; Vindigni 2016). Unfortunately, these medical therapies have the potential for significant adverse effects. Moreover, while these therapies provide some benefit in many cases (Abraham 2009; Vindigni 2016), there remain a significant number of patients who either do not respond to any of these treatment modalities or become refractory over time. Ultimately, some patients may require a surgical bowel resection (Vindigni 2016). This supports the need for alternative treatment strategies that target known pathogenic factors to supplement or replace existing treatment strategies.

\section{Description of the intervention}

There is growing evidence to suggest that 'dysbiosis' is one of the key elements in the pathogenesis of IBD and could be a potential therapeutic target (Assa 2016; Bejaoui 2015; Kostic 2014; Vindigni 2016). Dysbiosis is defined as any alteration in the composition of resident commensal bacteria communities relative to the communities found in healthy individuals (Petersen 2014). In IBD, a decrease in alpha biodiversity, an increase in certain pathogenic species, and an altered functional core of gut microbiota have been reported (De Preter 2012; Kostic 2014; Vindigni 2016).

Fecal microbiota transplantation (FMT) from healthy donors is one of the interventions used to correct dysbiosis (Cammarota 2017). While FMT is an increasingly studied intervention, most of the published literature on this intervention relates to the treatment of recurrent Clostridium difficile (C. difficile) infection ( $\mathrm{rCDI}$ ), where its efficacy is reported to be greater than 90\% (Austin 2014; Cammarota 2015; Kassam 2013; Kelly 2016; Lee 2016; Leffler 2015; van Nood 2013; Youngster 2014). The Food and Drug Administration (FDA) of the United States of America considers FMT to be a 'biologic product' and a 'drug' under its regulations, and labelled it as an investigational new drug, with exceptions for the treatment for $\mathrm{rCDI}$ where the FDA exercises enforcement discretion (FDA 2016; Moore 2014). Even though methods to perform FMT are evolving, a typical FMT procedure involves selection and screening of the donor, collection and preparation of the donor stool for infusion, preparation of the patient to receive the stool infusion and administration of the stool via the upper or lower gastrointestinal tract (Cammarota 2017). There is no universally agreed upon tool for donor screening; however, most studies have adopted a screening strategy similar to that used for a human tissue donor (Austin 2014; Cammarota 2017; Moore 2014; Owens 2013). The donor is screened with an interview and blood and stool studies to rule out chronic diseases and active infections. After a donor is screened, the stool is collected to be used either immediately for infusion or frozen for later use. At least 30 to $50 \mathrm{~g}$ of feces are typically collected and mixed with normal saline or sterile water in preparation for infusion. The patient is usually prepared with a lavage prior to the infusion. The donor feces can be administered via colonoscopy, enemas, an upper gastrointestinal delivery route such as duodenal or gastric tubes, or through orally-ingested frozen capsules. All modalities have been studied with overall comparable efficacy, even though the colonic route is thought to be the most efficacious (Cammarota 2017; Lee 2016;van Nood 2013; Youngster 2014). Per published international standards, infection control precautions should be adopted during FMT (Cammarota 2017).

\section{How the intervention might work}

The exact mechanism by which FMT might work for inducing remission in IBD is not well established at this time. However, the prevailing hypothesis is that FMT might correct the 'dysbiosis' associated with IBD, leading to a reversal or improvement of the associated inflammation (Moayyedi 2015; Paramsothy 2017a; Rossen 2015; Shi 2016; Sun 2016; Vindigni 2016). Knowledge around the use of FMT for treatment of IBD is evolving. Currently, there is no consensus on the volume, timing, route, and frequency of fecal administration necessary to achieve remission (Cammarota 2017; Kelly 2015; Moore 2014). While a single infusion of feces is enough to treat rCDI in most cases (Austin 2014; Cammarota 2015; Kassam 2013), multiple infusions might be required for the induction of remission in IBD as suggested by the recent FOCUS trial from Australia (Paramsothy 2017a). Similarly, response to FMT for rCDI may not vary much with the choice of donor (Osman 2016). However, donor selection might have a significant impact on the induction of remission in UC as reported by Moayyedi 2015, where seven out of nine patients who went into clinical remission received stool from a single donor.

The short and long term safety of FMT in patients with IBD is not well established (Cammarota 2017; Kelly 2015; Moore 2014). Some studies report relatively minor adverse effects such as diarrhea, abdominal bloating, abdominal cramping, and fever in the immediate post-procedure period (Khoruts 2016; Kunde 2013). In addition, FMT may increase the risk of a flare in IBD patients (Kelly 2014; Khoruts 2016). Concerns remain that feces may have microorganisms that can be pathogenic to the recipient, and that the change in the functional core of bacteria may confer an undesirable and unanticipated outcome (Alang 2015; Cammarota 2017). Animal models of FMT have demonstrated undesired weight changes that accompanied changes in the microbiome (Blanton 2016; Ridaura 2013). Serious adverse events have been reported in individual cases, including mortality (Kelly 2014), septic shock and toxic megacolon (Solari 2014), and aspiration pneumonia (Link 2016). 


\section{Why it is important to do this review}

As an increasing body of evidence associates 'dysbiosis' with the pathogenesis of IBD, there have been efforts to correct the dysbiosis and assess if this can improve IBD-associated outcomes (Chassaing 2011; Fuentes 2017; Morgan 2012; Nagao-Kitamoto 2016; Rapozo 2017; Schulberg 2016; Vindigni 2016). Some of the interventions that might target gut microbiota include the use of probiotics, prebiotics, synbiotics, nutrition therapy, and FMT (Vindigni 2016). Most of these interventions have been the subject of Cochrane reviews (Mallon 2007; Naidoo 2011; Singh 2015). However, FMT for treatment of IBD has not been evaluated in a Cochrane review. Moreover, available non-Cochrane reviews have not included some of the more recent studies (Colman 2014), only assessed a limited number of outcomes (Shi 2016), and meta-analysed cohort studies and randomized trials in the same analysis (Sun 2016). Furthermore, additional evidence has recently become available since the publication of previous reviews (Costello 2017a). The most recent reviews have included both cohort studies and randomized trials but analyzed limited outcomes (Costello 2017b; Paramsothy $2017 \mathrm{~b})$. None of the previous reviews systematically assessed the overall quality of the evidence supporting the use of FMT for treatment of IBD with the GRADE (Grading of Recommendations Assessment, Development, and Evaluation) criteria. Collectively, these observations make this an appropriate and opportune time to conduct a Cochrane systematic review.

\section{O B J E C T IVES}

The objective of this systematic review was to assess the efficacy and safety of FMT for the treatment of IBD.

\section{METHODS}

\section{Criteria for considering studies for this review}

\section{Types of studies}

We included randomized controlled trials and non-randomized studies with a comparator arm. Case reports, case series, casecontrol, and single-arm cohort studies were excluded.

\section{Types of participants}

Studies were included if the participants were diagnosed with UC or CD based on their history, physical examination, and gross endoscopic and histologic evaluations. We excluded studies where the diagnosis was made without endoscopic or histologic evaluation as these two measures were considered key initial diagnostic studies for IBD (Mowat 2011). There were no age restrictions for participants, and we included both pediatric and adult patients. We excluded studies using FMT for the treatment of pouchitis. We only included studies that followed participants for at least six weeks post-FMT (Feakins 2013). We excluded studies where participants had active enteric infections such as $C$. difficile, as these conditions may mimic IBD. We excluded studies in which FMT was performed for recurrent C.difficile infection in patients with IBD and not for induction of remission.

\section{Types of interventions}

We included studies that evaluated FMT for the treatment of IBD. FMT for this review was defined as, "the administration of fecal material containing distal gut microbiota from a healthy individual (donor) to a patient with a disease or condition related to dysbiosis, or an alteration in their normal gut microbiota (Kelly 2015)." Comparator groups included standard medication, placebo, other control, or no intervention. We included studies irrespective of the type of stool (liquid or frozen), the volume of stool, routes of administration, frequency (i.e. single versus multiple infusions) and timing of the transplant (at initial diagnosis or to treat a flare). We excluded studies that used selective microbes rather than whole stool from the donor, as this intervention did not fulfil the definition of FMT.

\section{Types of outcome measures}

\section{Primary outcomes}

The following primary outcomes were considered:

1) Induction of clinical remission (as defined by the included studies);

2) Relapse (as defined by the included studies); and

3) Serious adverse events as defined by the authors.

We measured the primary outcomes as the number of patients achieving clinical remission, relapsing, or having serious adverse events, expressed as a proportion of the number of patients randomized. Further details on how data were abstracted for primary outcomes is given in the section Measures of treatment effect.

\section{Secondary outcomes}

Secondary outcomes included:

1) Clinical response (as defined by the included studies);

2) Endoscopic remission (as defined by the included studies);

3) Endoscopic response (as defined by the included studies);

4) Lab measures of inflammation including erythrocyte sedimentation rate (ESR), C-reactive protein (CRP), and fecal calprotectin at the time of measurement of the primary outcome;

5) Quality of life (scores) at the time of the measurement of the primary outcome;

6) Any adverse events;

7) Withdrawals; and

8) Change in the alpha diversity of the fecal microbiome in the recipient.

\section{Search methods for identification of studies}

\section{Electronic searches}

We searched the MEDLINE, Embase, Cochrane Library, and Cochrane IBD Group Specialized Register databases from inception to 19 March 2018. Please see Appendix 1 for the detailed search strategy.

\section{Searching other resources}

We searched ClinicalTrials.gov (www.clinicaltrials.gov) and the ISRCTN metaRegister of Controlled Trials (mRCT; www.isrctn.com/ page/mrct) for ongoing trials. We searched the reference sections 
of previously published randomized trials and meta-analyses on this topic. We searched the Conference Proceedings Citation Index database to search for conference abstracts. We specifically searched the abstracts from the last 10 years from major conferences, such as Digestive Disease Week, Infectious Diseases Week, United European Gastroenterology Week, European Crohn's and Colitis Organization, North American Society of Pediatric Gastroenterology, Hepatology and Nutrition, and the European Society of Pediatric Gastroenterology, Hepatology and Nutrition. Finally, we contacted authors of published and ongoing studies to seek new or additional data when needed.

\section{Data collection and analysis}

\section{Selection of studies}

Two authors (Al and MN) conducted the initial screening to select potentially eligible studies by reviewing titles and abstracts. Any potential discrepancies were resolved by discussion. After initial title and abstract screening, selected studies were further assessed by two authors (Al and MN) by review of full text and a final decision was made about inclusion or exclusion. Any discrepancies were resolved by discussion and consensus between two authors (Al and $M N)$. If any conflict about the inclusion of a study persisted, a senior author (SA) was consulted to resolve the conflict.

\section{Data extraction and management}

Two authors (Al and MN) independently extracted data to a pretested Microsoft Excel sheet (available on request). We extracted information on the characteristics of included studies such as study authors, date of publication, journal, site of the study, type of study, age of participants, definition of study population (inclusion/ exclusion criteria), details of intervention (type, volume, frequency, route of administration of fecal transplant, source), outcomes (primary and secondary outcomes), and risk of bias. We extracted the raw values of events (numerators) in cases and controls along with a total number of subjects allocated (denominators) to intervention and control groups. For studies using randomized control trial designs, we extracted data on an intention-to-treat basis, which considers the initial allocation of participants to an intervention or control group irrespective of whether or not they received the intervention or completed the follow-up (Gupta 2011). When data for continuous outcomes were reported as medians with ranges, we converted it to means with standard deviations by methods given in Hozo 2005.

\section{Assessment of risk of bias in included studies}

We used the Cochrane risk-of-bias tool to assess the risk of bias in included randomized trials (Higgins 2011). Briefly, risk of bias assessments were based on six criteria: sequence generation, allocation concealment, masking, incomplete outcome data, publication bias, and other bias. Each category was assessed as 'Low', 'High' or 'Unclear' risk of bias.

For observational studies, we planned to use the Ottawa-Newcastle Scale to assess risk of bias (Wells 2017). Briefly, this scale assesses the risk of bias in observational studies based on three criteria: selection of the study groups, comparability of the groups, and ascertainment of either the exposure or outcome of interest for case-control or cohort studies, respectively.

\section{Measures of treatment effect}

We expected that the authors of included studies would report a range of clinical, endoscopic, and histologic outcomes in response to treatment with FMT. The most important of these outcomes were 'induction of clinical remission' and 'clinical relapse,' which were the primary outcomes of our systematic review. We used the definitions of clinical remission and clinical relapse as defined by the included studies (e.g. Mayo score for UC studies and the Crohn's disease activity index for $C D$ studies). If the primary outcome reported in the trial was a combination of clinical and endoscopic or histologic assessment, we tried to include clinical remission or relapse data only, if available. If disaggregated data were not available, we corresponded with the authors to obtain clinical remission or relapse data. If these data were not available from the authors of the original studies, we included the data for the combined outcome. All analyses from randomized trials were conducted on an intention-to-treat analysis basis.

We considered the primary outcome at 8 weeks and 12 weeks post-FMT. If a study did not report a primary outcome exactly at 8 weeks but between 6 to 10 weeks post-FMT, it was included as an outcome at 8 weeks. Similarly, if a study did not report the primary outcome exactly at 12 weeks but between $>10$ weeks and 16 weeks, it was included as an outcome at 12 weeks post-FMT. We planned to perform sensitivity analysis if there were a number of studies that did not report outcomes exactly at 8 or 12 weeks.

We calculated the risk ratio (RR) and corresponding 95\% confidence interval $(95 \% \mathrm{Cl})$ for all dichotomous outcomes. We calculated the mean difference (MD) and corresponding $95 \% \mathrm{Cl}$ for continuous outcomes. For continuous outcomes that used different scales to measure the same underlying construct (e.g. quality of life scores), we planned to calculate the standardized mean difference (SMD) and $95 \% \mathrm{Cl}$. For observational studies with a comparison group, we planned to calculate the odds ratio (OR) and corresponding $95 \% \mathrm{Cl}$ for dichotomous outcomes.

\section{Unit of analysis issues}

For studies that had multiple intervention groups (e.g. factorial design), the data were included in such a way that the only difference between the two groups was FMT. Co-interventions were permitted if the co-interventions were uniformly applied to both intervention and control groups. We considered outcomes at fixed intervals of follow-up (e.g. 8 weeks, 12 weeks) irrespective of how often the same outcome was measured before or after that time interval. We only considered the effect of the first treatment attempt as defined by the authors. The treatment may have included multiple infusions of FMT; however, if a patient received a standard study treatment (intervention or placebo) more than once, the subsequent attempts were ignored. Such a scenario might occur if authors decide to treat all the patients allocated to placebo with the study intervention at the end of a randomized study. Adverse events were considered as reported by authors, and we assumed that each adverse event was an independent event unless the published report indicated otherwise.

\section{Dealing with missing data}

Attrition is an important factor that may affect the validity of studies, and differential dropout rates between the two study groups can lead to biased estimates of effect size (Dumville 2006). We described missing data, including dropouts and reasons for 
dropout as reported by authors. We contacted authors if data were missing and no reasons were provided for missing data. When authors report data for completers as well as controlling for dropouts (for example, imputed using regression methods), we extracted the latter. If data were not available for the primary outcome of this review, we contacted the authors for additional information. All data from randomized trials were analyzed on an intention-to-treat basis. As such, patients with missing values for the primary outcomes were assumed to be treatment failures.

\section{Assessment of heterogeneity}

We assessed clinical, methodological and statistical heterogeneity among included studies. Clinical heterogeneity was assessed by comparing the distribution of important factors such as study participants, dose, and frequency of FMT. Methodological heterogeneity was assessed by comparing data included in the 'Risk-of-bias' tables. Statistical heterogeneity was assessed based on visual inspection of forest plots, the $\mathrm{I}^{2}$ statistic and the $\mathrm{P}$ value for the $\mathrm{Chi}^{2}$ test. If the forest plot was indicative of a heterogeneous effect (opposite direction or prominent difference in magnitude of effect), while $\mathrm{I}^{2}$ values were greater than $50 \%$ and $\mathrm{P}$ values for the $\mathrm{Chi}^{2}$ test were less than 0.1 , statistical heterogeneity was considered to be substantial. We explored potential explanations for heterogeneity using subgroup analyses as described below.

\section{Assessment of reporting biases}

We aimed to assess the potential publication bias based on the symmetry of the funnel plot. We planned to construct funnel plots if at least 10 studies were included in the pooled analysis.

\section{Data synthesis}

We synthesized data from individual trials using meta-analysis when the interventions, patient groups, and outcomes were sufficiently similar (as determined by consensus) using the software Review Manager version 5.3 (RevMan 2014). We planned to conduct separate meta-analyses for patients with UC and CD. For dichotomous outcomes, we calculated the pooled RR and corresponding $95 \% \mathrm{Cl}$. We combined risk ratios (events per participant) and rate ratios (events per participant-days/months/ year) for two reasons: Studies were expected to be completed in a relatively short duration, and the primary outcome (induction of remission) was not expected to be a recurrent event. All metaanalyses were conducted using the log risk ratio, with all reported results transformed back into the risk ratio metric for ease of interpretability.

For continuous outcomes, data were combined to get a pooled MD and corresponding $95 \% \mathrm{Cl}$. When different scales were used to measure the same underlying construct, we calculated the standardized mean difference (SMD; Hedges' g value) and corresponding $95 \% \mathrm{Cl}$. We used a random-effects model to conduct all the meta-analyses. The rationale for using a random-effects model was that we expected that there might be heterogeneity in the effect of FMT due to factors such as dose, frequency, or donor source (e.g. single donor or multi-donor), as noted in the results of published studies (Moayyedi 2015; Paramsothy 2017a; Rossen 2015).

The overall quality of the evidence supporting the primary outcomes and selected secondary outcomes was assessed using the Grading of Recommendations Assessment, Development and Evaluation (GRADE) criteria (Guyatt 2011). This method of evidence evaluation takes into consideration the impact of the type of studies (i.e. randomized versus observational), risk of bias, indirectness, inconsistency (i.e. unexplained heterogeneity), imprecision, and potential publication bias. The overall quality of the evidence was rated as 'high', 'moderate', 'low', or 'very low'. We presented the results of the GRADE evaluation in a 'Summary of Findings' table for all primary outcomes and selected secondary outcomes (e.g. clinical response, endoscopic remission).

\section{Subgroup analysis and investigation of heterogeneity}

We planned the following a priori subgroup analyses:

1) Route of administration: upper gastrointestinal tract (i.e. nasogastric, nasoduodenal, nasojejunal, gastric tube, capsulated) versus colonic (i.e. rectal or beyond);

2) Type of donor: single donor versus multiple donors;

We also planned subgroup analysis based on age of participants and frequency of administration; however, there were not enough studies to perform these subgroup analyses.

\section{Sensitivity analysis}

The following sensitivity analyses were performed:

1) Definition of clinical remission: studies that used clinical criteria only to define clinical remission or relapse versus studies that used a combination of clinical and endoscopic or histologic criteria to define remission or relapse and disaggregated data are not available; and

2) Choice of statistical model: random versus fixed-effect models for primary outcomes.

\section{RES U L T S}

\section{Description of studies}

\section{Results of the search}

A search conducted on 19 March 2018 identified 1020 studies (See Figure 1). After removal of duplicates, 665 studies were retained for title and abstract screening. Thirty-four studies met criteria for full-text review. Eleven studies were excluded for reasons outlined in the Characteristics of excluded studies table. Eight reports of four studies were included in this systematic review (Costello 2017a; Moayyedi 2015; Paramsothy 2017a; Rossen 2015). Thirteen ongoing studies were identified (NCT01790061; NCT01793831; NCT01961492; NCT02272868; NCT02291523; NCT02335281; NCT02390726; NCT02734589; NCT02998112; NCT03006809; NCT03016780; NCT03104036; NCT02487238). 


\section{Figure 1. Study flow diagram}

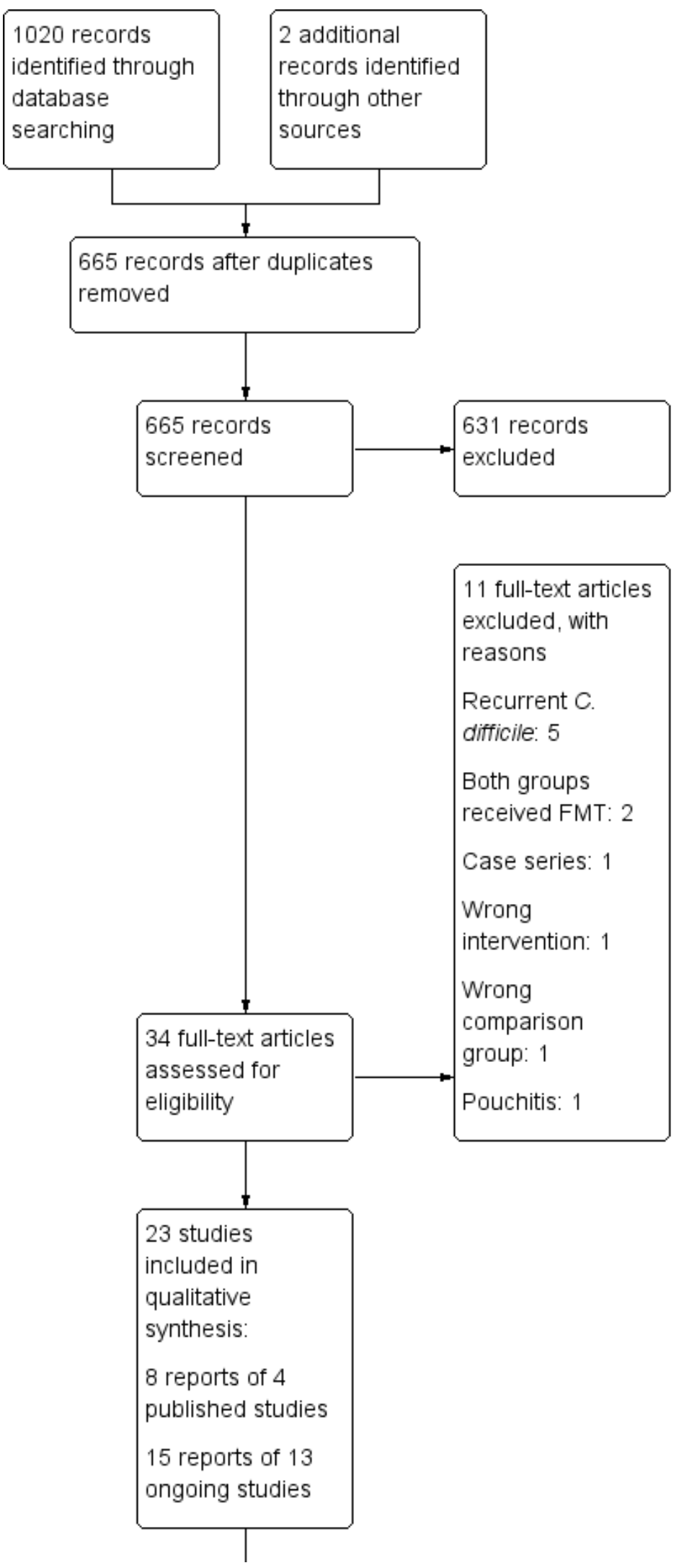


Figure 1. (Continued)

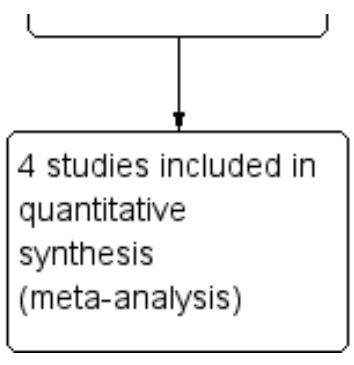

\section{Included studies}

Four randomized controlled trials assessed fecal microbiota transplantation for induction of remission in UC (Costello 2017a; Moayyedi 2015; Paramsothy 2017a; Rossen 2015). Three of the studies were published in peer-reviewed journals (Moayyedi 2015; Paramsothy 2017a; Rossen 2015), while one study was reported in abstract form (Costello 2017a). Please see complete details of these studies in the Characteristics of included studies tables. No randomized controlled studies were available that addressed the use of FMT for treatment of CD. No observational studies were included.

\section{Fecal microbiota transplantation for induction of remission in ulcerative colitis}

\section{Country}

Two studies were conducted in Australia (Costello 2017a; Paramsothy 2017a), one study was conducted in Canada (Moayyedi 2015, and one in the Netherlands (Rossen 2015). The study conducted in the Netherlands was a single center study (Rossen 2015), whereas the other three studies were conducted in multiple centers (Costello 2017a; Moayyedi 2015; Paramsothy 2017a).

\section{Study Population:}

Age and gender

The percentage of male participants in the included studies ranged from 55\% (Costello 2017a), to 59\% (Moayyedi 2015). The mean age of participants ranged from 35 years in the Paramsothy 2017a study to 40 years in the Costello 2017a study.

\section{Primary diagnosis and severity of disease}

All four studies included adult patients with active UC. The diagnosis of UC was based on the Mayo Clinic Score and the Endoscopic Mayo Clinic score in three studies (Costello 2017a; Moayyedi 2015; Paramsothy 2017a), whereas one study used the Lennard-Jones criteria (Rossen 2015). Disease location was reported in three studies (Moayyedi 2015; Paramsothy 2017a; Rossen 2015), and the proportions of patients who had pancolitis were as follows: $42 \%$ (Moayyedi 2015), 43\% (Rossen 2015), and 23\% (Paramsothy 2017a).

\section{Concomitant Medications}

Concomitant medications were allowed for participants in all of the included studies. The most commonly used medication was mesalamine and the proportion of patients who used mesalamine was: 54\% (Moayyedi 2015), 62\% (Rossen 2015) and 66\% (Paramsothy 2017a).

\section{Indications for FMT}

FMT was used as a rescue therapy rather than primary induction therapy in all of the studies, meaning that patients had a known history of UC and their disease remained inadequately controlled with current medications. The median disease duration ranged from 5.8 years in the Paramsothy 2017a study to 8 years in the Rossen 2015 study.

\section{Intervention}

\section{Donors}

All four studies used feces produced by apparently healthy donors. Appendix 2 reports the inclusion and exclusion criteria for donors in the included studies.

\section{Route}

The route of administration was nasoduodenal in one study (Rossen 2015), and rectal enema in another study (Moayyedi 2015). Two studies administered the first dose in the cecum via colonoscopy, while the subsequent treatments were given via rectal enemas (Costello 2017a; Paramsothy 2017a).

\section{Frequency}

The frequency of administration varied across the included studies. Rossen 2015 administered FMT once every three weeks for a total of two doses. Costello 2017a administered a total of three doses within a week. Paramsothy 2017a administered FMT five times a week for eight weeks for a total of 40 doses.

Volume

The volume of FMT administered ranged from $50 \mathrm{ml}$ in the Moayyedi 2015 study to $500 \mathrm{ml}$ in the Rossen 2015 study.

Single vs. multidonor

Two studies used feces from a single donor to perform FMT (Moayyedi 2015; Rossen 2015), while the other two studies pooled feces from multiple donors and administered them as a single FMT per treatment (Costello 2017a; Paramsothy 2017a). The weight of administered feces varied from $25 \mathrm{~g}$ in the Costello $2017 \mathrm{a}$ study to $60 \mathrm{~g}$ in the Rossen 2015 study.

Colon preparation 
One study used colon preparation before each dose of the transplant (Rossen 2015), while another study used no colon preparation (Moayyedi 2015). Two studies used colon preparation at the time of first administration via colonoscopy, but not for the subsequent enemas (Costello 2017a; Paramsothy 2017a). None of the included studies used antibiotics in the participants prior to FMT.

\section{Stool preparation for transplant}

The donor feces for transplant were prepared in aerobic conditions in three studies (Moayyedi 2015; Paramsothy 2017a; Rossen 2015), while one study prepared the feces in anaerobic conditions (Costello 2017a). One study used fresh fecal specimens from donors (Rossen 2015), while the other studies used either fresh or frozen specimens (Moayyedi 2015), or only frozen specimens (Costello 2017a; Paramsothy 2017a).

\section{Comparison:}

Two studies used autologous fecal administration as the comparison group (Costello 2017a; Rossen 2015), and the other two studies used placebo in the form of normal saline (Moayyedi 2015; Paramsothy 2017a). The volume, frequency of administration, and any colon preparation were similar between the control and intervention groups in the respective studies.

\section{Outcomes}

All four studies reported data on clinical and endoscopic outcomes. Please see the Effects of interventions section for details.

\section{Follow-up}

The follow-up time for measurement of primary outcomes ranged from 7 weeks in the Moayyedi 2015 study to 12 weeks in the Rossen 2015 study. Paramsothy 2017a followed participants for an additional eight weeks and offered the FMT to patients who were initially randomized to the placebo group, thus this part of the study was open label. Moayyedi 2015 conducted an open label follow-up at 12 months after the initial trial was completed.

\section{Excluded studies}

The characteristics of excluded studies are reported in the Characteristics of excluded studies table. In summary, five studies were excluded because FMT was performed for treatment of recurrent C-difficile rather than treatment of IBD (Angelberger 2016; Chin 2017; Fischer 2016; Mandalia 2016; Mintz 2016). Three studies were excluded because the comparison group did not include a group without FMT or the comparison groups included patients without IBD (Hourigan 2015; Ishikawa 2017; Wei 2016). One study each was excluded because it did not fulfil the criteria based on study design (Borody 2003), study population (Landy 2013) or study intervention (Gionchetti 2000).

\section{Risk of bias in included studies}

A summary of the risk of bias assessments is reported in Figure 2. 
Figure 2. Risk of bias summary: review authors' judgements about each risk of bias item for each included study.

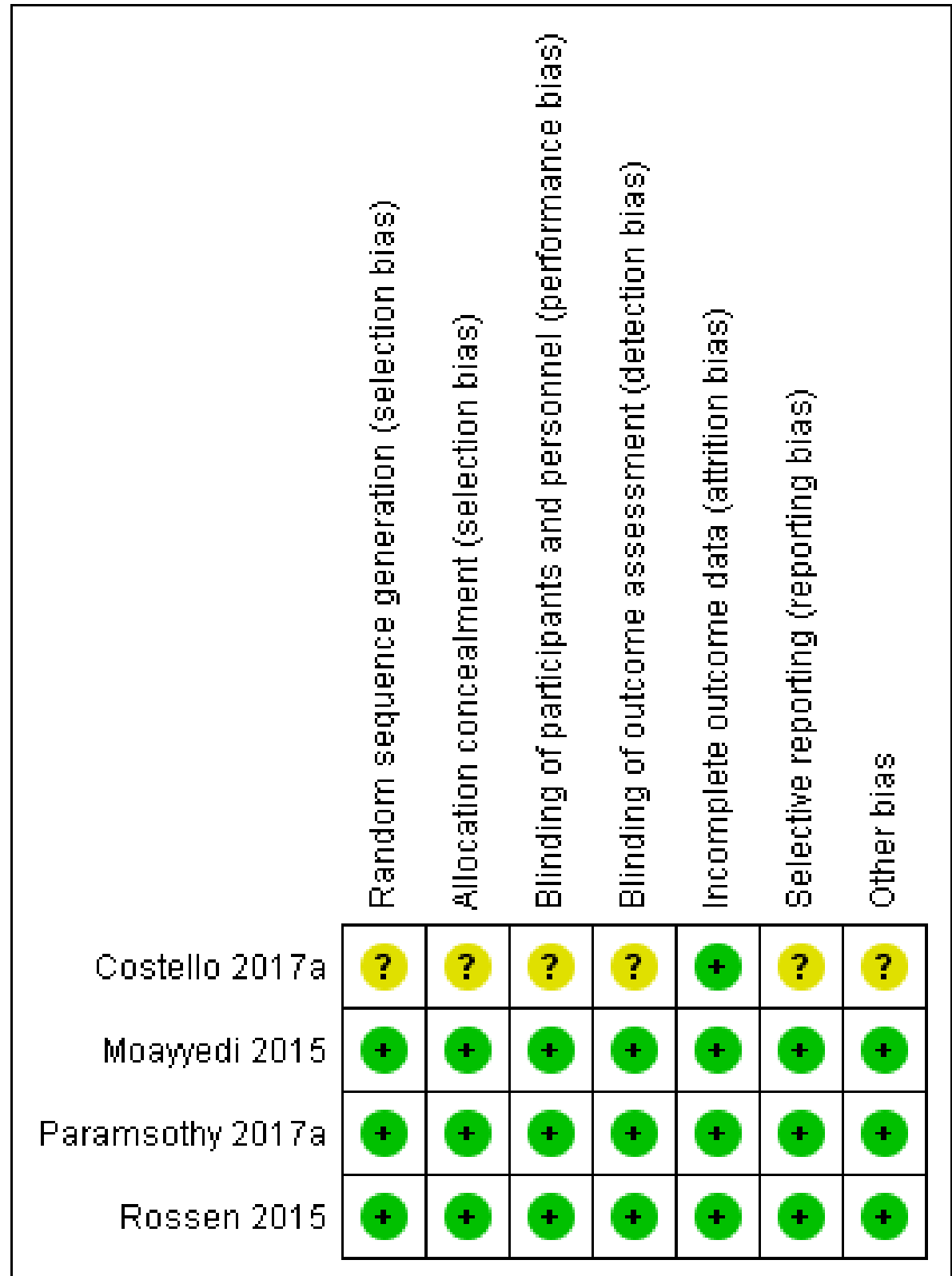

\section{Allocation}

Three of the included studies adequately described the methods for random sequence generation and were rated as 'low' risk of bias (Moayyedi 2015; Paramsothy 2017a; Rossen 2015). Information from one of the studies was available in abstract form only, and a complete assessment could not be made (Costello 2017a). Allocation was successfully concealed in three of the included studies and these studies were rated as low risk of bias for this item (Moayyedi 2015; Paramsothy 2017a; Rossen 2015). One study was rated as unclear risk of bias (Costello 2017a).

\section{Blinding}

Blinding was assessed as low risk of bias in three studies (Moayyed 2015; Paramsothy 2017a; Rossen 2015), and unclear in one study (Costello 2017a).

\section{Incomplete outcome data}

Two studies had attrition rates that were greater than $20 \%$ (Paramsothy 2017a; Rossen 2015). However, the drop-out rates and reasons for dropping out were balanced across groups so we judged these two studies to be at low risk of bias. Drop-out rates in the other two studies were low and we rated these studies as low risk of bias due to attrition (Costello 2017a; Moayyedi 2015).

\section{Selective reporting}

Selective reporting was assessed as low risk of bias for three studies (Moayyedi 2015; Paramsothy 2017a; Rossen 2015), while it was unclear in one study (Costello 2017a). 


\section{Other potential sources of bias}

We did not identify any other major risk of bias in three of the included studies (Moayyedi 2015; Paramsothy 2017a; Rossen 2015), whereas the full text was not available to make such an assessment for one study (Costello 2017a).

\section{Effects of interventions}

See: Summary of findings for the main comparison Fecal microbiota transplantation compared to control for treatment of ulcerative colitis
Induction of clinical remission for ulcerative colitis at eight weeks

Four randomized studies with a total of 277 participants contributed data for induction of clinical remission at 8 weeks. Thirty-seven per cent (52/140) of FMT participants achieved remission at week 8 compared to $18 \%$ (24/137) of the control group. The pooled results showed that the FMT group had two-fold higher rates of clinical remission compared to the control (RR 2.03, $95 \%$ $\mathrm{Cl} 1.07$ to $3.86 ; I^{2}=50 \%$; See Figure 3). The GRADE rating for the certainty of evidence was low.

Figure 3. Forest plot of comparison: 1 Fecal microbiota transplantation versus control for participants with ulcerative colitis, outcome: 1.1 Clinical remission at 8 weeks.

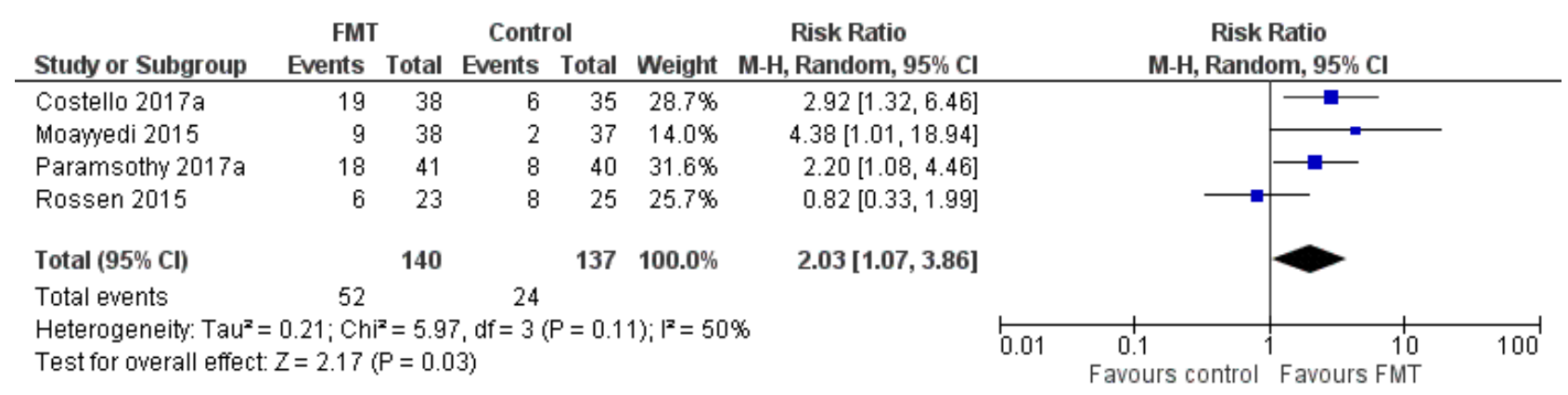

\section{Subgroup analyses}

Planned subgroup analyses included 'route of administration' and 'type of donor' (see Table 1). FMT given via the colonic route showed a homogenous effect for induction of remission at 8 weeks (RR 2.66, $95 \% \mathrm{Cl} 1.62$ to $4.37,3$ studies, 229 participants, $I^{2}=0 \%$ ) compared to upper gastrointestinal tract administration (RR $0.82,95 \% \mathrm{Cl}$ 0.33 to $1.99,1$ study, 48 participants). For 'type of donor' the test for subgroup difference showed no difference between the multidonor and single donor subgroups (test for subgroup differences $\mathrm{Chi}^{2}=0.17, \mathrm{df}=1, \mathrm{P}=0.68, \mathrm{I}^{2}=0 \%$ ), although there was not enough information to determine whether there was a difference between subgroups.

\section{Sensitivity analyses}

Sensitivity analyses were performed based on choice of model for meta-analysis and definition of clinical remission. A fixed-effect model showed similar results ( $R R 2.13,95 \% \mathrm{Cl} 1.39$ to $3.25, \mathrm{I}^{2}=50 \%$ ) compared to the primary random-effects model used in this review. We decided a priori that the primary outcome 'clinical remission' would be based on a clinical score such (e.g. Mayo score or the simple clinical colitis activity index). Three of the included studies defined clinical remission based on clinical scores. Remission in the Moayyedi 2015 study was defined by the Mayo clinical score and the Mayo endoscopic score. The exclusion of this study resulted in decrease in the overall effect (RR $1.79,95 \% \mathrm{Cl} 0.88$ to $3.63, \mathrm{I}^{2}=58 \%$ ).

All studies reported on a composite primary outcome where improvement in both clinical and endoscopic scores were

considered as part of the definition of remission. We performed a post-hoc sensitivity analysis where we pooled the primary outcomes based on the composite definition as reported by the primary studies. The pooled results from four studies showed similar results (RR $2.77,95 \% \mathrm{Cl} 1.54$ to $4.98, \mathrm{I}^{2}=0 \%$ ) to those reported in our primary analysis (See Figure 3 ).

\section{Induction of clinical remission 12 weeks}

One study (48 participants) reported on clinical remission at 12 weeks (Rossen 2015). Thirty per cent (7/23) of FMT participants achieved remission at week 12 compared to $32 \%(8 / 25)$ of the control group (RR 0.95, $95 \% \mathrm{Cl} 0.41$ to 2.21; Analysis 1.2).

\section{Clinical relapse at 12 weeks}

This outcome was reported by one study (Rossen 2015). Few patients relapsed after achieving clinical remission. None (0/7) of the FMT participants who achieved clinical remission relapsed at 12 weeks compared to $20 \%(2 / 10)$ of participants in the control group (RR $0.28,95 \% \mathrm{Cl} 0.02$, 4.98; Analysis 1.7). The overall certainty of the evidence according to the GRADE criteria was 'low'.

\section{Serious adverse events}

Four studies including 277 participants contributed data for this outcome. Serious adverse event rates were similar in both groups. Seven per cent of $(10 / 140)$ the FMT group had a serious adverse event compared to $5 \%(7 / 137)$ of the control group (RR 1.40, $95 \%$ $\mathrm{Cl} 0.55$ to $3.58, \mathrm{I}^{2}=0 \%$, see Figure 4 . The overall certainty of the evidence was rated according to the GRADE criteria as 'low'. 
Figure 4. Forest plot of comparison: 1 Fecal microbiota transplantation versus control for participants with ulcerative colitis, outcome: 1.8 Serious adverse events.

\begin{tabular}{|c|c|c|c|c|c|c|c|c|c|}
\hline Study or Subgroup & $\begin{array}{l}\text { FMT } \\
\text { Events }\end{array}$ & Total & \multicolumn{2}{|c|}{ Control } & Weight & \multicolumn{2}{|l|}{ Risk Ratio } & $\begin{array}{c}\text { Risk Ratio } \\
\text { M-H, Random, } 95 \% \mathrm{Cl}\end{array}$ & \\
\hline Costello 2017a & 3 & 38 & 2 & 35 & $29.6 \%$ & $1.38[0.25,7.79]$ & & & \\
\hline Moayedi 2015 & 3 & 38 & 2 & 37 & $29.5 \%$ & $1.46[0.26,8.25]$ & & & \\
\hline Paramsothy $2017 a$ & 2 & 41 & 1 & 40 & $15.9 \%$ & $1.95[0.18,20.68]$ & & & \\
\hline Rossen 2015 & 2 & 23 & 2 & 25 & $25.1 \%$ & $1.09[0.17,7.10]$ & & & \\
\hline Total $(95 \% \mathrm{Cl})$ & & 140 & & 137 & $100.0 \%$ & $1.40[0.55,3.58]$ & & & \\
\hline Total events & 10 & & 7 & & & & & & \\
\hline $\begin{array}{l}\text { Heterogeneity: Tau² } \\
\text { Test for overall effect }\end{array}$ & $\begin{array}{l}0.00 ; \mathrm{Ch} \\
Z=0.70\end{array}$ & $\begin{array}{l}P=0.1 \\
P=0.4\end{array}$ & $\begin{array}{l}\text { 5, } d f=3 \\
9)\end{array}$ & $P=0.9$ & 9); $\left.\right|^{2}=0 \%$ & & 0.01 & $\begin{array}{lll}0.1 & 1 \\
\text { Favours FMT } & \text { Favours co }\end{array}$ & 100 \\
\hline
\end{tabular}

Paramsothy 2017a reported two serious adverse events in FMT participants and both of these individuals had worsening ulcerative colitis. One participants required intravenous corticosteroids and other required colectomy. There was one serious adverse event in the control group. This individual required hospitalization for worsening ulcerative colitis. Moayyedi 2015 reported three serious adverse events in patients who received FMT; two of these individuals had worsening ulcerative colitis and one developed C. difficile infection. Two control participants had serious adverse events. Both of these individuals had worsening ulcerative colitis and one of them required colectomy. Rossen 2015 reported two serious adverse events in UC patients who received FMT. One of these individuals was found to have small bowel perforation and was ultimately diagnosed with $C D$ and the other had a cytomegalovirus infection that was thought to be unrelated to the FMT. Two control participants had serious adverse events with one participants admitted to hospital with UC exacerbation and abdominal pain and the other was diagnosed with cervix carcinoma. Costello 2017a reported three serious adverse events in participants who received FMT. One of these participants had worsening ulcerative colitis, one had $C$. difficile colitis requiring colectomy, and one had pneumonia. Two serious adverse events occurred in the control group and both of these individuals had worsening ulcerative colitis. No mortality was reported in any of the included studies.

\section{Subgroup analysis}

Table 1 shows subgroup analysis for 'Route of Administration' and 'Type of Donor' with results similar to the primary analysis.

\section{Sensitivity analysis}

The use of a fixed-effect statistical model showed results similar to the primary random-effects analysis (RR $1.41,95 \% \mathrm{Cl} 0.55$ to 3.59 , $\left.\mathrm{I}^{2}=0 \%\right)$

\section{Adverse events}

Ttwo studies including 129 participants reported on the proportion of participants who developed adverse events (Paramsothy 2017a; Rossen 2015). Adverse event rates were similar in both groups. Seventy-eight per cent (50/64) of the FMT group had an adverse event compared to $75 \%(49 / 65)$ of the control group (RR 1.03, 95\% $\mathrm{Cl} 0.81$ to $1.31, \mathrm{I}^{2}=31 \%$, Analysis 1.12 ).

Common adverse events reported in the Paramsothy 2017a study included abdominal pain, colitis, flatulence, bloating, upper respiratory tract infection, headache, dizziness, and fever. FMT and control group participants had similar rates of these adverse events. Common adverse events reported in the Rossen 2015 study included nausea, fever, diarrhea, vomiting, abdominal pain, headache and transient borborygmus. The rates for these events were similar in both groups.

\section{Clinical response at eight weeks}

Clinical response rates at eight weeks were higher in the FMT group compared to the control group. Forty-eight per cent (68/140) of FMT participants had a clinical response at week 8 compared to $28 \%$ $(38 / 137)$ of the control group (RR $1.70,95 \% \mathrm{Cl} 0.98$ to $2.95, \mathrm{I}^{2}=$ $64 \%$, Analysis 1.13). The overall GRADE rating for the certainty of the evidence for this outcome was 'low'.

\section{Clinical response at 12 weeks}

One study with 46 participants reported on clinical response rates at 12 weeks (Rossen 2015). Clinical response rates at week 12 were similar in both groups. Forty-eight per cent $(11 / 23)$ of FMT participants had a clinical response at 12 weeks compared to $52 \%$ $(13 / 25$ ) of participants in the control group (RR 0.92, $95 \% \mathrm{Cl} 0.52$ to 1.63, Analysis 1.14).

\section{Endoscopic remission at eight weeks}

Three studies including 229 participants reported on endoscopic remission at eight weeks (Costello 2017a; Paramsothy 2017a; Moayyedi 2015). Endoscopic remission rates were three times higher in the FMT group. Thirty per cent $(35 / 117)$ of the FMT group achieved endoscopic remission at 8 weeks compared to $10 \%$ (11/112) of the control group (RR 2.96, $95 \% \mathrm{Cl} 1.60$ to $5.48, \mathrm{I}^{2}=0 \%$, Analysis 1.15). The overall certainty of the evidence for this outcome was 'moderate'.

\section{Endoscopic remission at 12 weeks}

Rossen 2015 reported data for endoscopic remission at 12 weeks. Endoscopic remission rates were similar in both groups. Nine per cent (2/23) of FMT participants achieved endoscopic remission at 12 weeks compared to $8 \%(2 / 25)$ of the control participants (RR 1.09, $95 \% \mathrm{Cl} 0.17$ to 7.10 , Analysis 1.16).

\section{Endoscopic response at eight weeks}

Data for endoscopic response at 8 weeks were available from two studies including 129 participants (Paramsothy 2017a; Rossen 2015). Twenty-eight per cent (18/64) of FMT participants achieved 
an endoscopic response at 8 weeks compared to $20 \%(13 / 65)$ of control participants (RR $1.36,95 \% \mathrm{Cl} 0.26$ to $7.02, \mathrm{I}^{2}=82 \%$, Analysis 1.17). The overall certainty of the evidence for this outcome was 'very low'.

\section{Endoscopic response at 12 weeks}

One study including 48 participants reported data for endoscopic response at 12 weeks (Rossen 2015). Endoscopic response rates at 12 weeks were similar in both groups. Thirty-five per cent $(8 / 23)$ of FMT participants had an endoscopic response at 12 weeks compared to $36 \%(9 / 25)$ of the control participants (RR 0.97, $95 \%$ $\mathrm{Cl} 0.45$ to 2.08 , Analysis 1.18 ).

\section{Withdrawals}

Four studies with a total of 277 participants reported data on withdrawals for any reason (Costello 2017a; Moayyedi 2015; Paramsothy 2017a; Rossen 2015). Withdrawal rates were similar in both study groups. Thirteen per cent (18/140) of FMT participants withdrew before study completion compared to $14 \%(19 / 137)$ of control participants (RR $0.91,95 \mathrm{Cl} 0.50$ to $1.64, \mathrm{I}^{2}=0 \%$, Analysis 1.19).

\section{ESR at the longest follow-up}

Two studies including 113 participants reported data for ESR (Moayyedi 2015; Paramsothy 2017a). Mean ESR levels at longest follow-up were similar in both study groups (MD - $0.85,95 \% \mathrm{Cl}-4.86$ to $3.17, \mathrm{I}^{2}=0 \%$, Analysis 1.20 ).

\section{CRP at the longest follow-up}

Data on CRP levels at longest follow-up were available from two studies including 113 participants (Moayyedi 2015; Paramsothy 2017a). The pooled analysis showed similar mean CRP levels at longest follow-up (MD $-0.85,95 \% \mathrm{Cl}-4.86$ to $3.17, \mathrm{I}^{2}=80 \%$, Analysis 1.21). A high level of heterogeneity was detected for this comparison.

\section{Fecal calprotectin at the longest follow-up}

One study including 81 participants reported data for fecal calprotectin at longest follow-up (Paramsothy 2017a). Fecal calprotectin levels were lower in FMT participants compared to control participants (MD $-156.00,95 \% \mathrm{Cl}-535.39$ to 223.39 ).

\section{Quality of life scores}

Two studies including 156 participants reported inflammatory bowel disease quality of life (IBDQ) scores (Moayyedi 2015; Paramsothy 2017a). Although mean IBDQ scores were higher in FMT participants the difference does not appear to be clinically meaningful (MD $16.00,95 \% \mathrm{Cl} 0.09$ to $31.91, \mathrm{I}^{2}=60 \%$ ). One study reported quality of life scores between responders and nonresponders and thus could not be included in the meta-analysis (Rossen 2015).

\section{Microbiome outcomes}

Data on microbiome outcomes were reported by three studies(Moayyedi 2015; Paramsothy 2017a; Rossen 2015). We planned a priori to do meta-analysis for alpha diversity outcomes; however, data were presented in a way that we could not perform the meta-analysis. A summary of methods used and outcomes reported from included studies is given below.

Moayyedi 2015 sequenced the V3 region of the 16S rRNA gene using MiSeq Illumina technology. QIIME and the Phyloseq R package was used for curation of data and in-depth microbiota analyses. This study compared the microbiota of several different donors. Moreover, the authors compared the microbiota of FMT recipients during the time course of the study following FMT. Finally, responders and non-responders microbiota were compared. Microbiota structure analyses utilizing the Bray-Curtis dissimilarity metric demonstrated that patients receiving FMT showed a change in their microbiota following FMT. This shift lead to microbiota that was more similar to the donor microbiota over time. Moreover, the authors observed a difference in the microbiota between responders and non-responders. Interestingly, two donors were associated with more successful FMTs and these individuals harbored increased Ruminococcus and Lachnospiraceae and decreased abundance of Streptococci and Escherichia.

Paramsothy 2017a sequenced the V1 through V3 region of $16 \mathrm{~S}$ rRNA gene using MiSeq Illumina technology. Microbiota analysis and curation were performed utilizing mothur, and altered members of the microbiota were identified using the biomarker discovery algorithm linear discriminant analysis Effect Size (LEfSe). Shotgun metagenomics sequencing was also performed in subsequent follow-up studies. The authors performed RNA extraction to ensure that bacteria detected in their analyses were live and active bacteria. Microbiota analyses were done on 70 patients (314 fecal samples) and 113 donor fecal samples; 55 individual donors were used and 58 batched donor samples. The microbiota of donors was analyzed along with patients receiving individual or batched donor FMTs. For recipients, the microbiota composition was analyzed prior to and following FMT, and patients were binned into responders and non-responders. The microbiota of batched donor samples showed higher phylogenetic diversity than individual donors, and overall donor samples had higher diversity than baseline samples from patients with IBD. After four and eight weeks, patients receiving FMT saw an increase in phylogenetic diversity in the microbiota compared to baseline. LEfSe analysis determined that 295 microbial taxa were differentially altered following transplant and 78 of these members showed high linear discriminant analysis scores $(>3)$. Interestingly, regardless of clinical outcome, the authors observed decreased abundance of operational taxonomic units (OTUs) affiliated with the Bacteroides genera and increased abundance of OTUs affiliated with the Prevotella genera. The authors further describe that FMT was associated with increased diversity in all patients. Importantly, recipients who achieved a successful primary outcome had greater richness in OTUs at baseline, during fecal microbiota transplantation and at 8 weeks. Finally, the authors performed LEfSe analysis comparing patients who responded to non-responders; 87 Taxa were associated with primary outcomes in masked patients and 46 were associated with open-label patients. Remission was associated with taxa with Barnsiella, Parabacteroides, Clostridium cluster IV and Ruminococcus. Moreover, Fusobacterium and Sutterella were associated with a lack of remission in all patients.

Rossen 2015 used the Human Intestinal Tract chip (HITchip) phylogenetic microarray, to perform microbiome diversity analysis. The study compared microbiota profiles of donors and patients 
with UC. Moreover, this study characterized microbiota profiles prior to and following FMT with donor stool or FMT with autologous stool. Finally, responders and non-responders for each FMT group were compared. Microbiome analysis with HITchip showed that microbiota profiles and diversity indexes of patients with UC was different than healthy donors. This was highlighted by enrichment in taxa belonging to the Bacteroidetes, Proteobacteria, Bacilli, and Clostridium clusters IX and XI and decreased levels of Clostridium IV, IXIVa, and XVIII compared to donors. Following FMT with both donor stool and autologous stool, diversity increased in responders and did not increase in non-responders. Shifts in the community taxa of responders could be observed in both donor and autologous FMTs. However, the shift between these two responder groups was distinct. Microbiota of FMT responders from donors were highlighted by increases in taxa belonging to the Clostridium IV, XIVa, and IVIII groups. Alternatively, the microbiota of responders that received autologous FMT was highlighted by an increase in Bacilli, Proteobacteria, and Bacteroidetes. Correlation analysis further revealed that microbiota of responding recipients showed increased similarity to donor microbiota following FMT. Importantly, no shifts in microbiota were observed in nonresponders.

\section{DISCUSSION}

\section{Summary of main results}

This review synthesized findings from four studies that assessed the efficacy of FMT in 277 adult participants who had active UC. The pooled results showed that FMT may increase rates of clinical remission by two-fold compared to the control group. The rate of serious adverse events is uncertain due to the wide confidence interval around the pooled effect estimate, which includes the possibility of more than a three-fold increase in harms. The use of FMT may increase rates of endoscopic remission at eight weeks and increase rates of clinical response in patients with UC. Three of these studies sought to define the impact of FMT on the gut microbiota. In each of these three studies, FMT was shown to be effective in altering the microbiota by shifting the community structure to one similar to the donor community. However, only one study was able to establish a correlation between specific members of the gut microbiota and clinical response. We did not find any randomized or cohort study with a control arm that assessed the efficacy of FMT for treatment of CD. We did not find any studies that assessed FMT in pediatric participants. We did not find any studies that assessed long-term maintenance of remission in participants with quiescent IBD.

\section{Overall completeness and applicability of evidence}

This review systematically assessed the efficacy and safety of FMT for treatment of IBD. Our objective was to assess the efficacy of FMT for induction and maintenance of remission in patients with $U C$ and CD. No randomized or cohort studies with a control arm assessed FMT as a treatment of CD. Four randomized studies assessed treatment of UC with FMT and the main objective of these studies was to assess the efficacy of FMT for induction of remission. These studies did not assess FMT as maintenance therapy. The included studies reported data on clinical and endoscopic remission and serious adverse events. Other secondary outcomes such as quality of life and microbiome outcomes were also reported.
The successful use of FMT for the treatment of UC seems to be biologically plausible. This is based on earlier observations that suggest that UC patients have microbiota dysbiosis (Bejaoui 2015; Kostic 2014; Vindigni 2016). In addition, other therapeutics agents targeting the microbiome, such as probiotics, have demonstrated efficacy for maintenance of remission in UC (Mallon 2007). A causal association between dysbiosis and UC seems to be further supported by the studies in this review, as microbiome analyses suggest differential response in the microbiota of responders compared to non-responders, highlighted by a shift towards the donor community microbiota in FMT responders (Moayyedi 2015; Paramsothy 2017a; Rossen 2015). Notably, Paramsothy 2017a was also able to identify several taxa that were associated with induction of remission and presence of other taxa that were associated with lack of effect. Similarly, increased alpha-diversity was associated with an increased likelihood of a positive response. It is important to note that composition of human microbiota is highly heterogeneous with high inter-individual variability. Thus, more in-depth analyses exploring the functional impact of FMT on the microbiota of IBD patients are needed. Furthermore, these studies did not explore other components of the microbiome such as the virome or fungome, which have been recently appreciated as important factors for health and disease (Carding 2017; Witherden 2017). Finally, it is not clear if non-microbial components of stool, such as bile acids, have any impact on treatment outcomes.

The treatment effect of FMT for induction of remission in UC was observed to be modest compared to use of FMT for treatment of recurrent C. difficile infection (Austin 2014; Cammarota 2015; Kassam 2013; Kelly 2016; Lee 2016; Leffler 2015; van Nood 2013; Youngster 2014). The reported efficacy of FMT for prevention of recurrent $C$.difficle is approximately $90 \%$ compared to a remission rate of approximately 37\% for UC (Kassam 2013; Kelly 2016; Youngster 2014). Based on this observation, it can be deduced that the included studies were probably underpowered to detect the effect of FMT for induction of remission and future studies should calculate the required sample size based on expected clinical remission rates of around $35 \%$ to $40 \%$. Also, the logistics of the intervention might be different for the treatment of UC compared to recurrent $C$. difficile. For example, a single administration of FMT might not be adequate to induce remission in people with active UC and multiple administrations might be required (Costello 2017a; Paramsothy 2017a). Also, donor characteristics may be critical, and the use of pooled donors may be preferred (Costello 2017a; Paramsothy 2017a). The route of administration might also play a role, with lower GI tract administration of greater benefit than upper GI tract administration (Costello 2017a; Paramsothy 2017a; Moayyedi 2015; Rossen 2015).

We are uncertain about the rate of serious adverse events due to the wide confidence interval around the pooled effect estimate, which includes the possibility of an increase in harms. The overall occurrence of serious adverse events was low with 10 events in 140 patients who underwent FMT and $7 / 137$ events in patients receiving placebo. The most common serious adverse event was worsening of ulcerative colitis that necessitated the use of intravenous corticosteroids or surgery. However, worsening of ulcerative colitis seems to occur in similar rates among control group participants (Costello 2017a; Paramsothy 2017a; Moayyedi 2015; Rossen 2015). None of the included studies reported on long-term adverse effects so future studies are needed to assess the long-term safety of stool 
transplantation in patients with IBD. Thus, no conclusive statement can be made about the safety of FMT at this time.

Data on long-term maintenance of remission was not reported on by the included studies. The primary focus of the included studies was to assess the efficacy and short-term safety of FMT for induction of clinical remission in UC. Rossen 2015 reported on clinical relapse at 12 weeks among participants who achieved clinical remission. There were no relapses in the FMT group (0/7) compared to a $20 \%(2 / 10)$ relapse rate in control participants. Moayyedi 2015 also assessed 37 participants who received FMT in an open label fashion at 12 months from study onset. Eight of the nine participants who went into remission during the double blind phase of the trial were in remission at 52 weeks without relapsing. Four of these individuals were able to stop all of their medications and remained in remission. Three of these eight participants had been receiving FMT once a month. The one participant out of nine who eventually relapsed, did so after a course of antibiotics. Eleven participants who did not go into remission in the double blind stage of the study chose to have further open label treatment with FMT for 6 to 12 weeks and four of these individuals went into remission. Of all the participants that had FMT and were followed for 52 weeks, one required a colectomy during this period. Paramsothy 2017 a planned a follow-up at 8 weeks after double blind or open label allocation to FMT and this assessment included 63 participants. Of the 35 participants who achieved remission after double blind or open label allocation to FMT, $23(66 \%)$ were in remission at 8 week follow-up. Five patients who were not in clinical remission after eight weeks of FMT therapy (open label or double blind), went into clinical remission during the next 8 weeks. Twenty out of 63 patients who underwent FMT required escalation of therapy during the eight week follow-up after completion of therapy. Therefore, overall, no conclusive statement can be made about long-term maintenance of remission and future double blind studies are needed to further define the role of FMT for maintenance of remission in both UC and CD.

\section{Quality of the evidence}

The overall certainty of the evidence was low for most of the outcomes. The GRADE criteria considers type of studies, risk of bias, indirectness, inconsistency (i.e. unexplained heterogeneity), imprecision, and potential publication bias. Most of our assessments were downgraded to lower levels due to inconsistency and imprecision. The overall number of events for the primary outcome was small (76/277) and the confidence interval around the pooled effect estimate was wide, thus yielding an imprecise summary effect estimate. Two of the included studies were stopped early due to futility issues (Moayyedi 2015; Rossen 2015). However, the Cochrane Handbook guidelines do not consider these studies to be at high risk of bias (Higgins 2011). We graded evidence for serious side effect as 'low'. We downgraded the evidence for this outcome based on very serious imprecision (i.e. 17 events). In summary, the results for the outcomes assessed in this review are uncertain and no firm conclusions regarding the efficacy and safety of FMT in active UC can be drawn.

\section{Potential biases in the review process}

This review was conducted following the standardized methods of the Cochrane Collaboration. We searched for both published, and ongoing studies. However, the number of included studies was small so the subgroup analyses lacked adequate power to provide definitive conclusions. The number of included studies was less than 10 , so we could not perform analyses to assess potential publication bias. We initially aimed to include single arm cohort studies. However, it was decided post-hoc that we would only include randomized trials and observational studies with a control arm. This decision was related to our concern that single arm studies may not provide comparative evidence and that two recent reviews performed meta-analysis of single arm cohort studies and are discussed below in the section on Agreements and disagreements with other studies or reviews (Costello 2017b; Paramsothy 2017b).

Some of the pooled analyses (i.e. Analysis 1.1; Analysis 1.13; Analysis 1.17 ) had a high level of statistical heterogeneity and it can be argued in some cases that data should not be pooled for these outcomes. However, we think that role of FMT for treatment of UC is biologically plausible and the variation in the direction and magnitude of effect (two main contributors to statistically heterogeneity) might be related to the conduct of the FMT intervention. For example, exclusion of the study by Rossen 2015 that used a nasoduodenal route for administration of FMT reduced the statistical heterogeneity to zero in Analysis 1.1 and Analysis 1.4. The same was shown for the subgroup analysis for the primary outcome based on route of administration, which indicated that all three studies that used rectal route for administration of FMT had a homogeneous effect in favor of treatment (Analysis 1.3). Based on this observation, it can be suggested that the rectal route might be better than administration via the upper GI tract; however, more studies are needed before a more conclusive statement can be made.

Recent literature has suggested the need to assess mucosal healing as part of the assessment of response to therapy for IBD as it might better predict long term outcomes, including risk of surgery (Auzoux 2016; De Preter 2012; Dulai 2015). We decided a priori that the primary outcome of 'clinical remission' would be based on definitions derived from clinical scores. This decision was based on a lack of a standardized definition of mucosal healing as there is currently no consensus on the method of assessment of mucosal healing. There is also no consensus on the extent of mucosal healing that would be associated with desired longterm outcomes (Armuzzi 2012; Auzoux 2016; Dave 2012; Dulai 2015; Peyrin-Biroulet 2012). In any case, we conducted a sensitivity analysis and a post-hoc analysis of a composite outcome of clinical and endoscopic remission as reported by the primary studies. Data on clinical remission defined by improvement in clinical scores were available from all studies except Moayyedi 2015. When this study was excluded from the analysis, the direction of the effect remained in favor of FMT; however, the effect size decreased (RR $1.79,95 \% \mathrm{Cl} 0.88$ to $3.63, \mathrm{I}^{2}=58 \%$ ). This attenuated effect was likely related to the small number of studies and small number of events in the remaining three studies. A post-hoc analysis of data from the four studies with definition of clinical remission based on clinical scores and endoscopic scores showed similar results to the primary analysis ( $\mathrm{RR} 2.77,95 \% \mathrm{Cl} 1.54$ to $4.98, \mathrm{I}^{2}=0 \%$ ). Interestingly, there was no statistical heterogeneity in this analysis. Thus, overall it seems likely that FMT might have a biologically plausible effect in favor of FMT irrespective of how clinical remission was defined. 


\section{Agreements and disagreements with other studies or reviews}

Two recent reviews have assessed the effect of FMT on the treatment of IBD and included both observational and randomized studies (Costello 2017b; Paramsothy 2017b). Both of these reviews meta-analyzed observational and randomized studies separately. The summary estimates for randomized studies were reported as odds ratios (OR) compared to risk ratios in our review.

Costello 2017b included 14 cohort studies and 4 randomized trials and assessed efficacy of FMT for UC only. The overall results from RCTs showed that FMT was associated with a beneficial effect for clinical remission (OR 3.67, $95 \% \mathrm{Cl} 1.82$ to 7.39 ) and clinical response (OR $2.48,95 \% \mathrm{Cl} 1.18$ to 5.21 ). The pooled data from single-arm cohort studies showed that $24 \%$ of the UC patients went into clinical remission after FMT. No meta-analysis of safety outcomes or endoscopic or laboratory outcomes was performed and no overall assessment was made for the quality of the evidence. The follow-up time for the primary outcome was also not reported.

Paramsothy 2017b included 53 studies and assessed the efficacy of FMT for the treatment of UC, CD, and pouchitis. This review included case reports, case series, single arm cohort studies and RCTs. Pooled data from four RCTs for UC showed that use of FMT was associated with an improvement in clinical remission (OR 2.89, $95 \% \mathrm{Cl} 1.36$ to 6.13 ) and clinical response rates (OR $2.48,95 \% \mathrm{Cl} 1.18$ to 5.21 ). Pooled data from 14 observational studies showed that $33 \%$ of UC patients achieved clinical remission after FMT. Pooled data from 6 cohort studies showed that 52\% of CD patients achieved clinical remission after FMT. Pooled data from 4 cohort studies showed $63 \%$ of CD patients had a clinical response after FMT. Data on the effect of FMT on pouchitis were reported by 4 studies; however, no meta-analyses were performed for this outcome. Data on safety outcomes were described but again no meta-analysis was performed. Moreover, no overall quality assessment was made for the combined data.

\section{AUTHORS' CONCLUSIONS}

\section{Implications for practice}

Fecal microbiota transplantation may increase the proportion of participants achieving clinical remission in UC. However, the number of identified studies was small and the quality of evidence was low. There is uncertainty about the rate of serious adverse events. As a result, no solid conclusions can be drawn at this time.

\section{Implications for research}

More studies are needed to further delineate some aspects of the intervention in terms of route (rectal versus upper GI tract), frequency, type of donor (single versus pooled donor), timing (primary induction versus rescue therapy), and preparation of stool (aerobic versus anaerobic; frozen versus fresh). Most of the patients in the included studies had mild to moderate UC and it is not clear if the efficacy will be similar, better or worse in patients with severe disease. Also, it is not clear if a combination of interventions, such as the use of antibiotics before the transplant or use of nutritional therapy or probiotics have advantages over FMT alone. No data were available for efficacy of FMT in paediatric patients with IBD so future studies are needed in this population. Future clinical trials are also needed to assess the efficacy of FMT for induction of remission in $C D$ and to assess the efficacy of FMT for maintenance of remission in UC and CD. Further, additional evaluations of the microbiome and metabolome are needed to establish the exact mechanism of action of FMT for the treatment of IBD. Currently, there are 13 ongoing studies (estimated enrolment of 1170 participants). This review will be updated when the results of these studies are available.

\section{ACK N O WLEDGEMENTS}

Funding for the Cochrane IBD Group (May 1, 2017 - April 30, 2022) has been provided by Crohn's and Colitis Canada (CCC). 


\section{RE F E R E N C E S}

\section{References to studies included in this review}

\section{Costello 2017a \{published data only\}}

Costello S, Waters O, Bryant R, Katsikeros R, Makanyanga J, Schoeman M, et al. Short duration, low intensity pooled faecal microbiota transplantation induces remission in patients with mild moderately active ulcerative colitis: a randomised controlled trial. Journal of Crohn's and Colitis 2017;11(Suppl 1):S23.

\section{Moayyedi 2015 \{published and unpublished data\}}

Moayyedi P, Surette M, Wolfe M, Taraschi R, Kim P, Libertucci J, et al. A randomized, placebo controlled trial of fecal microbiota therapy in active ulcerative colitis. Gastroenterology 2014;146(5):S-159.

* Moayyedi P, Surette MG, Kim PT, Libertucci J, Wolfe M, Onischi C, et al. Fecal Microbiota Transplantation Induces Remission in Patients With Active Ulcerative Colitis in a Randomized Controlled Trial. Gastroenterology 2015;149(1):102-9.

\section{Paramsothy 2017a \{published data only\}}

* Paramsothy S, Kamm MA, Kaakoush NO, Walsh AJ, van den Bogaerde J, Samuel D, et al. Multidonor intensive faecal microbiota transplantation for active ulcerative colitis: a randomised placebo-controlled trial. Lancet 2017;389(10075):1218-28.

Paramsothy S, Kamm MA, Walsh A, Van Den Bogaerde J, Samuel D, Leong RW, et al. Multi donor intense faecal microbiota transplantation is an effective treatment for resistant ulcerative colitis: A randomised placebo-controlled trial. Gastroenterology 2016;150(4):S122-3.

Paramsothy S, Kamm MA, Walsh AJ, Bogaerde J, Samuel D, Leong RWL, et al. Multi donor intense faecal microbiota transplantation is an effective treatment for resistant ulcerative colitis: a randomised placebo controlled trial and microbiota analysis. Journal of Gastroenterology and Hepatology. 2016; Vol. 31:143.

\section{Rossen 2015 \{published data only\}}

Fuentes S, Rossen NG, van der Spek MJ, Hartman JH, Huuskonen L, Korpela K, et al. Microbial shifts and signatures of long-term remission in ulcerative colitis after faecal microbiota transplantation. ISME Journal 2017;11(8):1877-89.

* Rossen NG, Fuentes S, van der Spek MJ, Tissen JG, Duflou A, Lowenberg $\mathrm{M}$, et al. Findings from a randomized controlled trial of fecal transplantation for patients with ulcerative colitis. Gastroenterology 2015;149(1):110-8.

\section{References to studies excluded from this review}

\section{Angelberger 2016 \{published data only\}}

Allegretti JR, Kassam Z, Smith M, Korzenik JR, Chan W. Irregular bowel movements following fecal microbiota transplantation (FMT) are associated with pre-existing irritable bowel syndrome but not FMT-related factors. Gastroenterology 2016;150(4):S742.
Borody 2003 \{published data only\}

Borody TJ, Warren EF, Leis S, Surace R, Ashman O. Treatment of ulcerative colitis using fecal bacteriotherapy. Journal of Clinical Gastroenterology 2003;37(1):42-7.

\section{Chin 2017 \{published data only\}}

Chin SM, Sauk J, Mahabamunuge J, Kaplan JL, Hohmann EL, Khalili H. Fecal Microbiota Transplantation for Recurrent Clostridium difficile Infection in Patients with Inflammatory Bowel Disease: A Single-Center Experience. Clinical Gastroenterology \& Hepatology 2017;15:597-9.

\section{Fischer 2016 \{published data only\}}

Fischer M, Kao D, Kelly C, Kuchipudi A, Jafri SM, Blumenkehl M, et al. Fecal Microbiota Transplantation is Safe and Efficacious for Recurrent or Refractory Clostridium difficile Infection in Patients with Inflammatory Bowel Disease. Inflammatory Bowel Diseases 2016;22(10):2402-9.

\section{Gionchetti 2000 \{published data only\}}

Gionchetti P, Rizzello F, Venturi A, Brigidi P, Matteuzzi D, Bazzocchi G, et al. Oral bacteriotherapy as maintenance treatment in patients with chronic pouchitis: a double-blind, placebo-controlled trial. Gastroenterology 2000;119(2):305-9.

\section{Hourigan 2015 \{published data only\}}

Hourigan S, Ann Chen L, Grigoryan Z. Microbiome changes associated with sustained eradication of clostridium difficile after fecal microbiota transplantation in children with and without inflammatory bowel disease. Gastroenterology 2015:S45.

Ishikawa 2017 \{published data only\}

Ishikawa D, Sasaki T, Osada T, Kuwahara-Arai K, Haga K, Shibuya $T$, et al. Changes in intestinal microbiota following combination therapy with fecal microbial transplantation and antibiotics for ulcerative colitis. Inflammatory Bowel Diseases 2017;23(1):116-25.

\section{Landy 2013 \{published data only\}}

Landy J, Al-Hassi HO, Mann ER, Peake ST, McLaughlin SD, Ciclitira PJ, et al. A prospective controlled pilot study of fecal microbiota transplantation for chronic refractory pouchitis. Gastroenterology 2013;144(5):S897.

\section{Mandalia 2016 \{published data only\}}

Mandalia A, Ward A, Tauxe W, Kraft CS, Dhere T. Fecal transplant is as effective and safe in immunocompromised as nonimmunocompromised patients for Clostridium difficile. International Journal of Colorectal Disease 2016;31(5):1059-60.

\section{Mintz 2016 \{published data only\}}

Mintz M, Monzur F, Chowdhury T, Rowejl L, Grewal S, Li E, et al. Comparing fecal microbial transplant outcomes in patients with recurrent clostridium difficile or ulcerative colitis. Inflammatory Bowel Diseases 2016;22(1):S31. 
Wei 2016 \{published data only\}

Wei Y, Gong J, Zhu W, Tian H, Ding C, Gu L, et al. Pectin enhances the effect of fecal microbiota transplantation in ulcerative colitis by delaying the loss of diversity of gut flora. BMC Microbiology 2016;16:255

\section{References to ongoing studies}

NCT01790061 \{published data only\}

NCT01790061. Standardized Fecal Microbiota Transplantation for Ulcerative Colitis [Efficacy, Durability and Safety of Standardized Fecal Microbiota Transplantation in Patients With Moderate to Severe Ulcerative Colitis]. clinicaltrials.gov/ct2/ show/NCT01790061 (first received 13 February 2013).

NCT01793831 \{published data only\}

NCT01793831. Standardized Fecal Microbiota Transplantation for Crohn's Disease [Efficacy and Safety of Standardized Fecal Microbiota Transplantation for Moderate to Severe Crohn's Disease]. clinicaltrials.gov/ct2/show/NCT01793831 (first received 18 February 2013).

\section{NCT01961492 \{published data only\}}

NCT01961492. Fecal Microbiota Transplantation in Patients with Ulcerative Colitis [Single Fecal Microbiota Transplantation Via Colonoscope as an Adjunct Therapy in the Treatment of Ulcerative Colitis]. clinicaltrials.gov/ct2/show/NCT01961492 (first received 11 October 2013).

\section{NCT02272868 \{published data only\}}

NCT02272868. Fecal Microbial Transplant in Pediatric Crohn's Disease (FMTCD) [Fecal Microbial Transplant in Pediatric Crohn's Disease: A Double Blind Placebo Control Study]. clinicaltrials.gov/ct2/show/NCT02272868 (first received 23 October 2014).

\section{NCT02291523 \{published data only\}}

NCT02291523. The Effect of Therapeutic Fecal Transplant on the Gut Microbiome in Children with Ulcerative Colitis (FMT_UC) [The Effect of Therapeutic Fecal Transplant on the Gut Microbiome in Children With Ulcerative Colitis]. clinicaltrials.gov/ct2/show/NCT02291523 (first received 14 November 2014).

\section{NCT02335281 \{published data only\}}

NCT02335281. Standardized Fecal Microbiota Transplantation for Inflammatory Bowel Disease (SFMT-IBD) [Efficacy, Durability and Safety of Standardized Fecal Microbiota Transplantation for Severe Inflammatory Bowel Disease]. clinicaltrials.gov/ct2/ show/NCT02335281 (first received 9 January 2015).

\section{NCT02390726 \{published data only\}}

NCT02390726. Fecal Microbiota Transplant in the Treatment of Ulcerative Colitis (FMTUC) [Fecal Microbiota Transplant in the Treatment of Ulcerative Colitis]. clinicaltrials.gov/ct2/show/ NCT02390726 (first received 17 March 2015).
Placebo-Controlled Trial of Human Fecal Microbiota Transplantation for the Therapy of Pediatric Ulcerative Colitis and Inflammatory Bowel Disease Unclassified]. clinicaltrials.gov/ct2/show/NCT02487238 (first received 1 July 2015).

Pai N, Popov J. Protocol for a randomised, placebo-controlled pilot study for assessing feasibility and efficacy of faecal microbiota transplantation in a paediatric ulcerative colitis population: PediFETCh trial. BMJ Open 2017;7:1-8.

Pai N, Popov J, Lee C. A randomized, placebo-controlled trial of fecal microbial transplantation for pediatric ulcerative colitis (pedifetch trial). Journal of Pediatric Gastroenterology and Nutrition 2016;63:S79-80.

\section{NCT02734589 \{unpublished data only\}}

NCT02734589. Pilot Study of Fecal Transplantation Using a Unique Diet for Donor and Recipient in Mild to Moderate Treatment Refractory Colitis in Inflammatory Bowel Disease [Fecal Transplantation Using a Novel Conditioning Method for Donor and Recipient in Mild to Moderate Treatment Refractory Colitis in Inflammatory Bowel Disease]. clinicaltrials.gov/ct2/ show/NCT02734589 (first received 12 April 2016).

\section{NCT02998112 \{published data only\}}

NCT02998112. Fecal Microbiota Transplantation for Ulcerative Colitis Through Colonic Transendoscopic Enteral Tubing [Fecal Microbiota Transplantation for Ulcerative Colitis Through Colonic Transendoscopic Enteral Tubing]. clinicaltrials.gov/ct2/ show/NCT02998112 (first received 20 December 2016).

\section{NCT03006809 \{published data only\}}

NCT03006809. Optimal Fecal Microbiota Transplant Dosing for Mild to Moderate Ulcerative Colitis [Optimal Fecal Microbiota Transplant Dosing for Mild to Moderate Ulcerative Colitis]. clinicaltrials.gov/ct2/show/NCT03006809 (first received 30 December 2016).

\section{NCT03016780 \{unpublished data only\}}

NCT03016780. Fecal Microbiota Transplantation for Ulcerative Colitis (FMTFUC) [Evaluation of The Effect of Fecal Microbiota Transplantation on Ulcerative Colitis and Its Mechanism]. clinicaltrials.gov/ct2/show/NCT03016780 (first received 11 January 2017).

\section{NCT03104036 \{published data only\}}

NCT03104036. Faecal Bacteriotherapy for Ulcerative Colitis (FACTU) [Faecal Bacteriotherapy for Ulcerative Colitis]. clinicaltrials.gov/ct2/show/NCT03104036 (first received 7 April 2017).

\section{Additional references}

\section{Abraham 2009}

Abraham C, Cho JH. Inflammatory bowel disease. New England Journal of Medicine 2009;361(21):2066-78.

\section{NCT02487238 \{published data only\}}

NCT02487238. Pediatric FEcal Microbiota Transplant for Ulcerative Colitis (PediFETCh) [A Single-Blind, Randomized, 


\section{Abraham 2012}

Abraham BP, Mehta S, El-Serag HB. Natural history of pediatriconset inflammatory bowel disease: a systematic review. Journal of Clinical Gastroenterology 2012;46(7):581-9.

\section{Ahuja 2010}

Ahuja V, Tandon RK. Inflammatory bowel disease in the Asia-Pacific area: a comparison with developed countries and regional differences. Journal of Digestive Diseases 2010;11(3):134-47.

\section{Alang 2015}

Alang N, Kelly CR. Weight gain after fecal microbiota transplantation. Open Forum Infectious Diseases 2015;2(1):ofv004.

\section{Ananthakrishnan 2015}

Ananthakrishnan A. Epidemiology and risk factors for IBD. Nature Reviews. Gastroenterology \& Hepatology 2015;12(4):205-17.

\section{Armuzzi 2012}

Armuzzi A, Van Assche G, Reinisch W, Pineton de Chambrun G, Griffiths A, Sladek M, et al. Results of the 2nd scientific workshop of the ECCO (IV): therapeutic strategies to enhance intestinal healing in inflammatory bowel disease. Journal of Crohn's \& Colitis 2012;6(4):492-502.

\section{Assa 2016}

Assa A, Butcher J, Li J, Elkadri A, Sherman PM, Muise AM, et al. Mucosa-Associated Ileal Microbiota in New-Onset Pediatric Crohn's Disease. Inflammatory Bowel Diseases 2016;22(7):1533-9.

\section{Austin 2014}

Austin M, Mellow M, Tierney WM. Fecal microbiota transplantation in the treatment of Clostridium difficile infections. American Journal of Medicine 2014;127(6):479-83.

\section{Auzoux 2016}

Auzoux J, Boschetti G, Lahlou W, Aubourg A, Girault A, Lecomte T, et al. Assessment of Mucosal Healing in Inflammatory Bowel Disease. Journal of Clinical Gastroenterology and Hepatology 2016;1(1):1-8.

\section{Bejaoui 2015}

Bejaoui M, Sokol H, Marteau P. Targeting the Microbiome in Inflammatory Bowel Disease: Critical Evaluation of Current Concepts and Moving to New Horizons. Digestive Diseases 2015;33(Suppl 1):105-12.

\section{Blanton 2016}

Blanton LV, Charbonneau MR, Salih T, Barratt MJ, Venkatesh S, Ilkaveya $\mathrm{O}$, et al. Gut bacteria that prevent growth impairments transmitted by microbiota from malnourished children. Science 2016;351(6275):1-14.

\section{Cammarota 2015}

Cammarota G, Masucci L, Ianiro G, Bibbo S, Dinoi G, Costamagna G, et al. Randomised clinical trial: faecal microbiota transplantation by colonoscopy vs. vancomycin for the treatment of recurrent Clostridium difficile infection. Alimentary Pharmacology \& Therapeutics 2015;41(9):835-43.

\section{Cammarota 2017}

Cammarota G, Ianiro G, Tilg H, Rajilić-Stojanović M, Kump P, Satokari R, et al. European consensus conference on faecal microbiota transplantation in clinical practice. Gut 2017; Vol. 66, issue 4:569-80.

\section{Carding 2017}

Carding SR, Davis N, Hoyles L. Review article: the human intestinal virome in health and disease. Alimentary Pharmacology \& Therapeutics 2017;46(9):800-15

\section{Chassaing 2011}

Chassaing B, Darfeuille-Michaud A. The commensal microbiota and enteropathogens in the pathogenesis of inflammatory bowel diseases. Gastroenterology 2011;140(6):1720-28.

\section{Cleynen 2016}

Cleynen I, Boucher G, Jostins L, Schumm LP, Zeissig S, Ahmad T, et al. Inherited determinants of Crohn's disease and ulcerative colitis phenotypes: a genetic association study. Lancet 2016; Vol. 387, issue 10014:156-67.

\section{Colman 2014}

Colman RJ, Rubin DT. Fecal microbiota transplantation as therapy for inflammatory bowel disease: a systematic review and meta-analysis. Journal of Crohn's \& Colitis 2014;8(12):1569-81.

\section{Costello 2017b}

Costello SP, Soo W, Bryant RV, Jairath V, Hart AL, Andrews JM. Systematic review with meta-analysis: faecal microbiota transplantation for the induction of remission for active ulcerative colitis. Alimentary Pharmacology \& Therapeutics 2017;46(3):213-24

\section{Dahlhamer 2016}

Dahlhamer JM, Zammitti EP, Ward BW, Wheaton AG, Croft JB. Prevalence of Inflammatory Bowel Disease Among Adults Aged $\geq 18$ Years - United States, 2015. MMWR. Morbidity and Mortality Weekly Report 2016;65(42):1166-9.

\section{Dave 2012}

Dave M, Loftus EV Jr. Mucosal healing in inflammatory bowel disease-a true paradigm of success?. Gastroenterology and Hepatology 2012;8(1):29-38.

\section{De Preter 2012}

De Preter V, Arijs I, Windey K, Vanhove W, Vermeire S, Schuit F, et al. Decreased mucosal sulfide detoxification is related to an impaired butyrate oxidation in ulcerative colitis. Inflammatory Bowel Diseases 2012;18(12):2371-80.

\section{Dulai 2015}

Dulai PS, Levesque BG, Feagan BG, D'Haens G, Sandborn WJ. Assessment of mucosal healing in inflammatory bowel disease: review. Gastrointestinal Endoscopy 2015;82(2):246-55. 


\section{Dumville 2006}

Dumville JC, Torgerson DJ, Hewitt CE. Reporting attrition in randomised controlled trials. BMJ 2006;332(7547):969-71.

\section{FDA 2016}

FDA. Enforcement Policy Regarding Investigational New Drug Requirements for Use of Fecal Microbiota for Transplantation to Treat Clostridium difficile Infection Not Responsive to Standard Therapies. https:// www.fda.gov/downloads/biologicsbloodvaccines/ guidancecomplianceregulatoryinformation/guidances/ vaccines/ucm488223.pdf (accessed 28 June 2017).

\section{Feakins 2013}

Feakins RM, British Society of Gastroenterology. Inflammatory bowel disease biopsies: updated British Society of Gastroenterology reporting guidelines. Journal of Clinical Pathology 2013;66(12):1005-26.

\section{Fuentes 2017}

Fuentes S, Rossen NG, van der Spek MJ, Hartman JH, Huuskonen L, Korpela K, et al. Microbial shifts and signatures of long-term remission in ulcerative colitis after faecal microbiota transplantation. ISME Journal 2017;11(8):1877-89.

\section{Gupta 2011}

Gupta SK. Intention-to-treat concept: A review. Perspectives in Clinical Research 2011;2(3):109-12.

\section{Guyatt 2011}

Guyatt G, Oxman AD, Akl EA, Kunz R, Vist G, Brozek J, et al. GRADE guidelines: 1 . Introduction-GRADE evidence profiles and summary of findings tables. Journal of Clinical Epidemiology 2011;64(4):383-94

\section{Higgins 2011}

Higgins JPT, Green S (editors). Cochrane Handbook for Systematic Reviews of Interventions Version 5.1.0 [updated September 2011]. The Cochrane Collaboration, 2011. Available from www.cochrane-handbook.org.

\section{Hozo 2005}

Hozo SP, Djulbegovic B, Hozo I. Estimating the mean and variance from the median, range, and the size of a sample. $B M C$ Medical Research Methodology 2005;20(5):13.

\section{Kassam 2013}

Kassam Z, Lee CH, Yuan Y, Hunt RH. Fecal microbiota transplantation for Clostridium difficile infection: systematic review and meta-analysis. American Journal of Gastroenterology 2013;108(4):500-8

\section{Kelly 2014}

Kelly CR, Ihunnah C, Fischer M, Khoruts A, Surawicz C, Afzali A, et al. Fecal microbiota transplant for treatment of Clostridium difficile infection in immunocompromised patients. American Journal of Gastroenterology 2014;109(7):1065-71.

\section{Kelly 2015}

Kelly CR, Kahn S, Kashyap P, Laine L, Rubin D, Atreja A, et al. Update on Fecal Microbiota Transplantation 2015: Indications,
Methodologies, Mechanisms, and Outlook. Gastroenterology 2015;149(1):223-37.

\section{Kelly 2016}

Kelly CR, Khoruts A, Staley C, Sadowsky MJ, Abd M, Alani M, et al. Effect of Fecal Microbiota Transplantation on Recurrence in Multiply Recurrent Clostridium difficile Infection: A Randomized Trial. Annals of Internal Medicine 2016; Vol. 165, issue 9:609-16.

\section{Khoruts 2016}

Khoruts A, Rank KM, Newman KM, Viskocil K, Vaughn BP, Hamilton MJ, et al. Inflammatory Bowel Disease Affects the Outcome of Fecal Microbiota Transplantation for Recurrent Clostridium difficile Infection. Clinical Gastroenterology \& Hepatology 2016;14(10):1433-8.

\section{Kostic 2014}

Kostic AD, Xavier RJ, Gevers D. The microbiome in inflammatory bowel disease: current status and the future ahead. Gastroenterology 2014;146(6):1489-99.

\section{Kunde 2013}

Kunde S, Pham A, Bonczyk S, Crumb T, Duba M, Conrad H Jr, et al. Safety, tolerability, and clinical response after fecal transplantation in children and young adults with ulcerative colitis. Journal of Pediatric Gastroenterology \& Nutrition 2013;56(6):597-601.

\section{Lee 2016}

Lee CH, Steiner T, Petrof EO, Smieja M, Roscoe D, Nematallah A, et al. Frozen vs Fresh Fecal Microbiota Transplantation and Clinical Resolution of Diarrhea in Patients With Recurrent Clostridium difficile Infection: A Randomized Clinical Trial. JAMA 2016; Vol. 315, issue 2:142-9.

\section{Leffler 2015}

Leffler DA, Lamont JT. Clostridium difficile infection. New England Journal of Medicine 2015;372(16):1539-48.

\section{Link 2016}

Link A, Lachmund T, Schulz C, Weigt J, Malfertheiner P. Endoscopic peroral jejunal fecal microbiota transplantation. Digestive \& Liver Disease 2016;48(11):1336-9.

\section{Mallon 2007}

Mallon P, McKay D, Kirk S, Gardiner K. Probiotics for induction of remission in ulcerative colitis. Cochrane Database of Systematic Reviews 2007, Issue 4. [DOI: 10.1002/14651858.CD005573.pub2]

\section{Mehta 2016}

Mehta F. Report: economic implications of inflammatory bowel disease and its management. American Journal of Managed Care 2016;22(3 Suppl):s51-60.

\section{Molodecky 2012}

Molodecky NA, Soon IS, Rabi DM, Ghali WA, Ferris M, Chernoff G, et al. Increasing incidence and prevalence of the inflammatory bowel diseases with time, based on systematic review. Gastroenterology 2012;142(1):46-54. 


\section{Moore 2014}

Moore T, Rodriguez A, Bakken JS. Fecal microbiota transplantation: a practical update for the infectious disease specialist. Clinical Infectious Diseases 2014;58(4):541-5.

\section{Morgan 2012}

Morgan XC, Tickle TL, Sokol H, Gevers D, Devaney KL, Ward DV, et al. Dysfunction of the intestinal microbiome in inflammatory bowel disease and treatment. Genome Biology 2012;13(9):R79.

\section{Mowat 2011}

Mowat C, Cole A, Windsor A, Ahmad T, Arnott I, Driscoll R, et al. Guidelines for the management of inflammatory bowel disease in adults. Gut 2011; Vol. 60, issue 5:571-607.

\section{Nagao-Kitamoto 2016}

Nagao-Kitamoto H, Shreiner A B, Gillilland MG 3rd, Kitamoto S, Ishii C, Hirayama A, et al. Functional Characterization of Inflammatory Bowel Disease-Associated Gut Dysbiosis in Gnotobiotic Mice. Cellular and Molecular Gastroenterology and Hepatology 2016;2(4):468-81.

\section{Naidoo 2011}

Naidoo K, Gordon M, Fagbemi AO, Thomas AG, Akobeng AK. Probiotics for maintenance of remission in ulcerative colitis. Cochrane Database of Systematic Reviews 2011, Issue 12. [DOI: 10.1002/14651858.CD007443.pub2]

\section{Osman 2016}

Osman M, Stoltzner Z, O'Brien K, Ling K, Koelsch E, Dubois N, et al. Donor Efficacy in Fecal Microbiota Transplantation for Recurrent Clostridium difficile: Evidence From a 1,999-Patient Cohort. Open Forum Infectious Diseases 2016;3(Suppl 1):841.

\section{Owens 2013}

Owens C, Broussard E, Surawicz C. Fecal microbiota transplantation and donor standardization. Trends in Microbiology 2013;21(9):443-5.

\section{Paramsothy 2017b}

Paramsothy S, Paramsothy R, Rubin DT, Kamm MA, Kaakoush NO, Mitchell HM, et al. Faecal Microbiota Transplantation for Inflammatory Bowel Disease: A Systematic Review and Meta-analysis. Journal of Crohn's \& Colitis 2017;11(10):1180-99.

\section{Petersen 2014}

Petersen C, Round JL. Defining dysbiosis and its influence on host immunity and disease. Cellular Microbiology 2014;16(7):1024-33.

\section{Peyrin-Biroulet 2012}

Peyrin-Biroulet L, Ferrante M, Magro F, Campbell S, Franchimont $\mathrm{D}$, Fidder $\mathrm{H}$, et al. Results from the 2nd Scientific Workshop of the ECCO. I: Impact of mucosal healing on the course of inflammatory bowel disease. Journal of Crohn's \& Colitis 2011 Oct;5(5):477-83.

\section{Rapozo 2017}

Rapozo DC, Bernardazzi C, de Souza HS. Diet and microbiota in inflammatory bowel disease: The gut in disharmony. World Journal of Gastroenterology 2017;23(12):2124-40.

\section{RevMan 2014 [Computer program]}

The Nordic Cochrane Centre, The Cochrane Collaboration. Review Manager (RevMan). Version 5.3. Copenhagen: The Nordic Cochrane Centre, The Cochrane Collaboration, 2014.

\section{Ridaura 2013}

Ridaura VK, Faith JJ, Rey FE, Cheng J, Duncan AE, Kau AL, et al. Gut microbiota from twins discordant for obesity modulate metabolism in mice. Science 2013;341(6150):1-15.

\section{Schulberg 2016}

Schulberg J, De Cruz P. Characterisation and therapeutic manipulation of the gut microbiome in inflammatory bowel disease. Internal Medicine Journal 2016;46(3):266-73.

\section{Shi 2016}

Shi Y, Dong Y, Huang W, Zhu D, Mao H, Su P. Fecal Microbiota Transplantation for Ulcerative Colitis: A Systematic Review and Meta-Analysis. PLoS One 2016;11(6):e0157259.

\section{Singh 2015}

Singh S, Stroud AM, Holubar SD, Sandborn WJ, Pardi DS. Treatment and prevention of pouchitis after ileal pouchanal anastomosis for chronic ulcerative colitis. Cochrane Database of Systematic Reviews 2015, Issue 11. [DOI: 10.1002/14651858.CD001176.pub3]

\section{Solari 2014}

Solari PR, Fairchild PG, Noa LJ, Wallace MR. Tempered enthusiasm for fecal transplant. Clinical Infectious Diseases 2014;59(2):319.

\section{Sun 2016}

Sun D, Li W, Li S, Cen Y, Xu Q, Li Y, et al. Fecal Microbiota Transplantation as a Novel Therapy for Ulcerative Colitis: A Systematic Review and Meta-Analysis. Medicine 2016;95(23):e3765.

\section{van Nood 2013}

van Nood E, Vrieze A, Nieuwdorp M, Fuentes S, Zoetendal EG, de Vos WM, et al. Duodenal infusion of donor feces for recurrent Clostridium difficile. New England Journal of Medicine 2013; Vol. 368, issue 5:407-15.

\section{Vindigni 2016}

Vindigni SM, Zisman TL, Suskind DL, Damman CJ. The intestinal microbiome, barrier function, and immune system in inflammatory bowel disease: a tripartite pathophysiological circuit with implications for new therapeutic directions. Therapeutic Advances in Gastroenterology 2016;9(4):606-25.

\section{Weintraub 2014}

Weintraub Y, Mimouni FB, Cohen S. Temporal trends in inflammatory bowel disease publications over a 19-years period. World Journal of Gastroenterology 2014;20(44):16745-9. 


\title{
Wells 2017
}

Wells GA, Shea B, O'Connell D, Peterson J, Welch V, Losos M, et al. The Newcastle-Ottawa Scale (NOS) for assessing the quality of nonrandomised studies in meta-analyses. Department of Epidemiology and Community Medicine, University of Ottawa, Canada. Available from http://www.ohri.ca/programs/ clinical_epidemiology/oxford.asp (accessed 7 June 2017).

\section{Witherden 2017}

Witherden EA, Shoaie S, Hall RA, Moyes DL. The Human Mucosal Mycobiome and Fungal Community Interactions. Journal of Fungi 2017;3(4):56.

\section{CHARACTERISTICS OF STUDIES}

Characteristics of included studies [ordered by study ID]

Costello 2017a

\begin{tabular}{ll}
\hline Methods & A multi-center randomized, double-blind, placebo-controlled trial conducted in Australia \\
\hline Participants & Inclusion Criteria \\
& Adults with active UC (total Mayo 3 to 10 with an endoscopic Mayo sub-score $\geq 2)$ \\
$\mathrm{N}=73$
\end{tabular}

Interventions

\section{Intervention:}

Anaerobically prepared donor stool (pooled from 3 to 4 donors); $\mathrm{n}=38$

Route: First administration via colonoscopy followed by 2 enemas by day 7

\section{Comparison:}

Autologous FMT (placebo) $n=35$

\section{Outcomes}

\section{Primary outcome}

Steroid-free remission of UC as defined by a total Mayo score of $\leq 2$ with an endoscopic Mayo score of $\leq 1$ at week

\author{
Secondary Outcomes: \\ Clinical response ( $\geq 3$ point reduction in Mayo score) \\ Clinical remission (SCCAI $\leq 2)$ \\ Endoscopic remission (Mayo $\leq 1$ ) \\ Adverse Events
}

\begin{tabular}{ll}
\hline Notes & $\begin{array}{l}\text { Study information was available in the form of an abstract } \\
\text { Further information was provided by the authors on request; however, this did not include enough in- } \\
\text { formation that a complete risk of bias assessment could be made }\end{array}$ \\
\hline Risk of bias & Authors' judgement Support for judgement \\
\hline Bias &
\end{tabular}


Costello 2017a (Continued)

Random sequence genera- Unclear risk Study reported as an abstract and no further information was available tion (selection bias)

Allocation concealment $\quad$ Unclear risk Study reported as an abstract and no further information was available
(selection bias)
(selection bias)

Study reported as an abstract and no further information was available

Blinding of participants Unclear risk

and personnel (perfor-

Study reported as an abstract and no further information was available

mance bias)

All outcomes

Blinding of outcome as-
sessment (detection bias) $\quad$ Unclear risk Study reported as an abstract and no further information was available

All outcomes

Incomplete outcome data Low risk Comment: Overall attrition: $4 \%$

(attrition bias)

All outcomes

\begin{tabular}{lll}
\hline $\begin{array}{l}\text { Selective reporting (re- } \\
\text { porting bias) }\end{array}$ & Unclear risk & Study reported as an abstract and no further information was available \\
\hline Other bias & Unclear risk & Study reported as an abstract and no further information was available \\
\hline
\end{tabular}

Moayyedi 2015

Methods Randomized, double blind trial conducted in Canada

Participants

\section{The inclusion criteria}

Adult patients 18 years or older with UC $(\mathrm{N}=75)$

Active UC defined as a Mayo Clinic score $>4$ with an endoscopic Mayo Clinic score $>1$

Concomitant treatments for UC, such as mesalamine, glucocorticoids, immunosuppressive therapy

(e.g. azathioprine), or tumor necrosis factor antagonists were permitted, provided these had been used at a stable dose for at least 12 weeks (4 weeks for glucocorticoids) and disease remained active

\section{The Exclusion Criteria}

Use of antibiotics or probiotics in the last 30 days

Concomitant Clostridium difficile infection or another enteric pathogen

Disease severity that required hospitalization

Pregnancy

Unable to give informed consent

\section{Interventions Study Intervention}

Single donor feces (multiple donors recruited for study but one patient received feces from one donor only); $\mathrm{n}=38$

Route: Retention enema

Frequency: 1 times per weeks for 6 weeks, total 6 treatments 
Moayyedi 2015 (Continued)

Weight of stool: $50 \mathrm{~g}$

Volume administer per treatment: $50 \mathrm{ml}$

\section{Comparison:}

Placebo (water); $\mathrm{n}=37$

Route: Retention enema

Frequency: 1 times per weeks for 6 weeks, total 6 treatments

Volume administer per treatment: $50 \mathrm{ml}$

Primary Outcome:
UC remission at week 7 , defined as a full Mayo score $<3$ and complete healing of the mucosa at flexible
sigmoidoscopy (endoscopic Mayo score $=0$ )

\section{Secondary Outcomes:}

Clinical response: Improvement in UC symptoms (defined as 3 improvement in full Mayo score), change in Mayo score, IBDQ, EQ-5D scores, ESR, CRP, adverse events

\begin{tabular}{ll}
\hline Notes & Study was stopped early due to futility \\
Data on quality of life scores was reported as change from baseline
\end{tabular}

\section{Risk of bias}

\begin{tabular}{lll}
\hline Bias & Authors' judgement & Support for judgement \\
\hline $\begin{array}{ll}\text { Random sequence genera- } \\
\text { tion (selection bias) }\end{array}$ & Low risk & $\begin{array}{l}\text { Quote: "Eligible patients were randomized 1:1 according to a computer-gener- } \\
\text { ated randomization" }\end{array}$ \\
& & Comment: Most likely done
\end{tabular}

\begin{tabular}{ll}
\hline $\begin{array}{l}\text { Allocation concealment } \\
\text { (selection bias) }\end{array}$ & Low risk \\
& ogy Clinical Trials Unit to ensure concealment of allocation" \\
Comment: Most likely done
\end{tabular}

\begin{tabular}{ll}
\hline $\begin{array}{l}\text { Blinding of participants } \\
\text { and personnel (perfor- }\end{array}$ & Low risk \\
$\begin{array}{l}\text { mance bias) } \\
\text { All outcomes }\end{array}$ & $\begin{array}{l}\text { Quote: "The treatment location was masked to the patient, health care work- } \\
\text { ers caring for the patient, and investigators" }\end{array}$ \\
\end{tabular}

\begin{tabular}{|c|c|c|}
\hline $\begin{array}{l}\text { Blinding of outcome as- } \\
\text { sessment (detection bias) } \\
\text { All outcomes }\end{array}$ & Low risk & $\begin{array}{l}\text { Quote: "The treatment location was masked to the patient, health care work- } \\
\text { ers caring for the patient, and investigators" } \\
\text { Comment: Most likely done }\end{array}$ \\
\hline
\end{tabular}

\begin{tabular}{ll}
\hline $\begin{array}{l}\text { Incomplete outcome data } \\
\text { (attrition bias) }\end{array}$ & Low risk \\
All outcomes & $\begin{array}{l}\text { Comment: Overall loss to follow up was 6\%, the reason for attrition was similar } \\
\text { between the two groups }\end{array}$
\end{tabular}

\begin{tabular}{lll}
\hline $\begin{array}{l}\text { Selective reporting (re- } \\
\text { porting bias) }\end{array}$ & Low risk & Comment: Authors seem to report all the a priori outcomes \\
\hline Other bias & Low risk & $\begin{array}{l}\text { Comment: The trial was stopped early due to futility; however, the data was with } \\
\text { completely described for included patients }\end{array}$ \\
\hline \hline
\end{tabular}




Methods Randomized, double blind trial conducted in Australia

Participants

\section{The inclusion Criteria}

Adult patients aged 18 to 75 years with UC for greater than 3 months $(N=81)$

Clinically and endoscopically active UC, with a total Mayo score of 4 to 10 and the Mayo endoscopy subscore to be 1 or greater and physician's global assessment subscore 2 or less.

Provide written informed consent to participate as shown by a signature on the consent form

\section{Exclusion criteria}

Consent not obtained or unavailable or inability to communicate with the investigators.

Pregnancy, lack of contraception for non-pregnant women

Patient in remission, proctitis $<5 \mathrm{~cm}$, non-UC IBD, perianal disease, constipation-predominant $\mathrm{UC}$ with

$<3$ bowel motions/day, mild UC (Mayo score $<4$ )

Severe UC (Mayo score > 10), severe anaemia, leucopenia or granulocytopenia, toxic megacolon Active gastrointestinal infection, Irritable bowel syndrome, diverticulitis, neoplasm etc.

Significant gastrointestinal surgery e.g. colon resection, colectomy

Medications: antimicrobials (antibiotics, antifungals, antivirals), biologics e.g. infliximab, adalimumab;

calcineurin inhibitors; mammalian target of rapamycin inhibitors, chemotherapeutic anti-neoplastic

agents, lymphocyte depleting biological agents; probiotic therapy; experimental drug

Steroid dependency: requiring $>20 \mathrm{mg}$ prednisone or $>9 \mathrm{mg}$ budesonide daily

Clinical evidence of any major, co-morbid chronic disease

Patients with food hypersensitivity

\section{Study Intervention}

Donor: Multidonor feces; $n=41$

Route: First infusion in terminal Ileum, then colonic enemas

Frequency: 5 times per weeks for 8 weeks, total 40 treatments

Weight of stool: $37.5 \mathrm{~g}$

Volume per treatment: $150 \mathrm{ml}$

\section{Comparison}

Placebo: Isotonic Saline; $\mathrm{n}=40$

Route: First infusion in terminal Ileum, then colonic enemas

Frequency: 5 times per weeks for 8 weeks, total 40 treatments

Volume per treatment: $150 \mathrm{ml}$

Outcomes

Primary Outcome: composite of steroid-free clinical remission at week 8 (defined as a total Mayo score of 2 or less) and endoscopic remission or response which (Mayo subscores of 1 or less, and at least a 1 point reduction from baseline in the endoscopy subscore)

\section{Secondary Outcomes}

Steroid-free clinical remission at week 8 (defined as combined Mayo subscores of 1 or less for rectal bleeding plus stool frequency) 
Paramsothy 2017a (Continued)

Steroid-free clinical response (defined as either a decrease of 3 points or more on the Mayo score, a $50 \%$ or greater reduction from baseline in combined rectal bleeding plus stool frequency Mayo subscores, or both)

Steroid-free endoscopic response at week 8 (defined as a Mayo endoscopy subscore of 1 or less, with a reduction of at least 1 point from baseline)

Steroid-free endoscopic remission at week 8 (defined as a Mayo endoscopy subscore of 0)

Quality of life (assessed with the IBDQ)

Adverse events

Notes

Data on quality of life scores was reported as medians and range and was converted to mean and standard deviation by methods given in Hozo 2005

\section{Risk of bias}

\begin{tabular}{lll}
\hline Bias & Authors' judgement & Support for judgement \\
\hline $\begin{array}{ll}\text { Random sequence genera- } \\
\text { tion (selection bias) }\end{array}$ & Low risk & $\begin{array}{l}\text { Quote: "using a pre-established computer-generated randomisation list with } \\
\text { permutated blocks of four and stratified for study site and concomitant corti- } \\
\text { costeroid use" } \\
\text { Comment: Most likely done }\end{array}$ \\
& & \\
\hline
\end{tabular}

\begin{tabular}{ll}
\hline $\begin{array}{l}\text { Allocation concealment } \\
\text { (selection bias) }\end{array}$ & Low risk \\
& Quote: "Patients were randomized centrally by the Centre for Digestive Dis- \\
eases after screening in a 1:1 ratio"
\end{tabular}

Comment Most likely done

\begin{tabular}{ll}
\hline $\begin{array}{l}\text { Blinding of participants } \\
\text { and personnel (perfor- }\end{array}$ & Low risk \\
$\begin{array}{l}\text { mance bias) } \\
\text { All outcomes }\end{array}$ & Comment: Most likely done
\end{tabular}

Blinding of outcome as-
sessment (detection bias)
sessment (detection bias)

All outcomes Quote: "Study investigators who played a participants' assessment did not see
the investigational product at any time"

Comment: Most likely done

\begin{tabular}{ll}
\hline $\begin{array}{l}\text { Incomplete outcome data } \\
\text { (attrition bias) }\end{array}$ & Low risk \\
All outcomes & Overall attrition: $24 \%$ \\
& $\begin{array}{l}\text { The dropout rate was similar in both groups and reason for drop outs were giv- } \\
\text { en and they were similar in both groups }\end{array}$
\end{tabular}

\begin{tabular}{lll}
\hline $\begin{array}{l}\text { Selective reporting (re- } \\
\text { porting bias) }\end{array}$ & Low risk & $\begin{array}{l}\text { Comment: The authors seems to report all the a priori outcomes } \\
\text { The trial was registered with ClinicalTrials.gov, number NCT01896635 }\end{array}$ \\
\hline Other bias & Low risk & Comment: No other major risk of bias was noticed \\
\hline
\end{tabular}

Rossen 2015

Methods Randomized, double blind trial conducted in the Netherlands

Participants

\section{The Inclusion criteria}

Adult patients with UC $(\mathrm{N}=48)$ 
Rossen 2015 (Continued)

Established UC according to the Lennard-Jones criteria, a patient-reported SCCAI of between 4 and 11 and stable medication, which was continued during the study period

Subjects were allowed stable doses of thiopurines, mesalamine, or corticosteroids $10 \mathrm{mg} /$ day for the 8 weeks before inclusion

An endoscopic Mayo score of 1 at baseline sigmoidoscopy

\section{The exclusion criteria}

An infectious cause of a UC disease flare

A history of colectomy

A current stoma

A life expectancy of $<12$ months

Pregnancy

Hospital admission

Use antibiotics or probiotics within 6 weeks before inclusion.

Use of antitumour necrosis factor or methotrexate treatment within 8 weeks before inclusion, or cyclosporine within 4 weeks before inclusion

Interventions

\section{Study Intervention}

Stool transplant: Single donor feces; $\mathrm{n}=23$

Route: Nasoduodenal

Frequency: 1 times per 3 weeks, total 2 treatments

Weight of stool: $120 \mathrm{~g}$

Volume administer per treatment: $500 \mathrm{ml}$

Comparison:

Placebo: autologous feces; $n=25$

Route: Nasoduodenal

Frequency: 1 times per 3 weeks, total 2 treatments

Weight of stool: $120 \mathrm{~g}$

Volume administer per treatment: $500 \mathrm{ml}$

\section{Primary outcome:}

Combination of clinical remission (defined as a SCCAI score 2) and 1-point improvement on the combined Mayo endoscopic score of the sigmoid and rectum, as compared with baseline sigmoidoscopy at week 12

\section{Secondary Outcomes:}

Clinical response (defined as a reduction of 1.5 points on the SCCAI) at week 12

Clinical remission (defined as a SCCAI of 2) at week 12

Endoscopic response at week 12

Change in median IBDQ score at week 12 
Rossen 2015 (Continued)

Adverse events

Notes Study was stopped early due to futility

Multiple donors recruited for study but one patient received feces from one donor only

\section{Risk of bias}

\begin{tabular}{|c|c|c|}
\hline Bias & Authors' judgement & Support for judgement \\
\hline $\begin{array}{l}\text { Random sequence genera- } \\
\text { tion (selection bias) }\end{array}$ & Low risk & $\begin{array}{l}\text { Quote from study protocol: "Alea software will be used to perform randomisa- } \\
\text { tion" }\end{array}$ \\
\hline \multirow[t]{2}{*}{$\begin{array}{l}\text { Allocation concealment } \\
\text { (selection bias) }\end{array}$} & Low risk & $\begin{array}{l}\text { Quote from study protocol: "Randomisation and preparation of the feces will } \\
\text { be performed by one of the research nurses, she is the only person who will } \\
\text { know which treatment the patient will be given and will have no role in further } \\
\text { part of the study" }\end{array}$ \\
\hline & & Comment: Most likely done \\
\hline \multirow{2}{*}{$\begin{array}{l}\text { Blinding of participants } \\
\text { and personnel (perfor- } \\
\text { mance bias) } \\
\text { All outcomes }\end{array}$} & Low risk & $\begin{array}{l}\text { Quote from study protocol: "Patients will be blinded until Follow-up data until } \\
\text { the end of the study (t:12 months) is collected" }\end{array}$ \\
\hline & & Comment: Most likely done \\
\hline $\begin{array}{l}\text { Blinding of outcome as- } \\
\text { sessment (detection bias) } \\
\text { All outcomes }\end{array}$ & Low risk & $\begin{array}{l}\text { Quote from study protocol: "Blinding of participants and trial members was } \\
\text { guaranteed by collecting both donor and recipient feces on both treatment } \\
\text { days" }\end{array}$ \\
\hline \multirow{2}{*}{$\begin{array}{l}\text { Incomplete outcome data } \\
\text { (attrition bias) } \\
\text { All outcomes }\end{array}$} & Low risk & Overall, $25 \%$ attrition \\
\hline & & $\begin{array}{l}\text { The dropout rate was similar in both groups. Reason for drop outs were given } \\
\text { and they were similar in both groups }\end{array}$ \\
\hline \multirow{3}{*}{$\begin{array}{l}\text { Selective reporting (re- } \\
\text { porting bias) }\end{array}$} & Low risk & Comment: The authors seems to report all the a priori outcomes \\
\hline & & The trial was registered at ClinicalTrials.gov Number: NCT01650038 \\
\hline & & Study protocol was available for review \\
\hline Other bias & Low risk & $\begin{array}{l}\text { Comment: The trial was stopped earlier due to futility; however, the data was } \\
\text { completely described for included patients }\end{array}$ \\
\hline
\end{tabular}

UC: ulcerative colitis

FMT: fecal microbiota transplantation

SCCAI: Simple Clinical Colitis Activity Index

IBDQ: Inflammatory Bowel Disease Questionnaire

EQ-5D: EuroQoL Group Quality of Life Questionnaire

ESR: erythrocyte sedimentation rate

CRP: C-reactive protein

Characteristics of excluded studies [ordered by study ID]

\begin{tabular}{ll}
\hline Study & Reason for exclusion \\
\hline Angelberger 2016 & Cohort study that included patients with recurrent Clostridium difficile infection \\
\hline
\end{tabular}




\begin{tabular}{|c|c|}
\hline Study & Reason for exclusion \\
\hline Borody 2003 & This was a case series \\
\hline \multirow[t]{2}{*}{ Chin 2017} & Study included patients with IBD who had recurrent Clostridium difficile infection \\
\hline & FMT was done for treatment of recurrent Clostridium difficile infection \\
\hline Fischer 2016 & Study included patients with IBD who had recurrent Clostridium difficile infection \\
\hline Gionchetti 2000 & The intervention was probiotics (VSL\#3) and not FMT \\
\hline Hourigan 2015 & The comparison group included children without IBD \\
\hline Ishikawa 2017 & $\begin{array}{l}\text { Both the study groups received FMT, one group received FMT with antibiotics and the other group } \\
\text { received FMT without antibiotics }\end{array}$ \\
\hline Landy 2013 & This study included patients with pouchitis only \\
\hline Mandalia 2016 & Study included IBD patients who had recurrent Clostridium difficile infection \\
\hline \multirow[t]{2}{*}{ Mintz 2016} & The study also did not have the control arm \\
\hline & This study included patients with recurrent Clostridium difficile and UC \\
\hline Wei 2016 & $\begin{array}{l}\text { Both groups received FMT, one group received FMT plus pectin and the other group received FMT } \\
\text { only }\end{array}$ \\
\hline
\end{tabular}

IBD: inflammatory bowel disease

FMT: fecal microbiota transplantation

UC: ulcerative colitis

Characteristics of ongoing studies [ordered by study ID]

\begin{tabular}{ll}
\hline NCT01790061 & Standardized Fecal Microbiota Transplantation for Ulcerative Colitis \\
\hline Trial name or title & Interventional clinical trial, non-randomized \\
\hline Participants & Inclusion Criteria: \\
& - Moderate to severe UC (Montreal classification) \\
& Exclusion Criteria: \\
& - First diagnosis of UC \\
- No history of using biologic, immunomodulatory therapy or corticosteroid therapy \\
- Participants with contraindication for endoscopy
\end{tabular}

Interventions

Intervention: Standardized FMT

FMT by gastroscopy administration of fresh or frozen bacteria from healthy donor to the mid-gut or whole colon

\section{Comparison: Traditional treatments}

Traditional treatments according to associated guidelines 
NCT01790061 (Continued)

Outcomes

\section{Primary Outcome Measures}

- Efficacy of FMT [Time Frame: One year]

The efficacy and durability of clinical remission (days) after FMT procedure defined as Montreal score SO (clinical remission)

\section{Secondary Outcome Measures}

- Adverse events [Time Frame: Ten years]

\begin{tabular}{ll}
\hline Starting date & November 2012 \\
\hline Contact information & $\begin{array}{l}\text { Faming Zhang, Associate Professor, Gastroenterology, The Second Hospital of Nanjing Medical Uni- } \\
\text { versity }\end{array}$ \\
\hline Notes & Estimated enrolment: 500 \\
\hline
\end{tabular}

\section{NCT01793831}

\begin{tabular}{ll}
\hline Trial name or title & Standardized Fecal Microbiota Transplantation for Crohn's Disease \\
\hline Methods & Interventional (clinical trial), randomized \\
\hline Participants & Inclusion Criteria: \\
& - Moderate to severe CD defined as an HBI score $>4$ \\
& - Mgentreal classification: no limitation, except age $>6$ \\
& Exclusion Criteria: \\
& - First diagnosis of CD or first year \\
& No history of using 5-ASA, biological or immunomodulatory therapy
\end{tabular}

Interventions

\section{Experimental: Fecal microbiota transplantation}

Standard FMT, administered once.

\section{Sham Comparator: Traditional treatments, e.g. 5-ASA}

Traditional treatments according to associated guidelines, including 5-ASA, immunomodulatory therapy, corticosteroids, and biologics

\section{Outcomes}

\section{Primary Outcome Measures}

- Clinical remission [Time Frame: Up to one year]

- Clinical remission defined as $\mathrm{HBI}$ score $\leqq 4$. The endpoint for follow-up is the time of clinical recurrence

\section{Secondary Outcome Measures :}

- Costs [Time Frame: Up to one year]

- Social and medical costs Adverse events [Time Frame: During FMT and ten years after FMT]

- All possible adverse events: fever,abdominal pain, infectious diseases and others 
NCT01793831 (Continued)

Contact information

Faming Zhang, Associate Professor, Gastroenterology, The Second Hospital of Nanjing Medical University

Notes

Estimated enrolment: 30

NCT01961492

\begin{tabular}{ll}
\hline Trial name or title & Fecal Microbiota Transplantation in Patients With Ulcerative Colitis \\
\hline Methods & Interventional (clinical trial), randomized \\
\hline Participants & Inclusion Criteria: \\
& Active UC (PUCAI 10 to 64) in whom fecal microbiota transplantation via colonoscope can be per- \\
& formed \\
& Age 1 year to 75 years \\
& Exclusion Criteria: \\
& Severe ulcerative colitis (PUCAI > 65)
\end{tabular}

\section{Interventions Intervention: Fecal microbiota transplantation}

A single FMT via colonoscope as an adjunct therapy to standard medical treatment

\section{Comparison: Standard medical treatment}

Standard medical treatment as recommended by the ECCO Guidelines of UC therapy

\begin{tabular}{|c|c|}
\hline Outcomes & $\begin{array}{l}\text { Primary Outcome Measures } \\
\text { - Activity of UC [Time Frame: Within } 1 \text { year after the intervention] } \\
\text { - Change from baseline in the PUCAI at } 1 \text { month, } 3 \text { months, } 6 \text { months, and } 12 \text { months } \\
\text { Secondary Outcome Measures } \\
\text { - Colonic inflammation } \\
\text { - Change from baseline in fecal calprotectin levels at } 1 \text { month, } 3 \text { months, } 6 \text { months, and } 12 \text { months } \\
\text { - Colonic inflammation } \\
\text { - Endoscopic Mayo score at } 3 \text { and } 12 \text { months after the intervention } \\
\text { - Adverse events }\end{array}$ \\
\hline Starting date & October 2013 \\
\hline Contact information & Marko Kalliomäki, Specialist, Turku University Hospital \\
\hline Notes & Estimated enrolment: 40 \\
\hline
\end{tabular}

\begin{tabular}{ll}
\hline Trial name or title & Fecal Microbial Transplant in Pediatric Crohn's Disease (FMTCD) \\
\hline Methods & Interventional clinical trial, randomized \\
\hline Participants & Inclusion criteria: \\
\hline
\end{tabular}


- Children and adolescents (12 to 21 years)

- Diagnosis of CD made by a primary gastroenterologist based upon history, physical exam, laboratory/radiological studies and gastrointestinal histology

- Mild or moderate disease activity based upon PCDAl score (15 to 45)

- Parent/guardian and child must be able to comprehend the consent and assent in English; Parent/guardian and participant must be able to attend study visits at baseline, and weeks $+2,+6,+12$

- Patient must not have medication changes for his/her inflammatory bowel disease medications for at least 1 months prior to enrolment

- Stool donor available from family member

- Patient agreeable to nasogastric tube placement

\section{Exclusion Criteria}

- $\mathrm{PCDAl}<15$ or PCDAl $>45$

- Active or history of intraabdominal abscess, perianal abscess, perianal fistula, intraabdominal fistula, stricturing Crohn's disease

- Other serious medical conditions such as neurological, liver, kidney, autoimmune or systemic disease

- recipients allergic to any product used in the study, including rifaximin, omeprazole and MiraLAX

- Pregnant or nursing subjects will be excluded as transplant recipients

- Female recipients of child-bearing potential will abstinent or willing to use adequate birth control from screening until the end of the study

- Patients who cannot tolerate NG tube placement, such as those with recent surgery or trauma to the nares will be excluded

- Presence of a condition or abnormality that in the opinion of the investigator would compromise the safety of the patient or the quality of the data

\begin{tabular}{ll}
\hline Interventions & $\begin{array}{l}\text { intervention: Fecal microbiome transplant } \\
\text { Pretransplant (Rifaximin } 400 \mathrm{mg} 3 \text { times daily } \times 10 \text { days + omeprazole } 20 \text { mg night before trans- } \\
\text { plant and day of transplant + MiraLAX } 17 \mathrm{~g} 3 \text { times daily } \times 2 \text { days) + FMT } \\
\text { Comparison: Normal saline } \\
\text { Pretransplant (Rifaximin } 400 \mathrm{mg} 3 \text { times per day x } 10 \text { days + omeprazole } 20 \text { mg night before trans- } \\
\text { plant and day of transplant + miralax } 17 \mathrm{~g} 3 \text { times per day x 2 days) + normal saline }\end{array}$ \\
\hline Outcomes & Primary Outcome Measures \\
\hline Starting date & PCDAl \\
\hline Contact information & David Suskind, Principal Investigator, Seattle Children's Hospital \\
\hline Notes & Trial completed \\
No results available \\
7 participants
\end{tabular}


NCT02291523 (Continued)

Methods Interventional (clinical trial), randomized

Participants

Interventions

\section{Inclusion Criteria}

- Age: 7 to 21 years who have been diagnosed with UC

- Mild to moderate disease based on PUCAl with a score of 10 to 64

- Need for colonoscopy

\section{Exclusion Criteria}

- Children who are known to be resistant to steroid therapy, immunomodulators and biologics, or on a steroid dose greater than $0.5 \mathrm{mg} / \mathrm{kg} /$ day (maximum $20 \mathrm{mg}$ )

- Children with recent dose change of biologics (within 4 weeks), 5-ASA, steroids or immunomodulators (within 4 weeks)

- Allergy to or intolerance of mesalamine or 5-ASA products

- Any evidence of infectious colitis

- Concurrent infections that require anti-microbial therapy (such as abdominal abscess, pneumonia, etc.)

- Unable to give informed consent/assent

- Have received probiotic preparations $\leq 4$ weeks prior to randomization

- Pregnancy and breast feeding in patient subjects of childbearing potential

- Subjects with significant renal and liver dysfunction (creatinine $>2 \mathrm{mg} / \mathrm{dl}$ and direct bilirubin $>2$ $\mathrm{mg} / \mathrm{dl}$ ), Subjects with congenital or acquired immunodeficiency, or who are immunosuppressed due to conditions other than ulcerative colitis (such as neoplastic disease or organ transplantation), have received or are receiving chemotherapy, or have been diagnosed with HIV

\section{Intervention:}

FMT with healthy donor stool administered through colonoscopy and high dose 5-ASA (Pentasa)

\section{Comparison:}

Placebo and high dose 5-ASA (Pentasa)

Outcomes Primary Outcome

- Disease remission based on PUCAI scores $(<10)$

\section{Secondary Outcomes:}

- Changes in gut microbial diversity - determined by gut microbial genomics and proteomics

- Outcome measures for mucosal inflammation and repair including laboratory testing such as the level for CRP and ESR as well as the stool calprotectin level

\begin{tabular}{ll}
\hline Starting date & November 14, 2016 \\
\hline Contact information & Sonia Michail, MD, Professor of Clinical Pediatrics, Children's Hospital Los Angeles \\
\hline Notes & Estimated enrolment: 101 \\
\hline
\end{tabular}

\section{NCT02335281}

\begin{tabular}{ll}
\hline Trial name or title & Standardized Fecal Microbiota Transplantation for Inflammatory Bowel Disease (SFMT-IBD) \\
\hline Methods & Interventional (clinical trial), randomized \\
\hline Participants & Inclusion Criteria: \\
\hline
\end{tabular}

Fecal transplantation for treatment of inflammatory bowel disease (Review) 
NCT02335281 (Continued)

- Severe IBD define as $\mathrm{HBI}$ score $\geq 9$

- Moderate IBD define as $7<\mathrm{HBI}<9$

- Montreal classification: Age > 14 years old, Location L1-3, Behavior B1-3

- Age 16 to 70 years

\section{Exclusion Criteria:}

- Diarrhea activity scores $<3$

- Severely active disease with perianal diseases

- Severely active disease with indication of surgery

- Diagnosis as IBD first time or first year

- No history of using 5-ASA, biological (antibody), immunomodulatory therapy, corticosteroid therapy

Interventions

\section{Intervention: Standardized FMT}

Participants will receive standardized FMT administered once to the mid-gut by nose-jejunum nutrition tube

\section{Comparison: Mesalazine}

The patients will receive traditional medicine of mesalazine treatment

Primary Outcome
- Clinical remission (defined as HBI score $\leqq 4$ ) [Time Frame: up to one year]
Clinical remission defined as HBI score $\leqq 4$. The endpoint of follow-up is the time of clinical recur-
rence

\section{Secondary Outcome}

- Hospitalization days [Time Frame: up to one year]

Hospitalization days from administration to discharge when at clinical remission

\begin{tabular}{ll}
\hline Starting date & January 2015 \\
\hline Contact information & $\begin{array}{l}\text { Yanling Wei, Department of Gastroenterology, Research Institute of Surgery, Da Ping Hospital, The } \\
\text { Third Military Medical University, Third Military Medical University }\end{array}$ \\
\hline Notes & Estimated enrolment: 40 \\
\hline
\end{tabular}

\section{NCT02390726}

\begin{tabular}{ll}
\hline Trial name or title & Fecal Microbiota Transplant in the Treatment of ulcerative colitis (FMTUC) \\
\hline Methods & Interventional (clinical trial), randomized \\
\hline Participants & Inclusion Criteria: \\
- & Men or women 18 to 75 years of age \\
- & Established diagnosis of UC with known involvement of the left colon \\
& score 1 or 2 and total Mayo score ranging from 4-10 (the Mayo score ranges from 0 to 12, with \\
& higher scores indicating more severe disease. This score can be used for both initial evaluation \\
and monitoring treatment response) & Patients may be on any class of IBD-related medication (excluding steroids) \\
\hline
\end{tabular}


- Patients must be on stable medication regimen for at least 6 weeks prior to enrolment

- Ability to understand and willingness to sign informed consent document

\section{Exclusion Criteria:}

- Patients who are asymptomatic

- Patients with severe, refractory disease (defined as Mayo scores of $>10$, or endoscopic disease activity score of $>3$ ) or patients with any other significant condition which, in the opinion of the investigator, could confound or interfere with evaluation of safety, tolerability of the investigational treatment or prevent compliance with the study protocol

- Prior colectomy

- Positive stool test for any of the following: Clostridium difficile by PCR, Salmonella, Shigella, Yersinia, Campylobacter, enteropathogenic Escherichia coli by standard stool culture

- Use of the steroid medications (any formulation) in the prior 6 weeks to enrolment

- Systemic antibiotic use within prior 6 weeks to enrolment

- Regular probiotic supplement use within prior 48 hours to enrolment

- Pregnancy or breastfeeding

- Severe immunodeficiency, inherited or acquired (e.g. HIV, chemotherapy, or radiation therapy)

- History of anaphylaxis (severe allergic reaction)

- Documented allergy to fluoroquinolones, metronidazole

- Life expectancy less than 12 months

- Age less than 18 or greater than 75 years of age

- History of esophageal or gastric motility disorders

\section{Interventions}

\section{Intervention}

FMT and microbial maintenance plus standard therapy

\section{Comparison:}

Sham FMT and sham microbial maintenance plus standard therapy

\section{Outcomes}

\section{Primary Outcomes}

- Assess Endoscopic Stages of the Colon Pre/Post FMT [Time Frame: 2 years] Assess endoscopic stage of the inflamed colon (endoscopic Mayo score) and assess the histologic stage of the biopsied colon (quiescent/mild/moderate/severe) pre and post FMT

- Assess Biologic Inflammatory Markers [Time Frame: 2 years] Assess biologic inflammatory markers (ESR, CRP, fecal calprotectin, and fecal lactoferrin) pre and post FMT

- Review and Track Patient reported Outcomes via Validated Questionnaires [ Time Frame: 2 Years ] Assess patient-report outcomes (symptomatology and quality of life) calculated via validated questionnaires (symptomatic Mayo Score and SF36)

\section{Secondary Outcomes}

- Change in metagenomic sequencing in Stool samples after FMT treatment [Time Frame: After 6, 12, and 18 Weeks ] Trace the effect FMT therapy has on microbiome diversity and to track whether this effect is sustained during and after therapy via metagenomic sequencing of stool samples at time 0 , and weeks 6,12 , and 18

\begin{tabular}{ll}
\hline Starting date & December 2015 \\
\hline Contact information & Peter L Moses, MD \\
\hline Notes & 20 participants enrolled \\
\hline
\end{tabular}


NCT02487238

\begin{tabular}{ll}
\hline Trial name or title & PediFETCh trial \\
\hline Methods & Randomized, single-blinded, placebo controlled trial \\
\hline Participants & Pediatric patients aged 3 to 17 years with UC or IBD-U \\
\hline
\end{tabular}

Interventions

\section{Intervention}

FMT given via retention enema, 2 times per week for 6 weeks

\section{Comparison}

Normal saline enema, 2 times per week for six weeks

\begin{tabular}{|c|c|}
\hline Outcomes & $\begin{array}{l}\text { Outcomes } \\
\text { - Clinical remission ( } 6 \text { weeks) PUCAI } \leq 10 \\
\text { - Clinical remission ( } 30 \text { weeks) PUCAI } \leq 10 \\
\text { - Clinical remission ( } 6-30 \text { weeks) Sustained PUCAI }<10 \\
\text { - Clinical improvement ( } 6 \text { weeks) } \downarrow \text { PUCAI } \geq 15 \\
\text { - Clinical improvement ( } 6-30 \text { weeks) Sustained } \downarrow \text { PUCAI } \geq 15 \\
\text { - Biological improvement ( } 6 \text { weeks) } \downarrow \text { C-reactive protein } \\
\text { - Biological improvement ( } 6 \text { weeks) } \downarrow \text { faecal calprotectin } \\
\text { - Biological improvement ( } 30 \text { weeks) } \downarrow \text { C-reactive protein } \\
\text { - Biological improvement ( } 30 \text { weeks) } \downarrow \text { faecal calprotectin } \\
\text { - Mucosal healing ( } 30 \text { weeks) Endoscopy } \\
\text { - Change in microbiota ( } 6 \text { weeks) } \Delta 16 \text { s rRNA profile, metagenomics profile } \\
\text { - Change in microbiota ( } 30 \text { weeks) } \Delta 16 \text { s rRNA profile, metagenomics profile }\end{array}$ \\
\hline
\end{tabular}

Starting date November 2015

Contact information Dr. Nikhil Pai; pain@ mcmaster.ca, Division of Pediatric Gastroenterology \& Nutrition, Department of Pediatrics, McMaster University, Hamilton, Canada

Notes

Authors presented data on three patients in a recent conference; however, mainly secondary outcomes were described and no data were available on clinical remission

We decided to not include data from 3 patients at this time

Authors were contacted to ask if they plan to present further data and they replied that they have not complied the results as the trial is ongoing

Estimated enrolment: 50

\section{NCT02734589}

Trial name or title Pilot Study of Fecal Transplantation Using a Unique Diet for Donor and Recipient in Mild to Moderate Treatment Refractory Colitis in Inflammatory Bowel Disease

\begin{tabular}{ll}
\hline Methods & Interventional (Clinical Trial), randomized \\
\hline Participants & Inclusion Criteria: \\
& - Informed consent \\
& Established diagnosis of UC, disease confined to the large intestine, involving the rectosigmoid \\
& for at least 3 months \\
\hline
\end{tabular}


- Age: 18 - 60 years ( inclusive)

- Mild to Moderate active disease, SCCAI of $\geq 5$ and $\leq 11$ with endoscopic subscore $\geq 2$

- Refractory to mesalamine for 6 weeks, or steroids $>14$ days, or immunomodulator for 12 weeks or biologics for at least 12 weeks of therapy

- No use or stable use for 2 weeks of medical cannabis

\section{Exclusion Criteria:}

- Start of a new biologic in the previous 12 weeks

- Evidence for Clostridium difficile infection

- Any proven current infection such as CMV, positive stool culture or parasite,

- Current extra intestinal manifestation of UC such as active arthritis or PSC

- Immune deficiency (other than drug induced)

- Current use of a calcineurin inhibitor

- Pregnancy

- Suspected toxic megacolon, guarding on palpation, or signs of peritoneal inflammation

- Patients with other IBD unrelated disease such as autoimmune disorders, renal failure, fever or current infection (UTI, strep throat, pneumonia, etc.)

- Prior or current neoplasia

- Fecal Transplantation in the last 6 months

- Fever $>38$ degrees

- Participation in another clinical interventional trial

- An active malignant disease or a prior malignancy during the previous 5 years (excluding skin BCC)

- Inability or reluctance to use an enema

- Anticipation for antibiotic use within the study period (such as for elective surgery or dental treatment)

- Acute severe UC in the past 3 months

- Presence of a pouch or pouchitis
Interventions

\section{Intervention: FMT with Diet for the donor and for the recipient}

Undergo standard fecal transplantation by colonoscopy on day 1 and $60 \mathrm{ml}$ rectal enemas on days 2 and 14 with dietary pre-conditioning of the donor for 14 days and dietary treatment of the recipient immediately after transplantation and for the following 12 weeks.

\section{Comparison I: Fecal microbiota transplantation (FMT) without Diet}

Undergo standard fecal transplantation by colonoscopy on day 1 and $60 \mathrm{ml}$ rectal enemas on days 2 and 14 from the same donor without dietary conditioning.

\section{Comparison II: Dietary therapy only}

The patient will receive detailed instructions regarding the UC diet to be used over 12 weeks without FMT.

Outcomes

\section{Primary outcome:}

- Clinical remission determined by SCCAI score $<5$

\section{Secondary outcomes:}

- Improvement in SCCAI score [Time Frame: Days 56 \& 84]

- Mayo endoscopic score < 2 (for patients undergoing sigmoidoscopy) [Time Frame: Day 56]

- Fecal calprotectin < $250 \mu \mathrm{g} / \mathrm{g}$ [Time Frame: Day 56]

- The need for additional therapy [Time Frame: Week 12] according to the physician discretion

- Change in the microbiome compared to baseline [Time Frame: For donor- day 14 and for recipient day 56] according to analysis of fecal samples 
NCT02734589 (Continued)

Starting date January 24, 2017

Contact information

Prof. Arie Levine, Director, Pediatric Gastroenterology and Nutrition unit., Wolfson Medical Center

Notes

Estimated enrolment: 34

NCT02998112

\begin{tabular}{ll}
\hline Trial name or title & $\begin{array}{l}\text { Fecal Microbiota Transplantation for ulcerative colitis Through Colonic Transendoscopic Enteral } \\
\text { Tubing }\end{array}$ \\
\hline Methods & Interventional (Clinical Trial), randomized \\
\hline Participants & Inclusion Criteria: \\
- Active, moderate to severe severity (Mayo score more than 6) & - Able to undergo endoscopy examination \\
& - Age 18 to 65 years \\
Exclusion Criteria: & Immunosuppressive drugs and glucocorticoids using in 4 weeks \\
- Antibiotic using in 7 days \\
- High risk of toxic megacolon \\
- Colon cancer or neoplasia in pathophysiology \\
- Other severe diseases (e.g.: cardiovascular, respiratory, gastrointestinal and kidney diseases)
\end{tabular}

Interventions

\section{Intervention}

5-ASA $4 \mathrm{~g}$ /day enema through TET for 1 week; $200 \mathrm{ml}$ fecal microbiota suspension infusion through TET for 3 times every other day in one week

\section{Comparison: Placebo}

5-ASA $4 \mathrm{~g} /$ day enema through TET for 1 week; $200 \mathrm{ml}$ saline infusion through TET for 3 times every other day in one week

\begin{tabular}{|c|c|}
\hline Outcomes & $\begin{array}{l}\text { Primary Outcomes } \\
\text { - Clinical remission [Time Frame: } 12 \text { weeks] total Mayo score less than } 2 \text { and no signal item more } \\
\text { than } 1 \\
\text { - Clinical improvement [Time Frame: } 12 \text { weeks] total Mayo score decreased more than } 3 \text { or de- } \\
\text { creased more than } 30 \% \\
\text { Secondary Outcomes: } \\
\text { - Intestinal microbiota changing [Time Frame: } 12 \text { weeks] } \\
\text { The change of intestinal microbiota composition after FMT compared with subject original micro- } \\
\text { biota and donor's microbiota }\end{array}$ \\
\hline Starting date & December 2016 \\
\hline Contact information & $\begin{array}{l}\text { Faming Zhang, Associate professor, Gastroenterology, The Second Hospital of Nanjing Medical Uni- } \\
\text { versity }\end{array}$ \\
\hline
\end{tabular}


NCT02998112 (Continued)

\section{Trial name or title}

Methods
Optimal Fecal Microbiota Transplant Dosing for Mild to Moderate Ulcerative Colitis

Interventional (Clinical Trial), randomized
Participants

\section{Inclusion Criteria:}

- Patients with history of mild to moderate ulcerative colitis confirmed by endoscopy and pathology

- Total Mayo score 4-9, endoscopic subscore $\geq 1$; patients who have not had endoscopic evaluation within one year of enrollment will have flexible sigmoidoscopy for evaluation

- Age 18 to 64 years and deemed otherwise healthy at the discretion of the investigator

- Concurrent therapies with mesalamine (stable $\times 4$ weeks), immunomodulators (stable $\times 3$ months), and biologic agents (stable $\times 3$ months) will be allowed to continue during study

- If patient is on prednisone, the dose must be $\leq 10 \mathrm{mg} / \mathrm{day}$ at the time of treatment and will be weaned by $2.5 \mathrm{mg} /$ week during the study period

\section{Exclusion Criteria:}

- Severe or refractory UC defined as Mayo score $\geq 10$, endoscopic disease activity score 3;

- Untreated enteric infection (positive stool test for any of the following: Clostridium difficile, Salmonella, Shigella, Yersinia, Campylobacter, enteropathogenic E. coli or other enteric infection at the discretion of the investigator

- History of colectomy

- Disease limited to distal proctitis

- Patients taking probiotics within 6 weeks of planned FMT therapy

- Severe immunodeficiency, inherited or acquired (e.g. HIV, chemotherapy or radiation therapy)

- Patients with the following laboratory abnormalities: ANC $<1000 / \mu \mathrm{l}$, platelets $<50 \times 10^{\wedge} 9 / \mathrm{L}$, hemoglobin $<6.5 \mathrm{~g} / \mathrm{dL}$

- History of anaphylaxis (severe allergic reaction) to food allergens (e.g. tree nuts, shellfish)

- Dysphagia

- History of recurrent aspiration episodes

- Documented severe gastroparesis

- Active intestinal obstruction

- Patients with renal insufficiency (GFR $<50 \mathrm{ml} / \mathrm{min})$

- Allergy to the following generally regarded as safe ingredients: glycerol, acid resistant HPMC, gellan gum, cocoa butter, titanium dioxide

- Adverse event attributable to any previous FMT

- Allergy/intolerance to proton pump inhibitor therapy

- Allergy/intolerance to vancomycin, metronidazole, or neomycin

- NSAIDs as long-term treatment, defined as use for at least 4 days a week each month

- Cholestyramine use

- Any condition in which the investigator thinks the FMT treatment may pose a health risk (e.g. severely immunocompromised)

- Simultaneous participation in another interventional clinical trial

- Patients who are pregnant, breast feeding or planning pregnancy during study trial period

- Non-use of appropriate contraceptives in females of childbearing potential; adequate by the responsible investigator during treatment) or well-founded doubt about the patient's cooperation 
NCT03006809 (Continued)

- Patients with any other significant medical condition that could confound or interfere with evaluation of safety, tolerability or prevent compliance with the study protocol at the discretion of the investigator

- Life expectancy $<6$ months

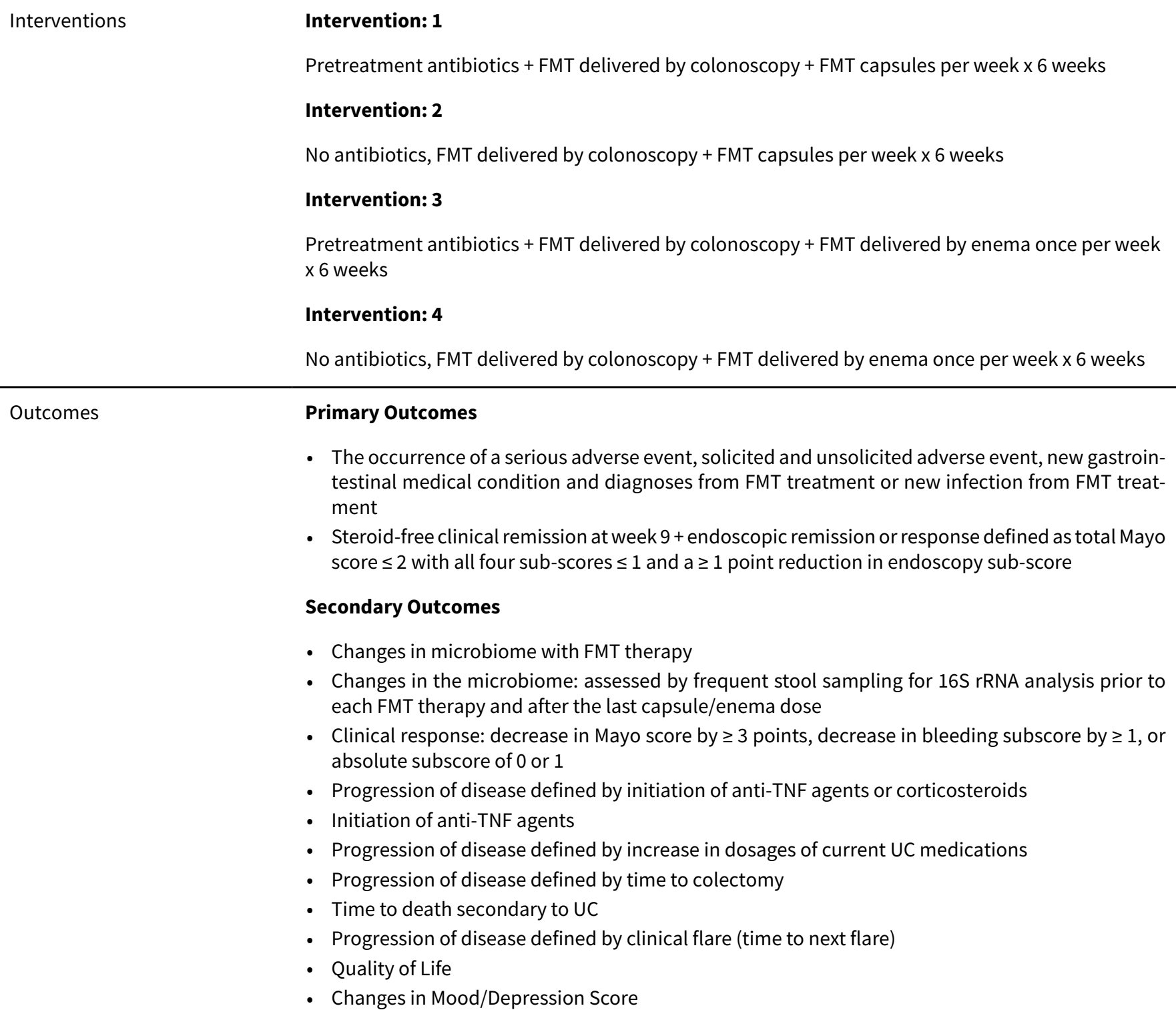

March 2, 2017

Najwa Elnachef, Assistant Clinical Professor, University of California, San Francisco

\begin{tabular}{ll}
\hline Contact information & Najwa Elnachef, Assistant Clinical Professor, University of California, San Francisco \\
\hline Notes & Estimated enrolment: 40 \\
\hline
\end{tabular}

\section{NCT03016780}

\begin{tabular}{ll}
\hline Trial name or title & Fecal Microbiota Transplantation for Ulcerative Colitis (FMTFUC) \\
\hline Methods & Interventional (Clinical Trial), randomized \\
\hline \hline
\end{tabular}


NCT03016780 (Continued)

Participants
Inclusion criteria:

- Participants voluntarily participate in the trial and sign informed consent

- Sex is not limited, ranging from 18 to 75 years old

- Meet the diagnostic criteria for UC in patients

- Be able to communicate well with the researchers and follow the verification requirements

Exclusion criteria:

- Pregnancy or people who are not to give informed consent

- use of major immunosuppressive agents, including the use of large doses of glucocorticoids, calcineurin inhibitors, mTOR inhibitors, depleted lymphocyte biological agents, anti-tumor necrosis factor and other conditions; chemotherapy of antineoplastic drugs

- decompensated cirrhosis, progressive AIDS and HIV infection or other serious immunodeficiency disease

- use of antibiotics and probiotics within six weeks

- with severe complications such as local stenosis, intestinal obstruction, intestinal perforation, toxic colon expansion, colon cancer, rectal cancer patients

- combined with cardiovascular, cerebrovascular, liver, kidney and hematopoietic system and other serious primary disease, mental illness
Active Comparator: Treatment in part 1

Fecal microbiota transplantation and traditional treatments will be used in patients with ulcerative colitis in part 1

Placebo Comparator: Placebo in part 2

The traditional treatments and normal saline will be used in patients with ulcerative colitis in part 2 according to associated guidelines
Primary outcome:

- Incidence of treatment-emergent adverse events

Secondary outcome:

- Improvement of clinical symptoms of the treatment [Time Frame: 4 week]

- The influence of interleukin-10 after the treatment [Time Frame: 0-4 week]

- Intestinal mucosal immunity [Time Frame: 4 week]

Starting date July 2016

\section{Contact information}

Xiaoan Li, Ph.D First Affiliated Hospital of Chengdu Medical College

Estimated enrolment: 60

\begin{tabular}{ll}
\hline NCT03104036 & \\
\hline Trial name or title & Faecal Bacteriotherapy for Ulcerative Colitis (FACTU) \\
\hline Methods & Interventional (Clinical Trial), randomized \\
\hline Participants & Inclusion Criteria: \\
& - Left-sided ulcerative colitis $>15 \mathrm{~cm}$ ongoing more than 3 month \\
& Mayo score $<10$
\end{tabular}


NCT03104036 (Continued)

- Endoscopic Mayo score $\geq 2$

- Adults 18 to 70 years

\section{Exclusion Criteria:}

- Anti-TNF medication in the previous 6 months

- Cyclosporine in the previous 4 weeks

- Methotrexate in the previous 2 months

- Prednisone $>10 \mathrm{mg}$

- The real risk of colectomy in the near future

- Positive stool culture (Salmonella, Shigella, Yersinia, Campylobacter, pathogenic E. coli)

- CMV infection

- Pregnancy, breastfeeding women

Interventions

\section{Intervention: Faecal bacterial transplantation enema}

Will be applied enema prepared from $50 \mathrm{~g}$ of stool of examined donor dissolved in $150 \mathrm{ml}$ of normal saline, the 1 st week 5 times, than one time a week until the end of the 6 th week

\section{Comparison: Mesalazine enema}

Will be treated with $4 \mathrm{~g}$ Mesalazine enema $1 \mathrm{x}$ daily for 2 weeks, then every other day until the end of the 6th week

Primary outcome:
Clinical remission [Time Frame: Week 12]
Mayo score $\leq 2$ with no subscore $>1$
Secondary Outcome
- Endoscopic remission [Time Frame: Week 6 and 12] Mayo endoscopic score $=0$
- Clinical response [Time Frame: Week 6 and 12] Decrease of Mayo score $\geq 2$

\begin{tabular}{ll}
\hline Starting date & April 2017 \\
\hline Contact information & Jan Březina, MUDr. (principal investigator), Institute for Clinical and Experimental Medicine \\
\hline Notes & Estimated enrolment: 60 \\
\hline
\end{tabular}

UC: ulcerative colitis

FMT: fecal microbiota transplantation

CD: Crohn's disease

HBI: Harvey Bradshaw Index

5-ASA: 5-aminosalicylic acid

PUCAI: Pediatric Ulcerative Colitis Activity Index

ECCO: European Crohn's and Colitis Organisation

PCDAI: Pediatric Crohn's Disease Activity Index

HIV: human immunodeficiency virus

CRP: C-reactive protein

ESR: erythrocyte sedimentation rate

IBD: Inflammatory Bowel Disease

PCR: Polymerase chain reaction

IBD-U: Inflammatory Bowel Disease Unclassified

SF-36: 36-item Short Form Health Survey (quality of life)

CMV: cytomegalovirus

PSC: primary sclerosing cholangitis

UTI: urinary tract infection 
BCC: basal cell carcinoma

TET: transendoscopic enteral tubing

ANC: absolute neutrophil count

GFR: glomerular filtration rate

NSAIDs: Non-steroidal anti-inflammatory drugs

AIDS: acquired immune deficiency syndrome

\section{DATA AND ANALYSES}

\section{Comparison 1. Fecal microbiota transplantation versus control for participants with ulcerative colitis}

\begin{tabular}{|c|c|c|c|c|}
\hline Outcome or subgroup title & No. of studies & $\begin{array}{l}\text { No. of partici- } \\
\text { pants }\end{array}$ & Statistical method & Effect size \\
\hline 1 Clinical remission at 8 weeks & 4 & 277 & $\begin{array}{l}\text { Risk Ratio (M-H, Random, 95\% } \\
\mathrm{Cl} \text { ) }\end{array}$ & $2.03[1.07,3.86]$ \\
\hline 2 Clinical remission at 12 Weeks & 1 & & $\begin{array}{l}\text { Risk Ratio (M-H, Random, 95\% } \\
\mathrm{Cl} \text { ) }\end{array}$ & Totals not selected \\
\hline $\begin{array}{l}3 \text { Clinical remission at } 8 \text { weeks: } \\
\text { Subgroup analysis by route of ad- } \\
\text { ministration }\end{array}$ & 4 & 277 & $\begin{array}{l}\text { Risk Ratio (M-H, Random, 95\% } \\
\mathrm{CI})\end{array}$ & $2.03[1.07,3.86]$ \\
\hline 3.1 Upper gastrointestinal tract & 1 & 48 & $\begin{array}{l}\text { Risk Ratio (M-H, Random, 95\% } \\
\mathrm{Cl} \text { ) }\end{array}$ & $0.82[0.33,1.99]$ \\
\hline 3.2 Colonic & 3 & 229 & $\begin{array}{l}\text { Risk Ratio (M-H, Random, 95\% } \\
\mathrm{CI} \text { ) }\end{array}$ & $2.66[1.62,4.37]$ \\
\hline $\begin{array}{l}4 \text { Clinical remission at } 8 \text { weeks: } \\
\text { Subgroup analysis by type of } \\
\text { donor }\end{array}$ & 4 & 277 & $\begin{array}{l}\text { Risk Ratio (M-H, Random, 95\% } \\
\mathrm{Cl} \text { ) }\end{array}$ & $2.03[1.07,3.86]$ \\
\hline 4.1 Single donor & 2 & 123 & $\begin{array}{l}\text { Risk Ratio (M-H, Random, 95\% } \\
\mathrm{Cl} \text { ) }\end{array}$ & $1.71[0.32,9.29]$ \\
\hline 4.2 Multidonor & 2 & 154 & $\begin{array}{l}\text { Risk Ratio (M-H, Random, 95\% } \\
\mathrm{Cl} \text { ) }\end{array}$ & $2.49[1.47,4.23]$ \\
\hline $\begin{array}{l}5 \text { Clinical remission at } 8 \text { weeks: } \\
\text { Sensitivity analysis using fixed-ef- } \\
\text { fect model }\end{array}$ & 4 & 277 & Risk Ratio (M-H, Fixed, 95\% Cl) & $2.13[1.39,3.25]$ \\
\hline $\begin{array}{l}6 \text { Clinical remission: Composite } \\
\text { of clinical score and endoscopic } \\
\text { score }\end{array}$ & 4 & 277 & $\begin{array}{l}\text { Risk Ratio (M-H, Random, 95\% } \\
\mathrm{Cl})\end{array}$ & $2.77[1.54,4.98]$ \\
\hline 7 Clinical relapse at 12 weeks & 1 & & $\begin{array}{l}\text { Risk Ratio (M-H, Random, 95\% } \\
\mathrm{Cl} \text { ) }\end{array}$ & Totals not selected \\
\hline 8 Serious adverse events & 4 & 277 & $\begin{array}{l}\text { Risk Ratio (M-H, Random, 95\% } \\
\mathrm{Cl} \text { ) }\end{array}$ & $1.40[0.55,3.58]$ \\
\hline $\begin{array}{l}9 \text { Serious adverse events: Sub- } \\
\text { group analysis by route of adminis- } \\
\text { tration }\end{array}$ & 4 & 277 & $\begin{array}{l}\text { Risk Ratio (M-H, Random, 95\% } \\
\mathrm{CI} \text { ) }\end{array}$ & $1.40[0.55,3.58]$ \\
\hline
\end{tabular}




\begin{tabular}{|c|c|c|c|c|}
\hline Outcome or subgroup title & No. of studies & $\begin{array}{l}\text { No. of partici- } \\
\text { pants }\end{array}$ & Statistical method & Effect size \\
\hline 9.1 Upper Gastrointestinal & 1 & 48 & $\begin{array}{l}\text { Risk Ratio (M-H, Random, 95\% } \\
\mathrm{Cl} \text { ) }\end{array}$ & $1.09[0.17,7.10]$ \\
\hline 9.2 Colonic & 3 & 229 & $\begin{array}{l}\text { Risk Ratio (M-H, Random, 95\% } \\
\mathrm{Cl} \text { ) }\end{array}$ & $1.52[0.51,4.50]$ \\
\hline $\begin{array}{l}10 \text { Serious adverse events: Sub- } \\
\text { group analysis by type of donor }\end{array}$ & 4 & 277 & $\begin{array}{l}\text { Risk Ratio (M-H, Random, 95\% } \\
\mathrm{Cl})\end{array}$ & $1.40[0.55,3.58]$ \\
\hline 10.1 Single donor & 2 & 123 & $\begin{array}{l}\text { Risk Ratio (M-H, Random, 95\% } \\
\mathrm{Cl} \text { ) }\end{array}$ & $1.28[0.36,4.55]$ \\
\hline 10.2 Multidonor & 2 & 154 & $\begin{array}{l}\text { Risk Ratio (M-H, Random, 95\% } \\
\text { Cl) }\end{array}$ & $1.56[0.39,6.29]$ \\
\hline $\begin{array}{l}11 \text { Serious adverse events: Sensi- } \\
\text { tivity analysis using fixed-effect } \\
\text { model }\end{array}$ & 4 & 277 & Risk Ratio (M-H, Fixed, 95\% Cl) & $1.41[0.55,3.59]$ \\
\hline 12 Any adverse events & 2 & 129 & $\begin{array}{l}\text { Risk Ratio (M-H, Random, 95\% } \\
\mathrm{Cl})\end{array}$ & $1.03[0.81,1.31]$ \\
\hline 13 Clinical response at 8 weeks & 4 & 277 & $\begin{array}{l}\text { Risk Ratio (M-H, Random, 95\% } \\
\mathrm{Cl})\end{array}$ & $1.70[0.98,2.95]$ \\
\hline 14 Clinical response at 12 weeks & 1 & & $\begin{array}{l}\text { Risk Ratio (M-H, Random, 95\% } \\
\text { Cl) }\end{array}$ & Totals not selected \\
\hline $\begin{array}{l}15 \text { Endoscopic remission at } 8 \\
\text { weeks }\end{array}$ & 3 & 229 & $\begin{array}{l}\text { Risk Ratio (M-H, Random, 95\% } \\
\mathrm{Cl} \text { ) }\end{array}$ & $2.96[1.60,5.48]$ \\
\hline $\begin{array}{l}16 \text { Endoscopic remission at } 12 \\
\text { weeks }\end{array}$ & 1 & & $\begin{array}{l}\text { Risk Ratio (M-H, Random, 95\% } \\
\mathrm{Cl} \text { ) }\end{array}$ & Totals not selected \\
\hline $\begin{array}{l}17 \text { Endoscopic response at } 8 \\
\text { weeks }\end{array}$ & 2 & 129 & $\begin{array}{l}\text { Risk Ratio (M-H, Random, 95\% } \\
\text { Cl) }\end{array}$ & $1.36[0.26,7.02]$ \\
\hline $\begin{array}{l}18 \text { Endoscopic response at } 12 \\
\text { weeks }\end{array}$ & 1 & & $\begin{array}{l}\text { Risk Ratio (M-H, Random, 95\% } \\
\mathrm{Cl} \text { ) }\end{array}$ & Totals not selected \\
\hline 19 Withdrawals & 4 & 277 & $\begin{array}{l}\text { Risk Ratio (M-H, Random, 95\% } \\
\mathrm{Cl} \text { ) }\end{array}$ & $0.91[0.50,1.64]$ \\
\hline 20 ESR at the longest follow up & 2 & 113 & $\begin{array}{l}\text { Mean Difference (IV, Random, } \\
95 \% \mathrm{CI})\end{array}$ & $-0.85[-4.86,3.17]$ \\
\hline $21 \mathrm{CRP}$ at the longest follow-up & 2 & 113 & $\begin{array}{l}\text { Mean Difference (IV, Random, } \\
95 \% \mathrm{CI})\end{array}$ & $-3.35[-14.67,7.98]$ \\
\hline $\begin{array}{l}22 \text { Fecal calprotectin at the longest } \\
\text { follow-up }\end{array}$ & 1 & & $\begin{array}{l}\text { Mean Difference (IV, Random, } \\
95 \% \mathrm{Cl})\end{array}$ & Totals not selected \\
\hline 23 Quality of life score: IBDQ & 2 & 156 & $\begin{array}{l}\text { Mean Difference (IV, Random, } \\
95 \% \mathrm{CI})\end{array}$ & $16.00[0.09,31.91]$ \\
\hline
\end{tabular}


Analysis 1.1. Comparison 1 Fecal microbiota transplantation versus control for participants with ulcerative colitis, Outcome 1 Clinical remission at 8 weeks.

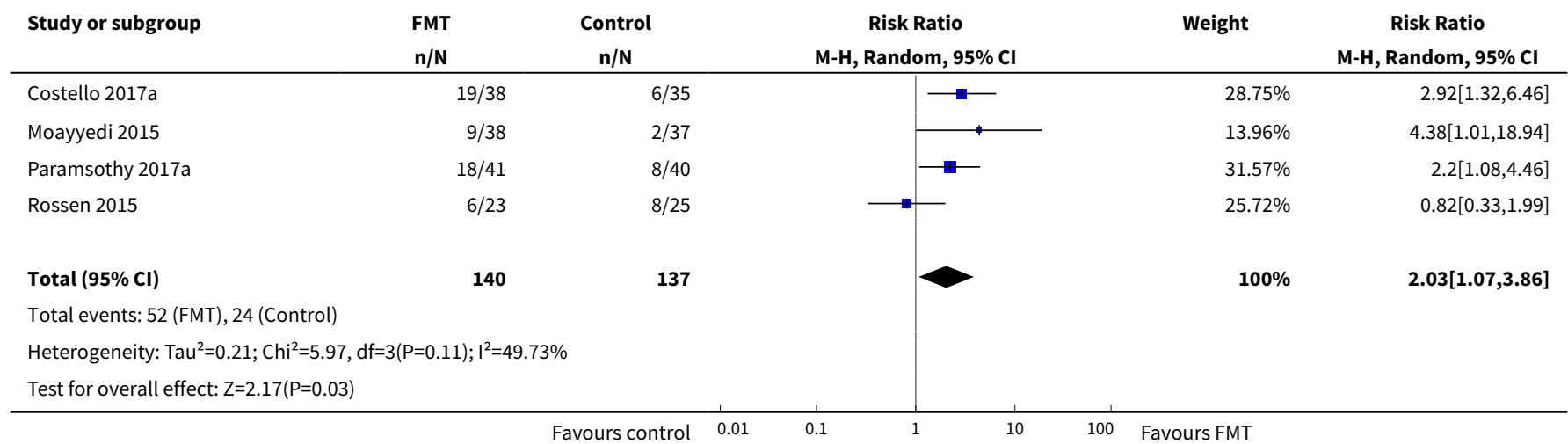

Analysis 1.2. Comparison 1 Fecal microbiota transplantation versus control for participants with ulcerative colitis, Outcome 2 Clinical remission at 12 Weeks.

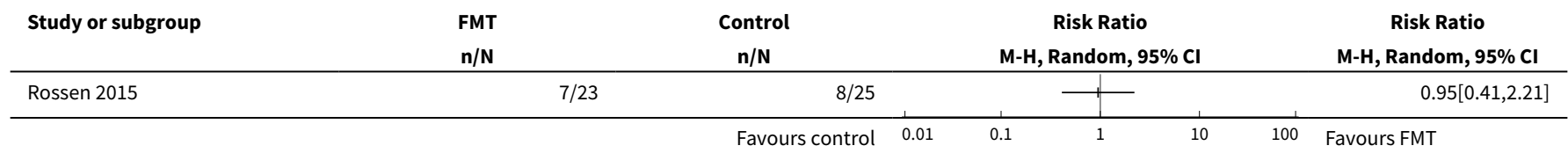

Analysis 1.3. Comparison 1 Fecal microbiota transplantation versus control for participants with ulcerative colitis, Outcome 3 Clinical remission at 8 weeks: Subgroup analysis by route of administration.

\begin{tabular}{|c|c|c|c|c|c|}
\hline Study or subgroup & $\begin{array}{l}\text { FMT } \\
\mathrm{n} / \mathrm{N}\end{array}$ & $\begin{array}{c}\text { Control } \\
\mathrm{n} / \mathrm{N}\end{array}$ & $\begin{array}{c}\text { Risk Ratio } \\
\text { M-H, Random, } 95 \% \text { CI }\end{array}$ & Weight & $\begin{array}{c}\text { Risk Ratio } \\
\text { M-H, Random, } 95 \% \mathrm{CI}\end{array}$ \\
\hline \multicolumn{6}{|c|}{ 1.3.1 Upper gastrointestinal tract } \\
\hline Rossen 2015 & $6 / 23$ & $8 / 25$ & $\longrightarrow$ & $25.72 \%$ & $0.82[0.33,1.99]$ \\
\hline Subtotal $(95 \% \mathrm{Cl})$ & 23 & 25 & & $25.72 \%$ & $0.82[0.33,1.99]$ \\
\hline \multicolumn{6}{|c|}{ Total events: 6 (FMT), 8 (Control) } \\
\hline \multicolumn{6}{|c|}{ Heterogeneity: Not applicable } \\
\hline \multicolumn{6}{|l|}{ 1.3.2 Colonic } \\
\hline Costello 2017a & $19 / 38$ & $6 / 35$ & $\longrightarrow$ & $28.75 \%$ & $2.92[1.32,6.46]$ \\
\hline Moayyedi 2015 & $9 / 38$ & $2 / 37$ & & $13.96 \%$ & $4.38[1.01,18.94]$ \\
\hline Paramsothy $2017 a$ & $18 / 41$ & $8 / 40$ & $\longrightarrow$ & $31.57 \%$ & $2.2[1.08,4.46]$ \\
\hline Subtotal $(95 \% \mathrm{CI})$ & 117 & 112 & & $74.28 \%$ & $2.66[1.62,4.37]$ \\
\hline \multicolumn{6}{|c|}{ Heterogeneity: $\operatorname{Tau}^{2}=0 ; \mathrm{Chi}^{2}=0.79, \mathrm{df}=2(\mathrm{P}=0.67) ; \mathrm{I}^{2}=0 \%$} \\
\hline \multicolumn{6}{|c|}{ Test for overall effect: $Z=3.85(P=0)$} \\
\hline Total $(95 \% \mathrm{Cl})$ & 140 & 137 & & $100 \%$ & $2.03[1.07,3.86]$ \\
\hline Total events: 52 (FM & & & & & \\
\hline
\end{tabular}




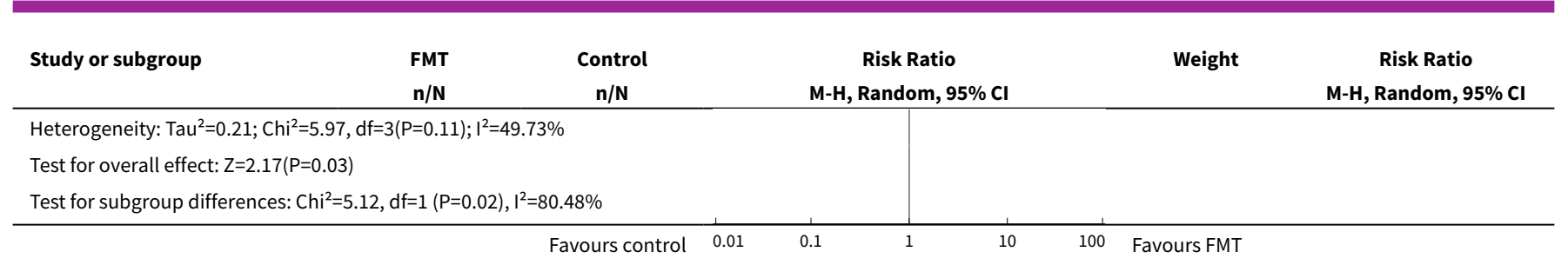

\section{Analysis 1.4. Comparison 1 Fecal microbiota transplantation versus control for participants with ulcerative colitis, Outcome 4 Clinical remission at 8 weeks: Subgroup analysis by type of donor.}

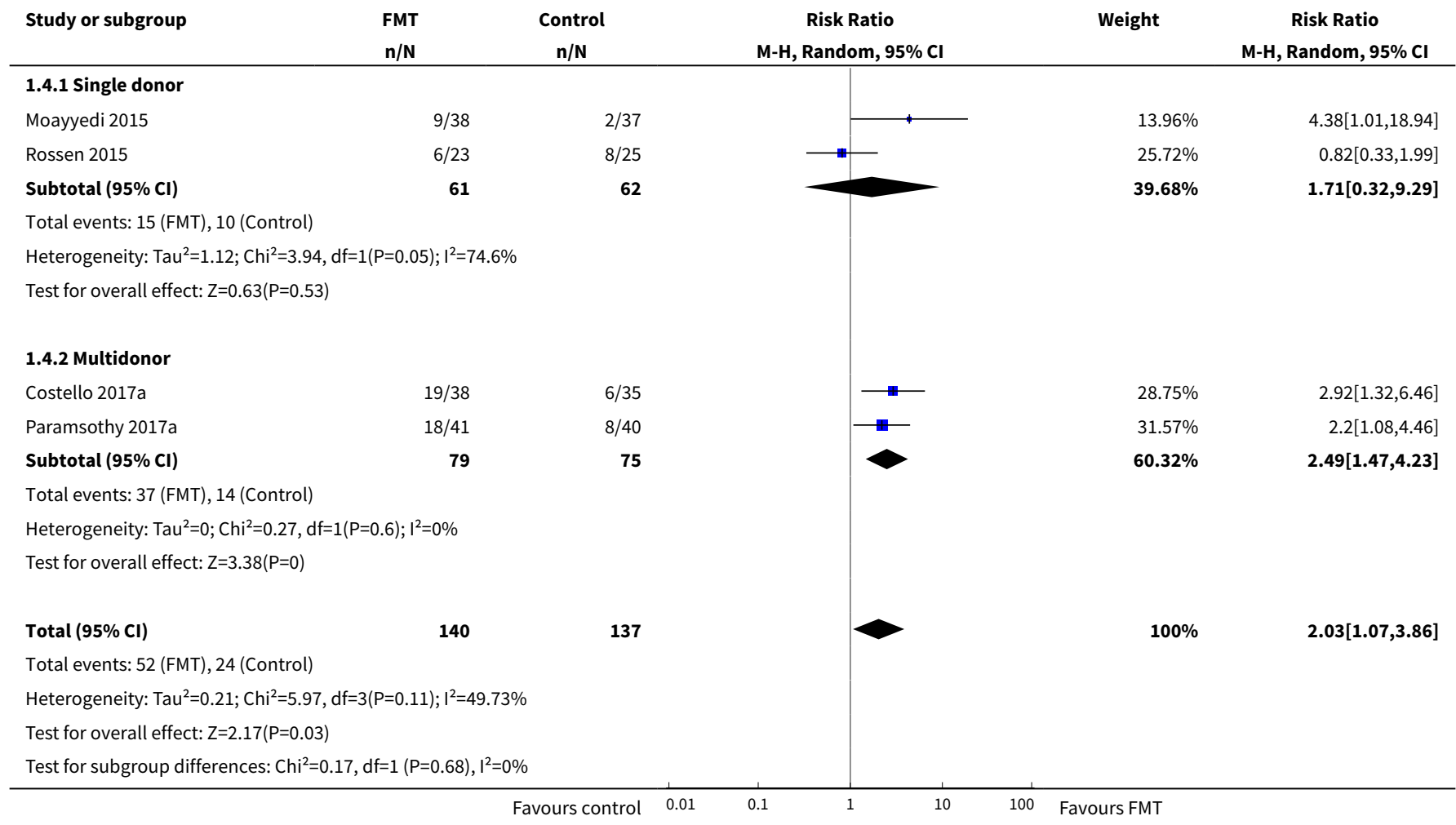

Analysis 1.5. Comparison 1 Fecal microbiota transplantation versus control for participants with ulcerative colitis, Outcome 5 Clinical remission at 8 weeks: Sensitivity analysis using fixed-effect model.

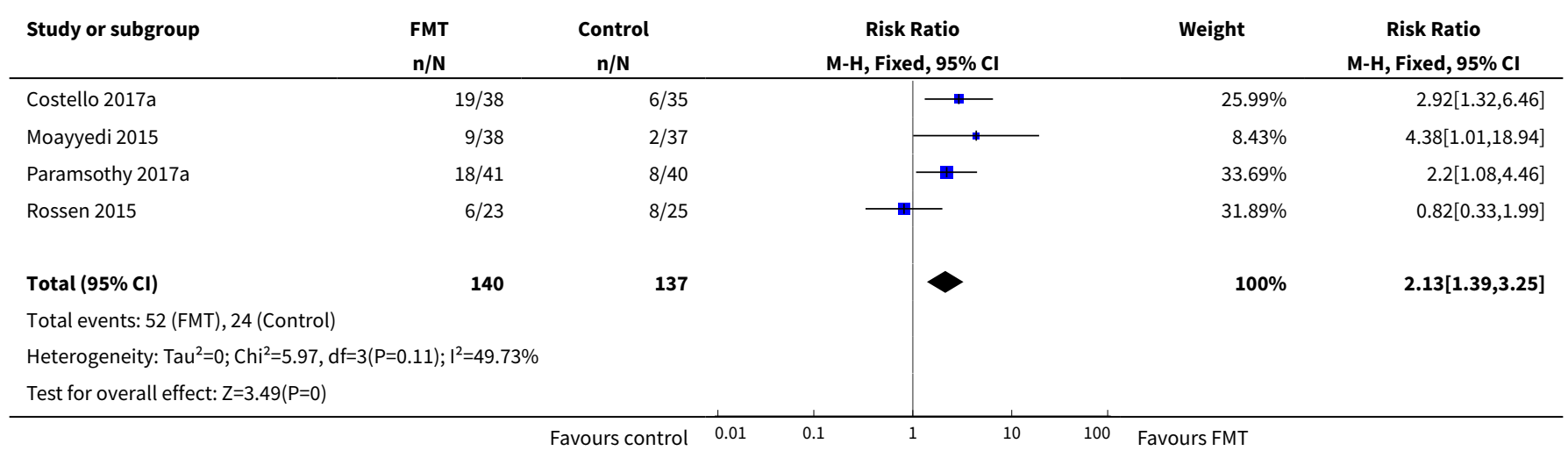


Analysis 1.6. Comparison 1 Fecal microbiota transplantation versus control for participants with ulcerative colitis, Outcome 6 Clinical remission: Composite of clinical score and endoscopic score.

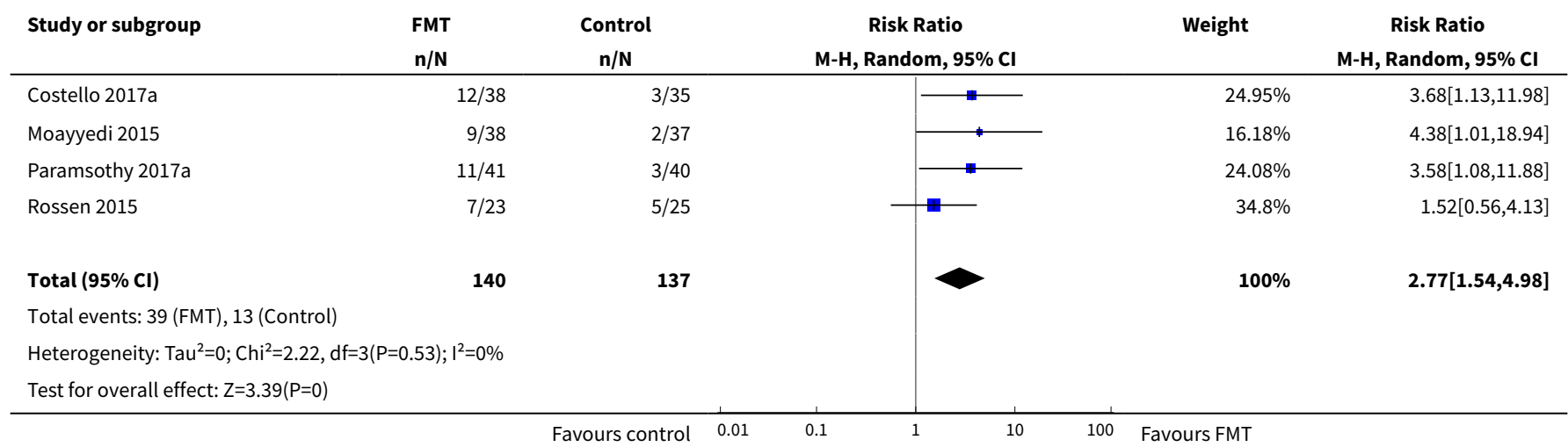

Analysis 1.7. Comparison 1 Fecal microbiota transplantation versus control for participants with ulcerative colitis, Outcome 7 Clinical relapse at 12 weeks.

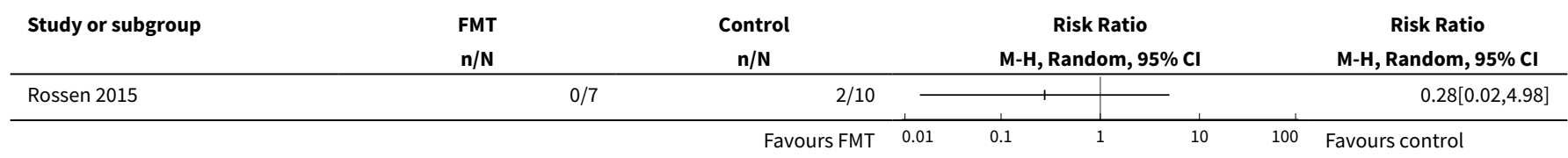

Analysis 1.8. Comparison 1 Fecal microbiota transplantation versus control for participants with ulcerative colitis, Outcome 8 Serious adverse events.

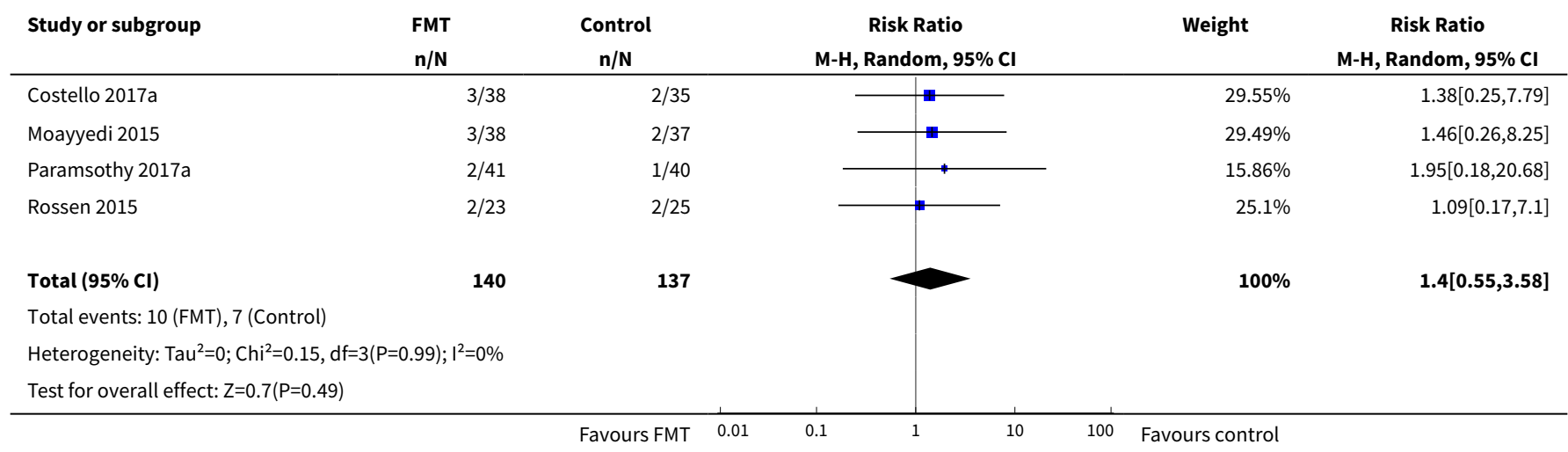


Analysis 1.9. Comparison 1 Fecal microbiota transplantation versus control for participants with ulcerative colitis, Outcome 9 Serious adverse events: Subgroup analysis by route of administration.

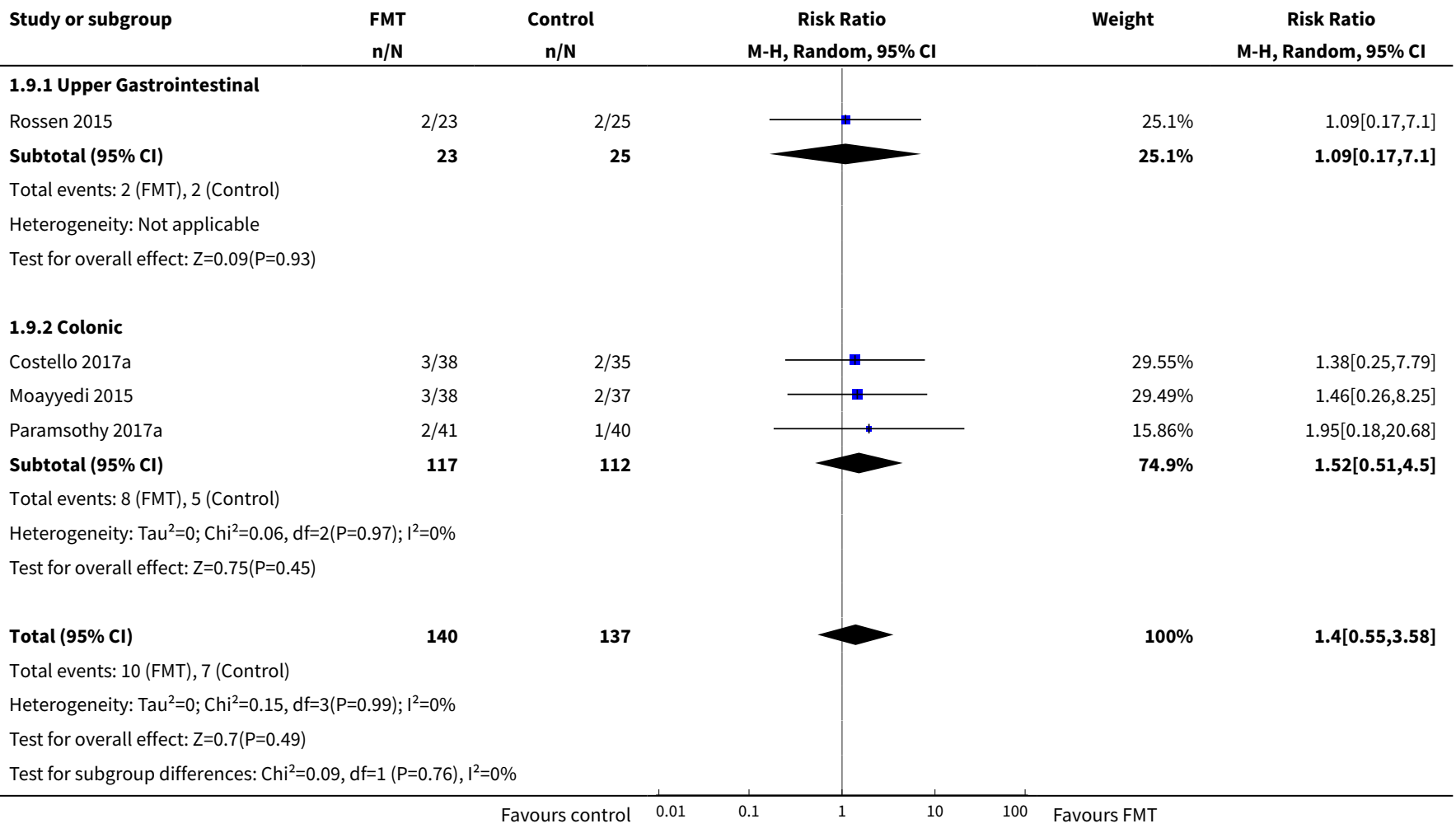

Analysis 1.10. Comparison 1 Fecal microbiota transplantation versus control for participants with ulcerative colitis, Outcome 10 Serious adverse events: Subgroup analysis by type of donor.

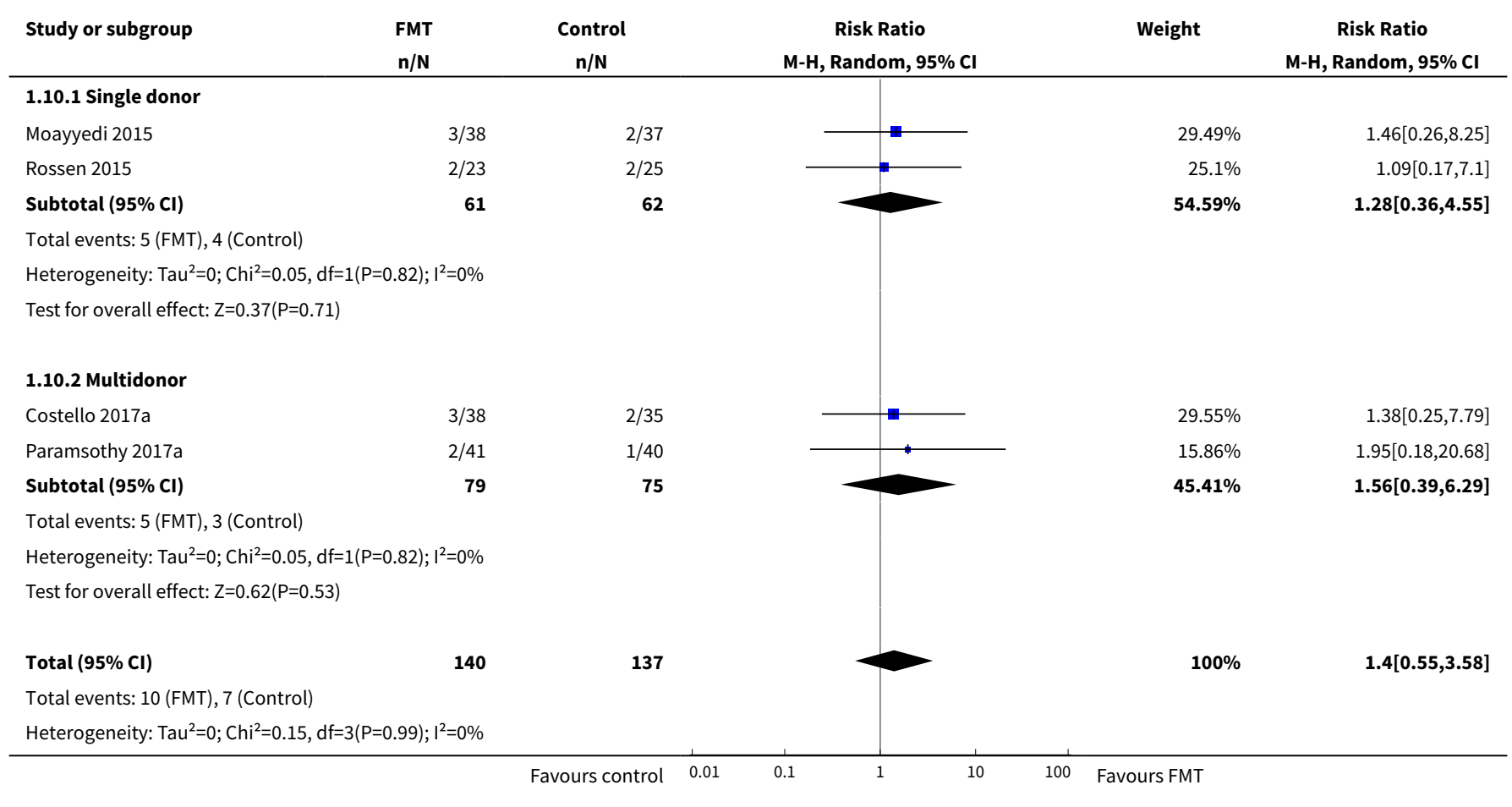




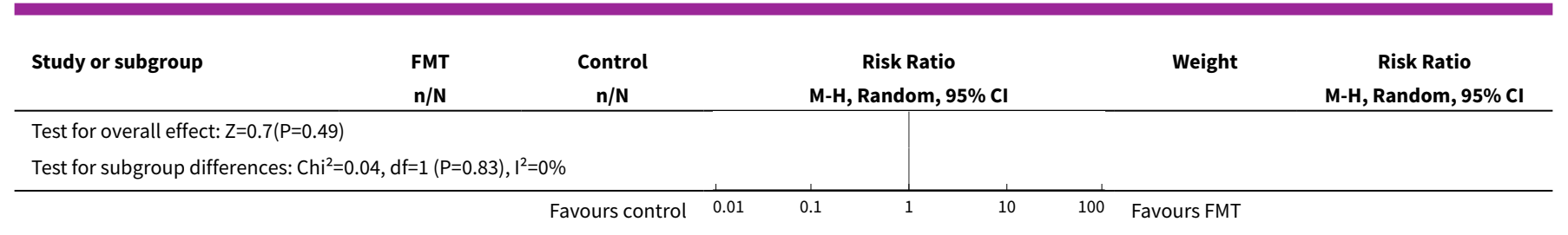

Analysis 1.11. Comparison 1 Fecal microbiota transplantation versus control for participants with ulcerative colitis, Outcome 11 Serious adverse events: Sensitivity analysis using fixed-effect model.

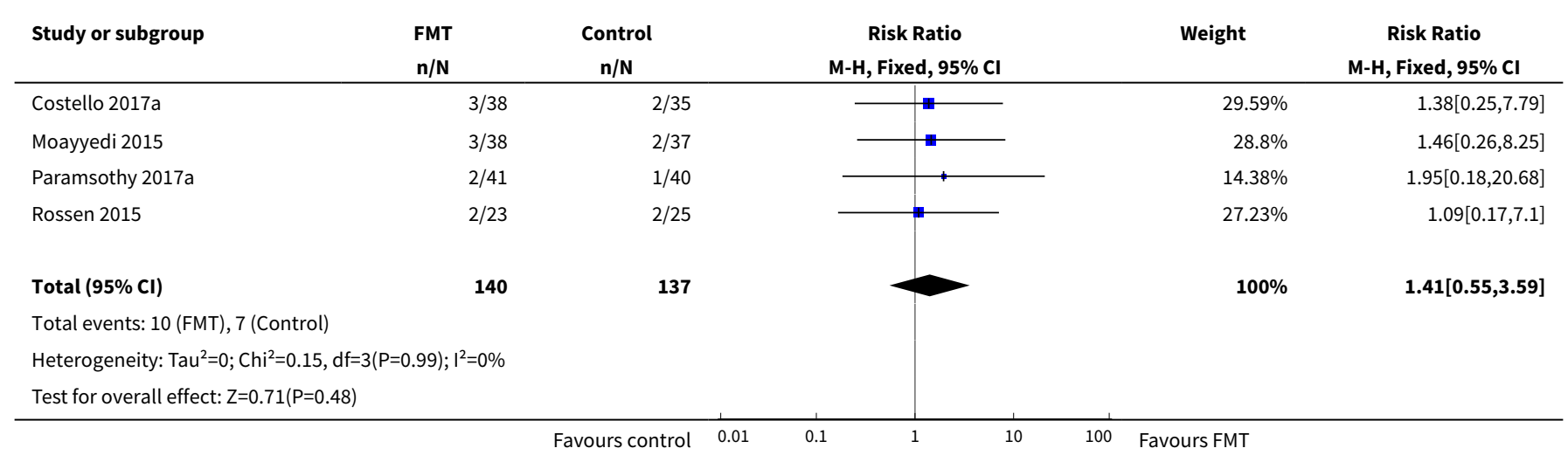

Analysis 1.12. Comparison 1 Fecal microbiota transplantation versus control for participants with ulcerative colitis, Outcome 12 Any adverse events.

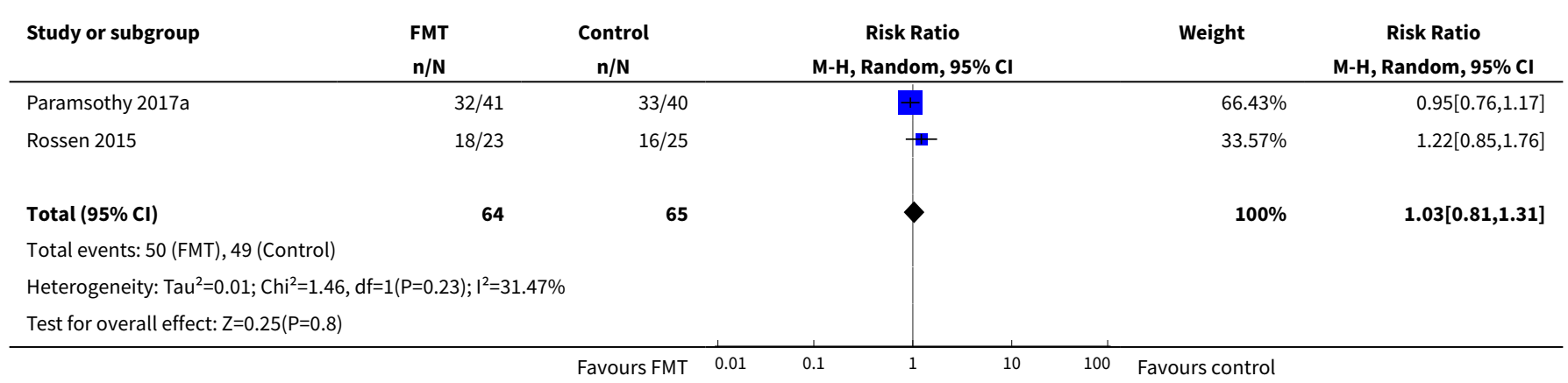

Analysis 1.13. Comparison 1 Fecal microbiota transplantation versus control for participants with ulcerative colitis, Outcome 13 Clinical response at 8 weeks.

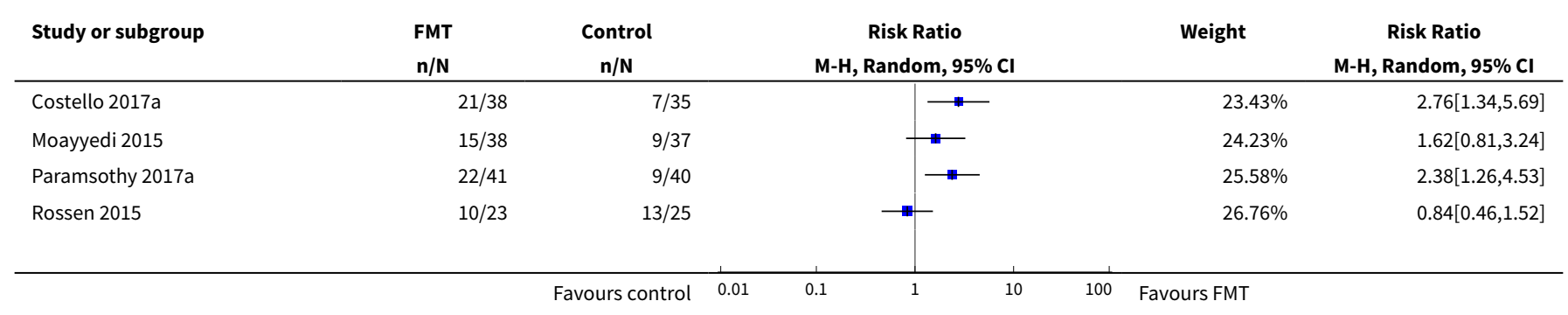




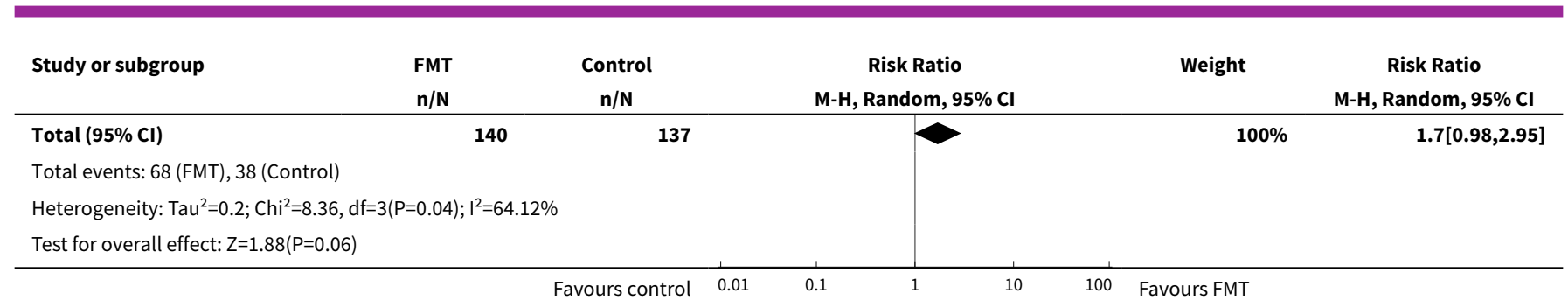

Analysis 1.14. Comparison 1 Fecal microbiota transplantation versus control for participants with ulcerative colitis, Outcome 14 Clinical response at 12 weeks.

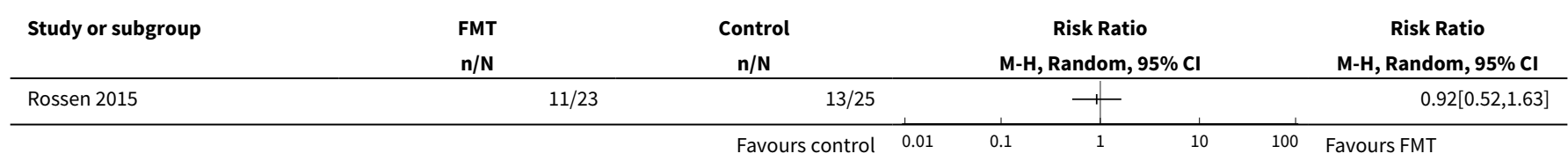

Analysis 1.15. Comparison 1 Fecal microbiota transplantation versus control for participants with ulcerative colitis, Outcome 15 Endoscopic remission at 8 weeks.

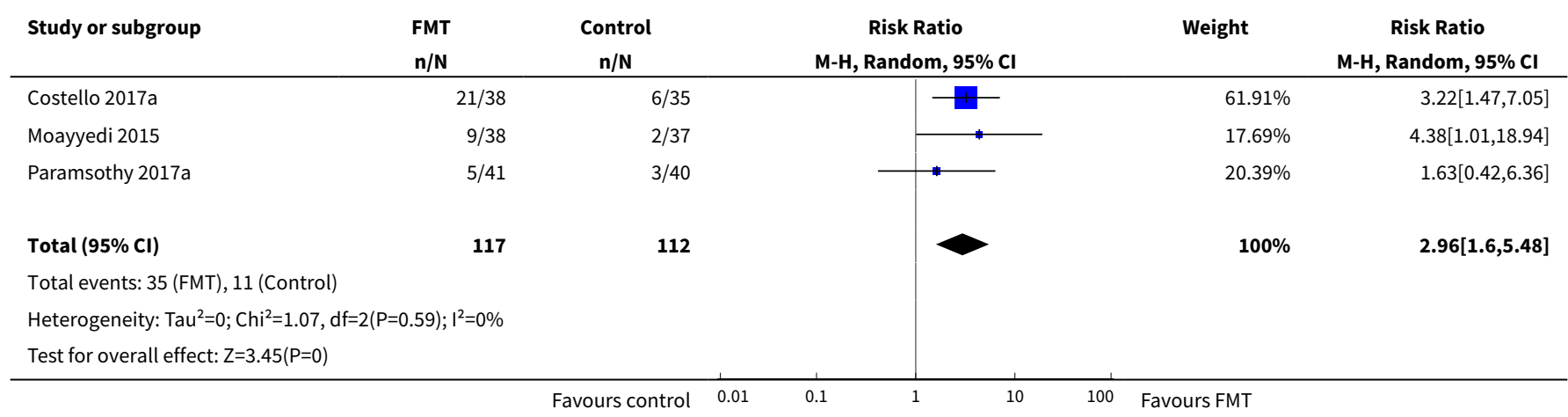

Analysis 1.16. Comparison 1 Fecal microbiota transplantation versus control for participants with ulcerative colitis, Outcome 16 Endoscopic remission at 12 weeks.

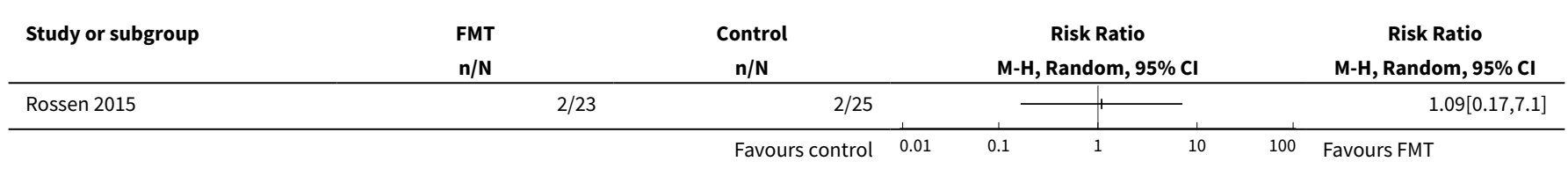


Analysis 1.17. Comparison 1 Fecal microbiota transplantation versus control for participants with ulcerative colitis, Outcome 17 Endoscopic response at 8 weeks.

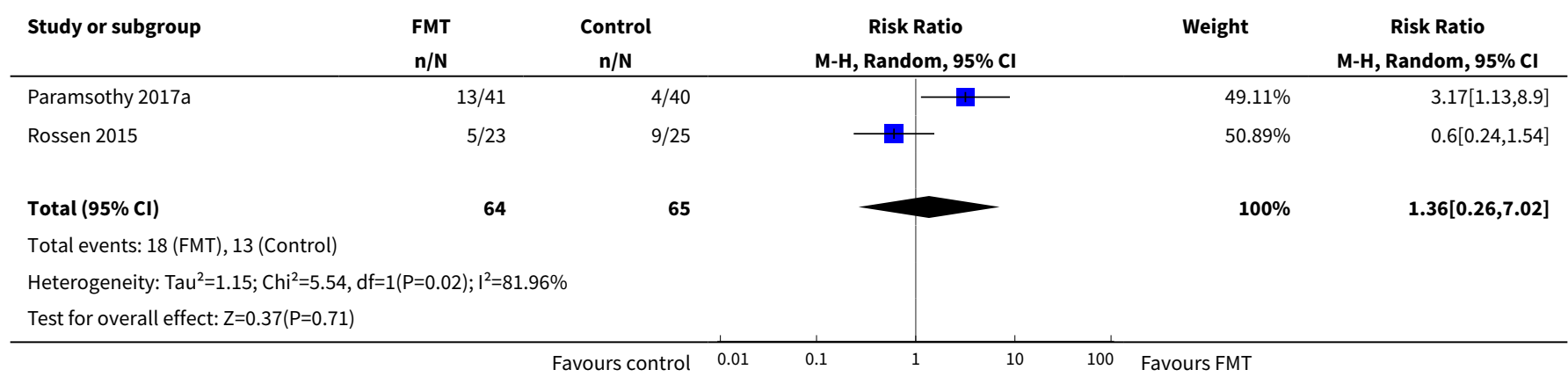

Analysis 1.18. Comparison 1 Fecal microbiota transplantation versus control for participants with ulcerative colitis, Outcome 18 Endoscopic response at 12 weeks.

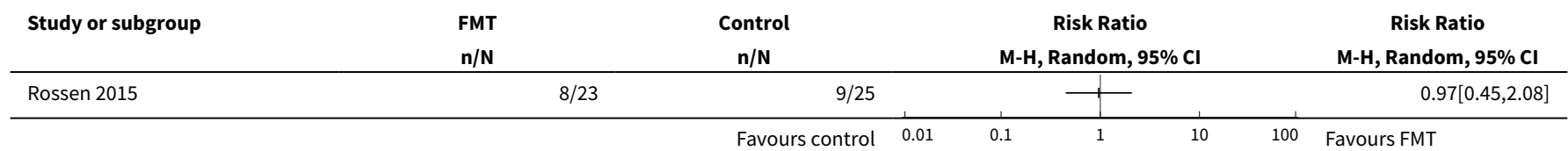

Analysis 1.19. Comparison 1 Fecal microbiota transplantation versus control for participants with ulcerative colitis, Outcome 19 Withdrawals.

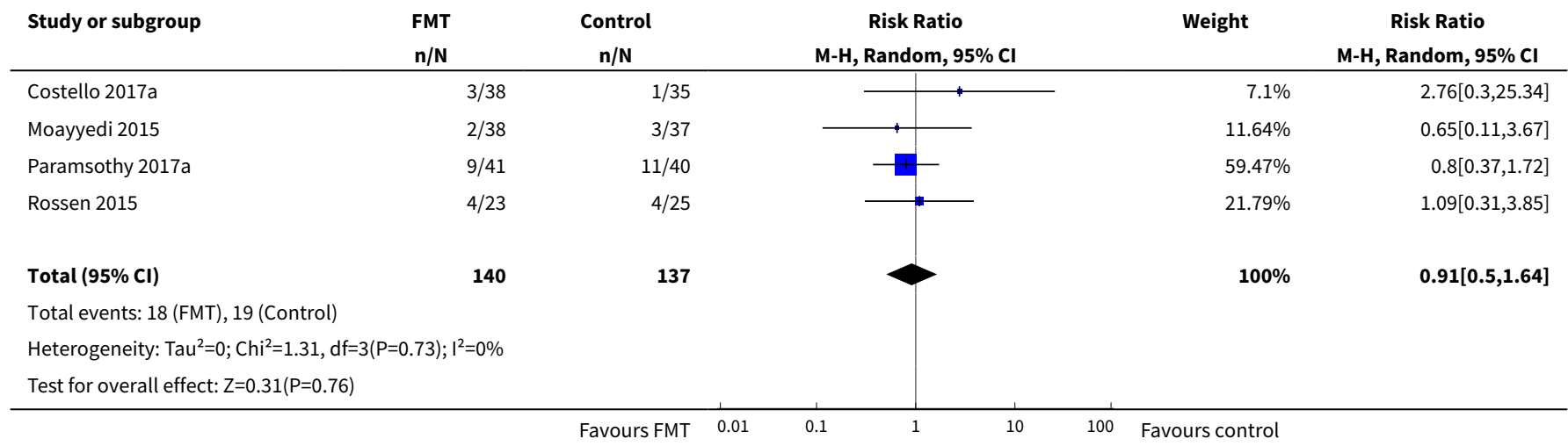

Analysis 1.20. Comparison 1 Fecal microbiota transplantation versus control for participants with ulcerative colitis, Outcome 20 ESR at the longest follow up.

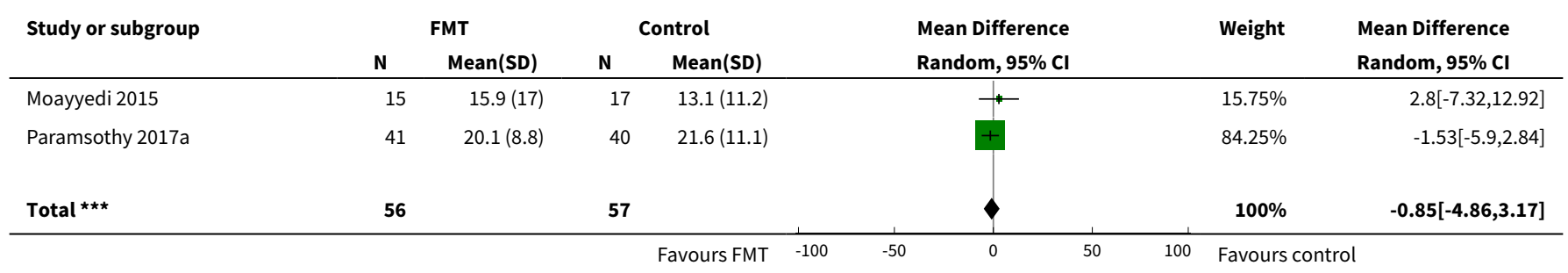




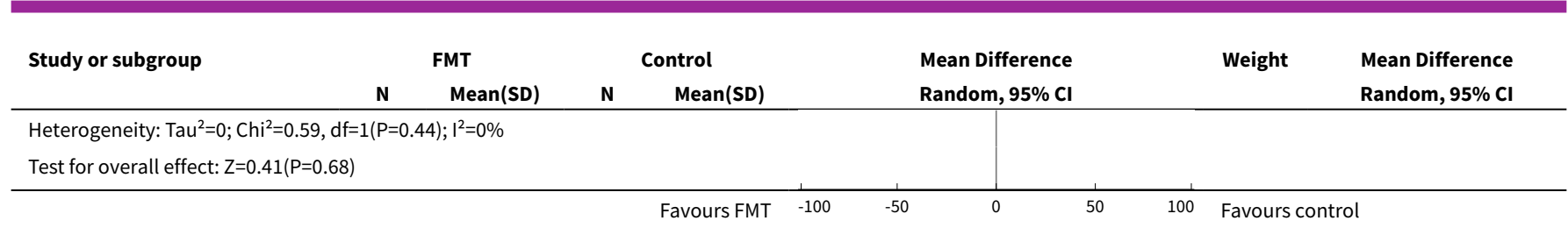

Analysis 1.21. Comparison 1 Fecal microbiota transplantation versus control for participants with ulcerative colitis, Outcome 21 CRP at the longest follow-up.

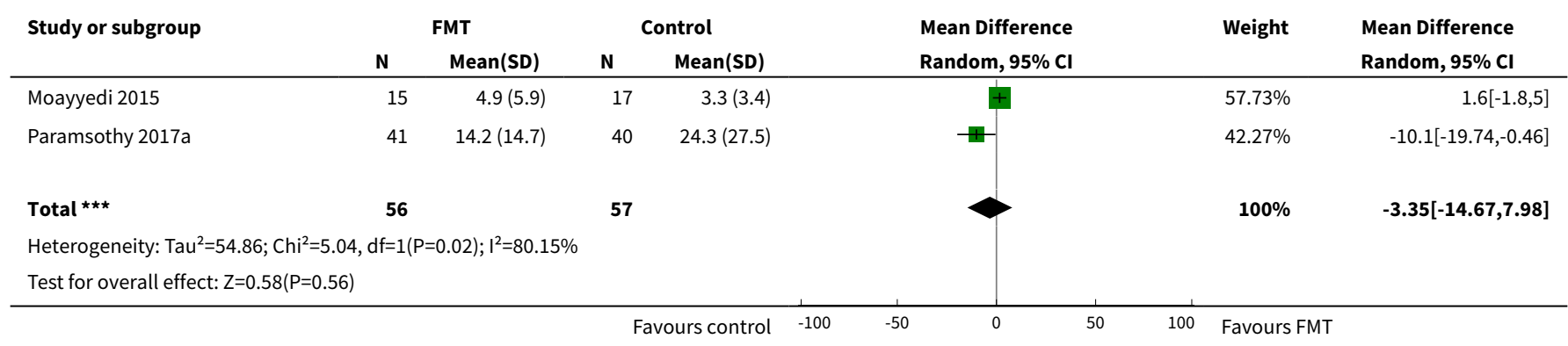

Analysis 1.22. Comparison 1 Fecal microbiota transplantation versus control for participants with ulcerative colitis, Outcome 22 Fecal calprotectin at the longest follow-up.

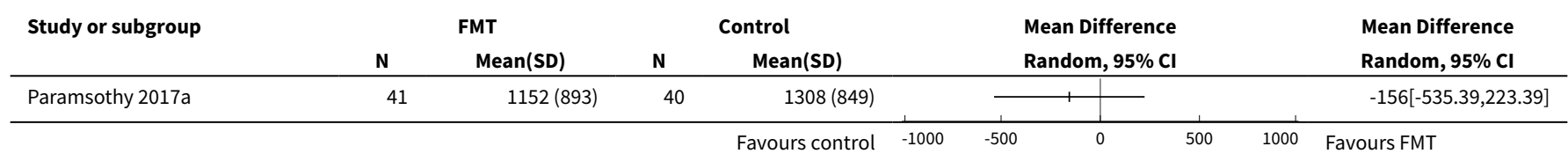

Analysis 1.23. Comparison 1 Fecal microbiota transplantation versus control for participants with ulcerative colitis, Outcome 23 Quality of life score: IBDQ.

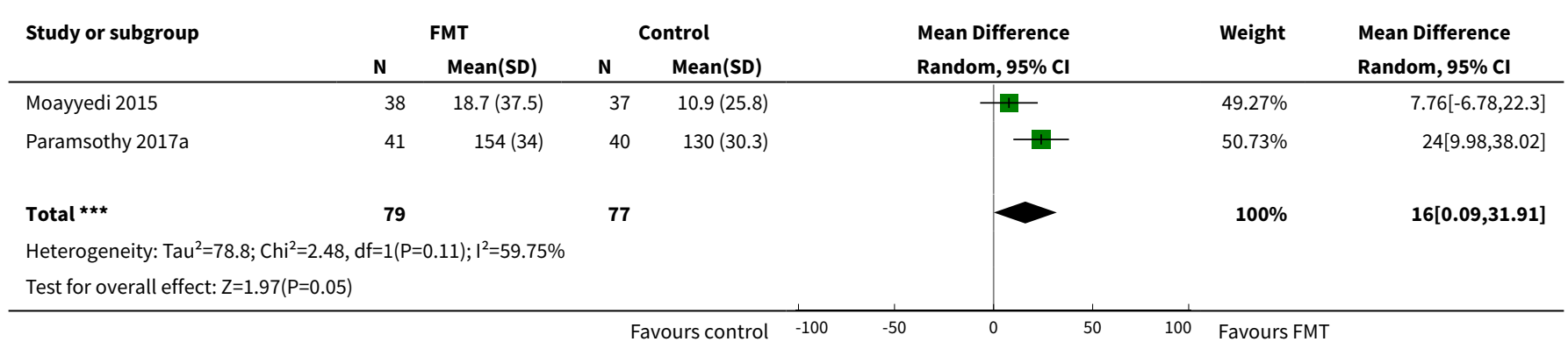

\section{ADDITIONAL TABLES}


Table 1. Subgroup Analyses

\begin{tabular}{|c|c|c|c|c|c|c|}
\hline Outcome & $\begin{array}{l}\text { Subgroup Analy- } \\
\text { ses }\end{array}$ & $\begin{array}{l}\text { Number of } \\
\text { Studies }\end{array}$ & $\begin{array}{l}\text { Number of } \\
\text { events/partici- } \\
\text { pants }\end{array}$ & Heterogeneity & $\begin{array}{l}\text { Risk Ratio } \\
(95 \% \mathrm{Cl})\end{array}$ & $\begin{array}{l}\text { Test for Sub- } \\
\text { group Differ- } \\
\text { ence: }\end{array}$ \\
\hline \multirow[t]{2}{*}{$\begin{array}{l}\text { Clinical Re- } \\
\text { mission at } \\
8 \text { weeks }\end{array}$} & $\begin{array}{l}\text { Route of Admin- } \\
\text { istration: Upper } \\
\text { Gastrointestinal }\end{array}$ & 1 & $\begin{array}{l}\text { FMT = 6/23 } \\
\text { Control = 8/25 }\end{array}$ & NA & $\begin{array}{l}0.82[0.33 \text { to } \\
1.99]\end{array}$ & \multirow{2}{*}{$\begin{array}{l}\mathrm{Chi}^{2}=5.12 \\
\mathrm{df}=1(\mathrm{P}= \\
0.02), \mathrm{I}^{2}= \\
80.5 \%\end{array}$} \\
\hline & $\begin{array}{l}\text { Route of Adminis- } \\
\text { tration: Colonic/ } \\
\text { Enema }\end{array}$ & 3 & $\begin{array}{l}\text { FMT }=46 / 117 \\
\text { Control }=16 / 112\end{array}$ & $\begin{array}{l}\mathrm{Tau}^{2}=0.00 ; \mathrm{Chi}^{2}=0.79, \mathrm{df}= \\
2(\mathrm{P}=0.67) ; \mathrm{I}^{2}=0 \%\end{array}$ & $\begin{array}{l}2.66[1.62 \text { to } \\
4.37]\end{array}$ & \\
\hline \multirow[t]{2}{*}{$\begin{array}{l}\text { Clinical Re- } \\
\text { mission at } \\
8 \text { weeks }\end{array}$} & $\begin{array}{l}\text { Donor: Single } \\
\text { donor }\end{array}$ & 2 & $\begin{array}{l}\text { FMT }=15 / 61 \\
\text { Control }=10 / 62\end{array}$ & $\begin{array}{l}\mathrm{Tau}^{2}=1.12 ; \mathrm{Chi}^{2}=3.94, \mathrm{df}= \\
1(\mathrm{P}=0.05) ; \mathrm{I}^{2}=75 \%\end{array}$ & $\begin{array}{l}1.71[0.32 \text { to } \\
9.29]\end{array}$ & \multirow[t]{2}{*}{$\begin{array}{l}\mathrm{Chi}^{2}=0.17 \\
\mathrm{df}=1(\mathrm{P}= \\
0.68), \mathrm{I}^{2}=0 \%\end{array}$} \\
\hline & Donor: Multidonor & 2 & $\begin{array}{l}\text { FMT }=52 / 140 \\
\text { Control }=24 / 137\end{array}$ & $\begin{array}{l}\mathrm{Tau}^{2}=0.21 ; \mathrm{Chi}^{2}=5.97, \mathrm{df}= \\
3(\mathrm{P}=0.11) ;\left.\right|^{2}=50 \%\end{array}$ & $\begin{array}{l}2.03[1.07 \text { to } \\
3.86]\end{array}$ & \\
\hline \multirow[t]{2}{*}{$\begin{array}{l}\text { Serious } \\
\text { Adverse } \\
\text { Events }\end{array}$} & $\begin{array}{l}\text { Route of Admin- } \\
\text { istration: Upper } \\
\text { Gastrointestinal }\end{array}$ & 1 & $\begin{array}{l}\text { FMT = 2/23 } \\
\text { Control = 2/25 }\end{array}$ & NA & $\begin{array}{l}1.09[0.17 \text { to } \\
7.10]\end{array}$ & \multirow[t]{2}{*}{$\begin{array}{l}\mathrm{Chi}^{2}=0.09, \\
\mathrm{df}=1(\mathrm{P}= \\
0.76), \mathrm{I}^{2}=0 \%\end{array}$} \\
\hline & $\begin{array}{l}\text { Route of Adminis- } \\
\text { tration: Colonic/ } \\
\text { Enema }\end{array}$ & 3 & $\begin{array}{l}\text { FMT }=8 / 117 \\
\text { Control }=5 / 112\end{array}$ & $\begin{array}{l}\mathrm{Tau}^{2}=0.00 ; \mathrm{Chi}^{2}=0.06, \mathrm{df}= \\
2(\mathrm{P}=0.97) ; \mathrm{I}^{2}=0 \%\end{array}$ & $\begin{array}{l}1.52[0.51 \text { to } \\
4.50]\end{array}$ & \\
\hline \multirow[t]{2}{*}{$\begin{array}{l}\text { Serious } \\
\text { Adverse } \\
\text { Events }\end{array}$} & $\begin{array}{l}\text { Donor: Single } \\
\text { donor }\end{array}$ & 2 & $\begin{array}{l}\text { FMT = 5/61 } \\
\text { Control = 4/62 }\end{array}$ & $\begin{array}{l}\mathrm{Tau}^{2}=0.00 ; \mathrm{Chi}^{2}=0.05, \mathrm{df}= \\
1(\mathrm{P}=0.82) ; \mathrm{I}^{2}=0 \%\end{array}$ & $\begin{array}{l}1.28[0.36 \text { to } \\
4.55]\end{array}$ & \multirow[t]{2}{*}{$\begin{array}{l}\mathrm{Chi}^{2}=0.04, \\
\text { df }=1(\mathrm{P}= \\
0.83), \mathrm{I}^{2}=0 \%\end{array}$} \\
\hline & Donor: Multidonor & 2 & $\begin{array}{l}\text { FMT }=5 / 79 \\
\text { Control }=3 / 75\end{array}$ & $\begin{array}{l}\mathrm{Tau}^{2}=0.00 ; \mathrm{Chi}^{2}=0.15, \mathrm{df}= \\
3(\mathrm{P}=0.99) ; \mathrm{I}^{2}=0 \%\end{array}$ & $\begin{array}{l}1.40[0.55 \text { to } \\
3.58]\end{array}$ & \\
\hline
\end{tabular}

Abbreviations:

FMT: fecal microbiota transplantation

NA: Not applicable

\section{AP PE N D I E S}

\section{Appendix 1. Search strategies}

\section{MEDLINE}

1. Exp Inflammatory bowel disease/

2. Crohn*.mp.

3. Ulcerative colitis.mp

4. IBD.mp.

5. Inflammatory bowel disease ${ }^{\star} . \mathrm{mp}$.

6. $\mathrm{Or} / 1-5$

7. Fecal microbiota transplant ${ }^{\star} . \mathrm{mp}$. 
8. Faecal microbiota transplant ${ }^{\star} . \mathrm{mp}$.

9. fecal microbiome transplant ${ }^{\star} . \mathrm{mp}$.

10. Stool transplant*.mp.

11. FMT.mp.

12. Fecal transfusion ${ }^{\star} . \mathrm{mp}$.

13. Fecal bacteriotherap^.mp.

14. $\mathrm{Or} / 7-13$

15. 6 and 14

\section{Embase}

1. Exp Inflammatory bowel disease/

2. Crohn*.mp.

3. Ulcerative colitis ${ }^{\star} . \mathrm{mp}$

4. IBD.mp.

5. Inflammatory bowel disease ${ }^{\star} . \mathrm{mp}$.

6. $\mathrm{Or} / 1-5$

7. Fecal microbiota transplant ${ }^{\star} . \mathrm{mp}$.

8. Faecal microbiota transplant ${ }^{\star} . \mathrm{mp}$.

9. fecal microbiome transplant ${ }^{\star} . \mathrm{mp}$.

10. Stool transplant*.mp.

11. FMT.mp.

12. Fecal transfusion ${ }^{\star} . \mathrm{mp}$.

13. Fecal bacteriotherap ${ }^{\star} . \mathrm{mp}$.

14. $\operatorname{Or} / 7-13$

15. 6 and 14

\section{Cochrane CENTRAL}

\#1 MeSH: [Inflammatory bowel disease] explode all trees

\#2 Crohn

\#3 Ulcerative colitis

\#4 IBD

\#5 \#1 or \#2 or \#3 or \#4

\#6 MeSH: [Fecal transplant] explode all trees

\#7 Fecal microbiota transplant*

\#8 Faecal microbiota transplant*

\#9 Fecal microbiome transplant ${ }^{\star}$

\#10 Stool transplant*

Fecal transplantation for treatment of inflammatory bowel disease (Review) 
\#11 FMT

\#12 Fecal transfusion*

\#13 Fecal bacteriotherap*

\#14 Fecal bacteriotherap*

$\# 15 \# 7$ or \#8 or \#9 or \#10 or \#11 or \#12 or \#13 or \#14

\#16 \#5 and \#15

Clinical Trials. Gov

1. Fecal transplantation and Inflammatory Bowel Disease

2. Fecal transplant and Inflammatory Bowel Disease

3. Fecal microbiota transplant and Inflammatory Bowel Disease

\section{Appendix 2. Characteristics of donors in the included studies}

Moayyedi 2015

\section{Donor inclusion criteria:}

- Volunteers

- Age between 18 and 60 years of age

- otherwise healthy, as assessed by a screening questionnaire

Donor exclusion criteria:

- Use of antibiotics in the previous 3 months

\section{Lab testing for donors}

Blood studies: human immunodeficiency virus (HIV) $1 / 2$, hepatitis A immunoglobulin M, hepatitis B surface antigen, hepatitis C antibody, syphilis, human T- lymphotrophic virus 1/II, vancomycin-resistant enterococcus, or methicillin-resistant Staphylococcus aureus

Stool studies: Salmonella, Shigella, Campylobacter, Escherichia coli 0157 H7, Yersinia, ova, cysts, and parasites, or C. difficile toxin.

Paramsothy 2017 a

Donors eligibility criteria: Males and females aged 18 to 65 years, No history or current symptoms of gastrointestinal disease including but not limited to IBD and irritable bowel syndrome (IBS), No other major active medical co-morbidities, Minimal regular medications with no medications that may interfere with stool viability including no antimicrobials (antibiotics, antivirals, antifungals), probiotics and proton pump inhibitors in the preceding three months, provide written informed consent to participate as shown by a signature on the consent form.

Donors exclusion criteria: Known HIV, hepatitis B or hepatitis C infection, known exposure to HIV or viral hepatitis within the previous 12 months, high risk sexual behavior (e.g. sexual contact with anyone with HIV/AIDS or viral hepatitis, men who have sex with men, sex for drugs or money), use of illicit drugs, tattoo or body piercing within the preceding 6 months, incarceration or history of incarceration, known current communicable disease (e.g. upper respiratory tract infection), risk factors for variant Creutzfeldt-Jakob disease, travel within last two weeks to areas of the world where diarrhoeal illnesses are endemic or risk of traveller's diarrhea is high, history of or current IBS, chronic constipation, chronic diarrhea or other intrinsic gastrointestinal illness or condition, history of or current gastrointestinal malignancy or known polyposis or strong family history of colorectal cancer, history of major gastrointestinal surgery (e.g. gastric bypass, partial colectomy), antimicrobials (antibiotics, antivirals, antifungals), probiotics or proton pump inhibitors (PPIs) within the preceding three months, major immunosuppressive medications (e.g. calcineurin inhibitors, biological agents, exogenous glucocorticoids), systemic anti-neoplastic agents, household members with active GI infection, systemic autoimmunity (e.g. multiple sclerosis, connective tissue disease), atopic disease (e.g. moderate - severe asthma, eosinophilic disorders of the gastrointestinal tract), metabolic syndrome, obesity (body mass index $>30$ ) or moderate to severe under-nutrition or malnutrition, chronic pain syndromes (e.g. chronic fatigue syndrome, fibromyalgia) or neurologic or neurodevelopmental disorders, history of malignant illness or ongoing oncologic therapy.

\section{Donors: Lab Testing}


Stool testing: Clostridium difficile toxin polymerase chain reaction, fecal microscopy/culture/sensitivity with routine bacterial culture for enteric pathogens, fecal Giardia antigen, fecal Cryptosporidium antigen, fecal ova, cysts or parasites (including Blastocystis hominis and Dientamoeba fragilis), norovirus enzyme immunoassay.

Blood testing: Complete blood count, electrolytes, urea and creatinine, liver function tests, erythrocyte sedimentation rate, C-reactive protein, HIV type 1 and 2, hepatitis A virus immunoglobulin M, hepatitis B virus surface antigen, hepatitis B virus core antibody (immunoglobulin $\mathrm{M}$ and imunoglobulin $\mathrm{G}$ ), hepatitis $\mathrm{B}$ virus surface antibody, hepatitis $\mathrm{C}$ virus antibody, rapid plasma reagin or fluorescent treponemal antibody-absorbed, human T-cell lymphotropic virus 1 and 2.

Rossen 2015

\section{Donors eligibility criteria:}

- Healthy partners, relatives, or volunteers (18 years of age) were screened for fecal donation using the Dutch Red Cross Questionnaire addressing risk factors for potential transmissible diseases used for screening of blood donors in the Netherlands.

\section{Donors lab testing:}

Blood: Lues serologie (syphilis), cytomegalovirus, Epstein-Barr virus, hepatitis A virus (total antibody), hepatitis B surface antigen, hepatitis C virus antibody, HIV (1p2 antibodies/antigen), human T-cell lymphotropic virus (I + II antibodies), antibodies against Entamoeba histolytica, Strongyloides (strongyloides enzyme-linked immunosorbent assay).

Stool: Salmonella, Shigella, Yersinia, Campylobacter bacteria, Clostridium difficile toxin, multiplex polymerase chain reaction containing probes against enteral viruses (rotavirus, norovirus, enterovirus parechovirus, sapovirus, adenovirus 40/41/52, astrovirus), feces test plus triple feces test: Giardia polymerase chain reaction.

\section{CONTRIBUTIONS OF AUTHORS}

Al and SA conceptualised the idea of the study. Al, MN, and SA wrote the manuscript. ETS assisted with formulating the methods for the protocol. SA, OG, JZ, DMBB and ETS helped with revisions and provided overall supervision for completion of the manuscript.

\section{DECLARATIONSOF INTEREST}

Aamer Imdad: None known

Maribeth R Nicholson: None known

Sari Acra: None known

Oscar Gomez-Duarte: receives funding from the NIH for research on enteric pathogens. In addition to his employment at the University at Buffalo, he offers lectures at the University of Santander for which he receive honoraria. He is a member of the Revista Colombiana de Anestesiologia Editorial board which compensates him for time as an editor.

Emily E Tanner-Smith: None known

Joseph P Zackular: None known

Dawn M Borromeo Beaulieu: a consultant for Abbvie, Takeda and Janssen

\section{SOURCES OF SUPPORT}

\section{Internal sources}

- None, Other.

\section{External sources}

- None, Other.

\section{DIFFERENCES BETWEEN PROTOCOL AND REVIEW}

1) We decided to exclude single-arm phase I trials because of the lack of a control arm and the inability to make a causal association from these studies.

2) A post-hoc analysis was conducted to include data for primary outcome of clinical remission based on clinical score and endoscopic assessment. 


\section{N D EX TERMS}

\section{Medical Subject Headings (MeSH)}

Colitis, Ulcerative [^therapy]; Crohn Disease [*therapy]; Dysbiosis [complications] [ ${ }^{\star}$ therapy]; Fecal Microbiota Transplantation [adverse effects] [ ${ }^{\star}$ methods]; Randomized Controlled Trials as Topic; Recurrence; Remission Induction

\section{MeSH check words}

Humans 